US Army Corps

of Engineers ${ }_{\circledast}$

Engineer Research and

Development Center

Optical and Acoustical Separation and Identification of Ballistic Noise Signatures

\title{
Optical and Acoustical Measurement of Ballistic Noise Signatures
}

Matthew G. Blevins, Gregory W. Lyons, Carl R. Hart, and

Michael J. White

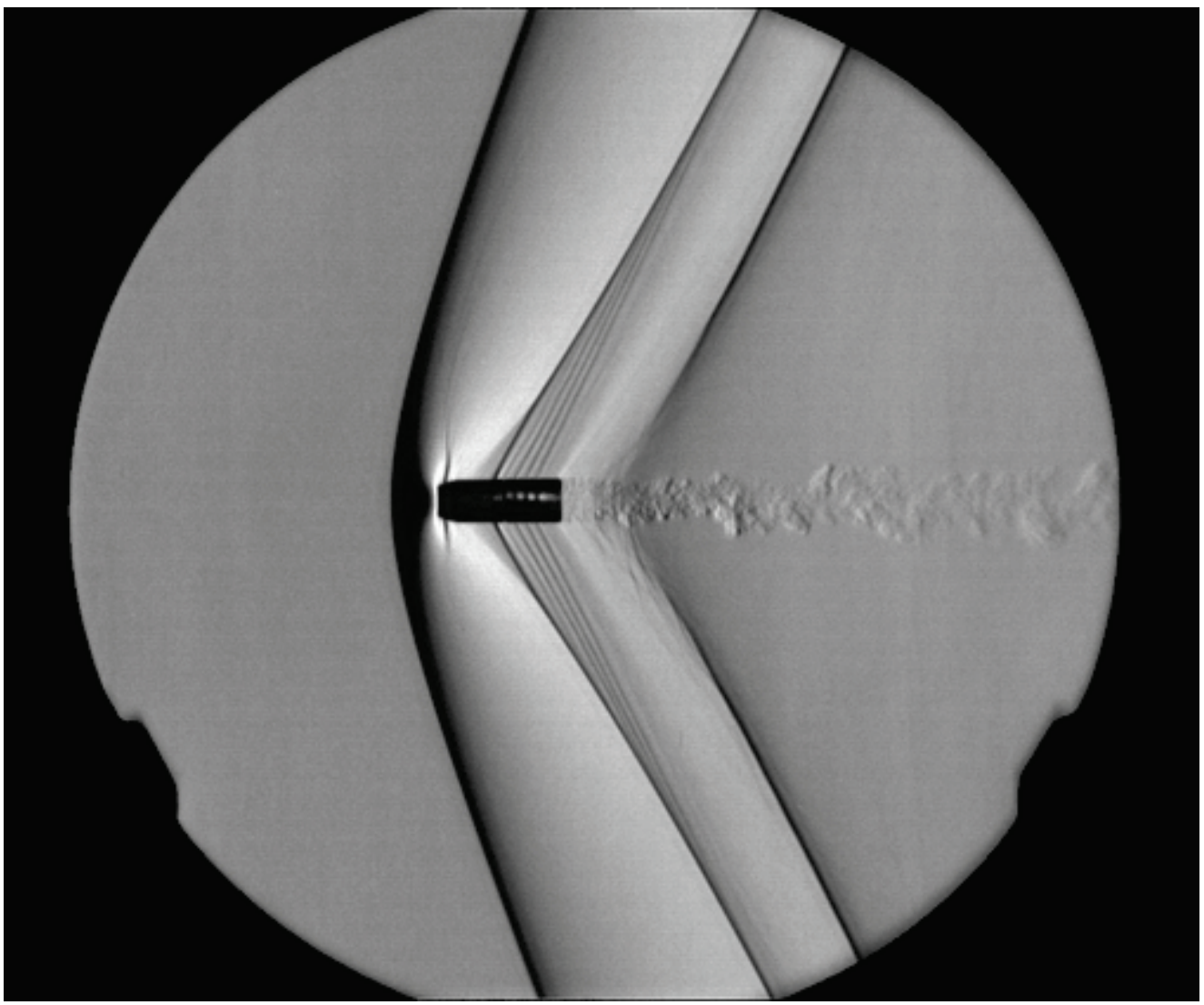


The U.S. Army Engineer Research and Development Center (ERDC) solves the nation's toughest engineering and environmental challenges. ERDC develops innovative solutions in civil and military engineering, geospatial sciences, water resources, and environmental sciences for the Army, the Department of Defense, civilian agencies, and our nation's public good. Find out more at www.erdc.usace.army.mil.

To search for other technical reports published by ERDC, visit the ERDC online library at https://erdclibrary.on.worldcat.org/discovery. 


\section{Optical and Acoustical Measurement of Ballistic Noise Signatures}

Matthew G. Blevins, Gregory W. Lyons, and Michael J. White

U.S. Army Engineer Research and Development Center (ERDC)

Construction Engineering Research Laboratory (CERL)

2902 Newmark Dr.

Champaign, IL 61824

Carl R. Hart

U.S. Army Engineer Research and Development Center (ERDC)

Cold Regions Research and Engineering Laboratory (CRREL)

72 Lyme Road

Hanover, NH 03755-1290

Final Technical Report (TR)

Approved for public release; distribution is unlimited.

Prepared for Headquarters, U.S. Army Corps of Engineers

Washington, DC 20314-1000

Under Program Element 06011102, “Protection Maneuver, Geospatial, Natural Sciences"; Project AB2, "Fundamental Mapping, Remote Sensing, Sig-nature Physics and Terrain State Research"; Task SAB201, "Optical and Acoustical Separation and Identification of Ballistic Noise Signatures (OASIS)." 


\section{Abstract}

Supersonic projectiles in air generate acoustical signatures that are fundamentally related to the projectile's shape, size, and velocity. These characteristics influence various mechanisms involved in the generation, propagation, decay, and coalescence of acoustic waves. To understand the relationships between projectile shape, size, velocity, and the physical mechanisms involved, an experimental effort captured the acoustic field produced by a range of supersonic projectiles using both conventional pressure sensors and a schlieren imaging system. The results of this ongoing project will elucidate those fundamental mechanisms, enabling more sophisticated tools for detection, classification, localization, and tracking. This paper details the experimental setup, data collection, and preliminary analysis of a series of ballistic projectiles, both idealized and currently in use by the U.S. Military.

DISCLAIMER: The contents of this report are not to be used for advertising, publication, or promotional purposes. Citation of trade names does not constitute an official endorsement or approval of the use of such commercial products. All product names and trademarks cited are the property of their respective owners. The findings of this report are not to be construed as an official Department of the Army position unless so designated by other authorized documents.

DESTROY THIS REPORT WHEN NO LONGER NEEDED. DO NOT RETURN IT TO THE ORIGINATOR. 


\section{Contents}

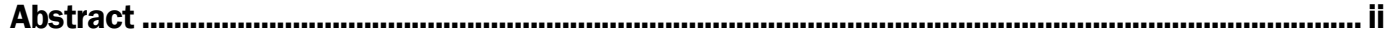

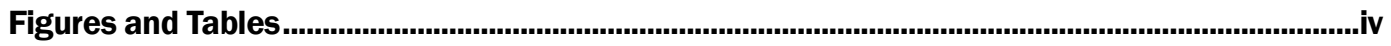

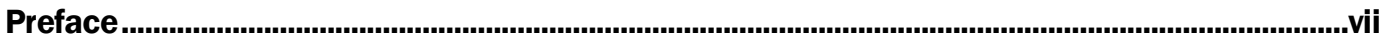

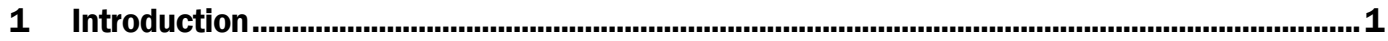

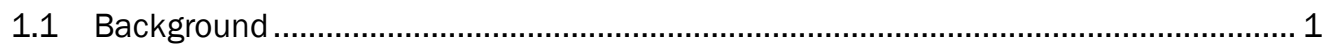

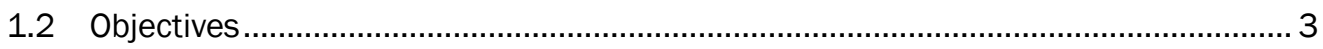

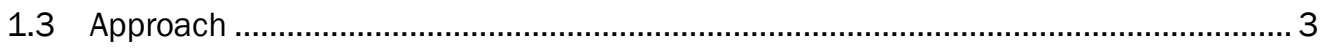

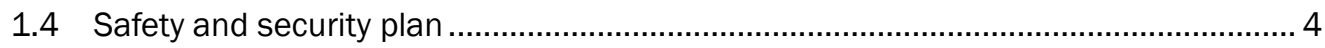

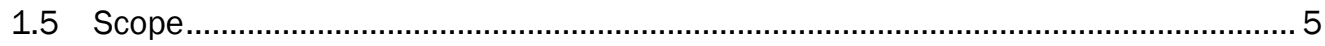

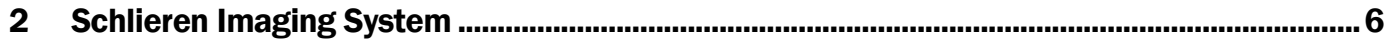

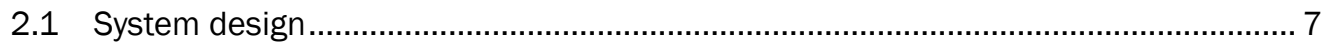

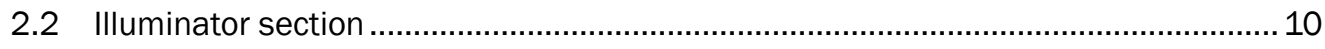

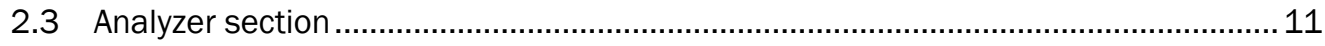

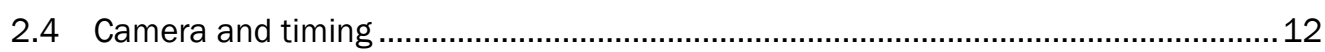

2.5 System operation ............................................................................................. 13

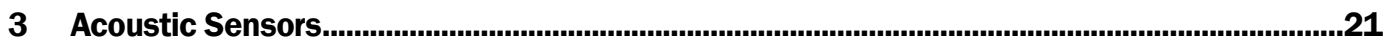

3.1 System design ............................................................................................ 21

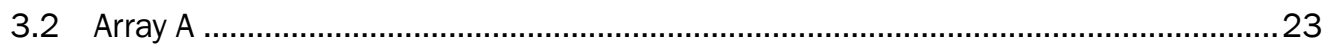

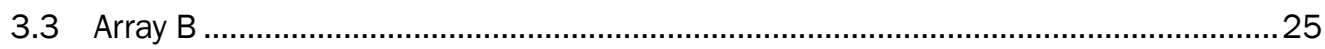

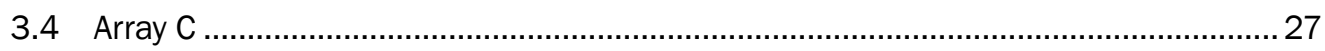

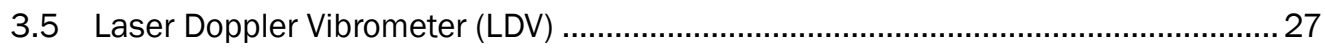

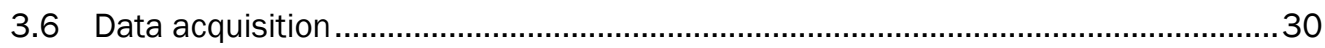

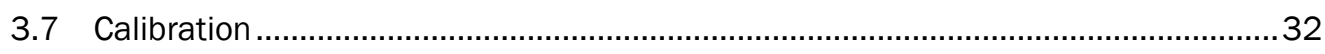

4 Data Collection ................................................................................................................34

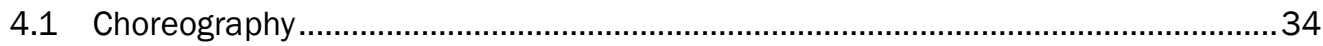

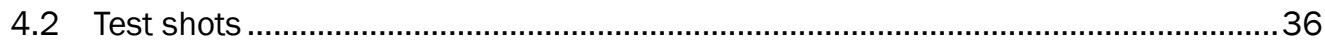

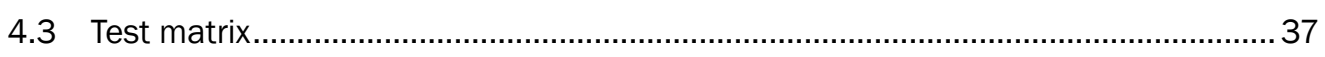

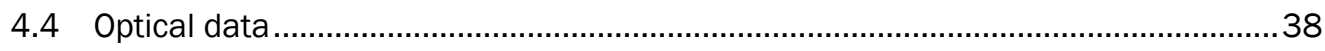

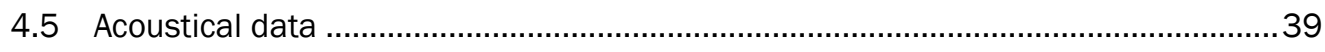

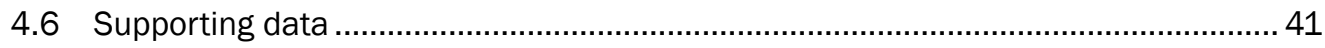

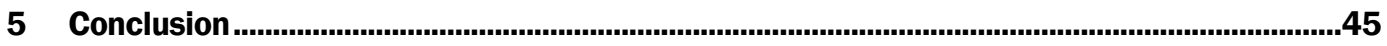

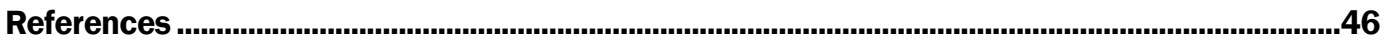

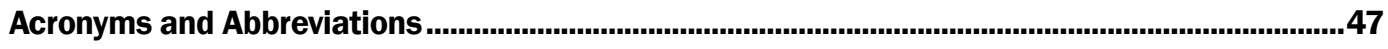

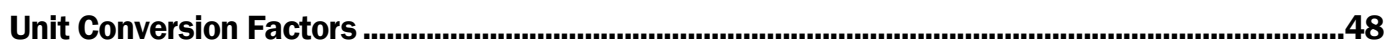

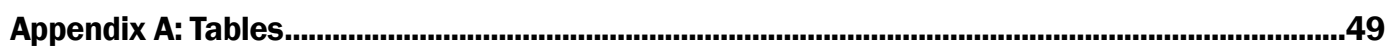

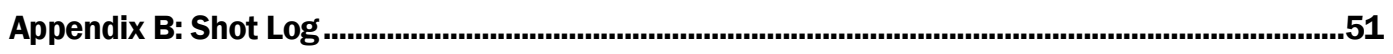

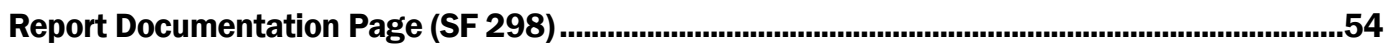




\section{Figures and Tables}

Figure

Page

1 A measured (solid black line) $\mathrm{N}$-wave produced by ballistic shock compared to an ideal (dashed red line) N-wave

2 A single frame from a schlieren image sequence showing a .50 caliber M33 Ball round traveling at Mach 1.1

3 Layout of schlieren imaging system

$4 \quad$ Illuminator portion (right side of Fig. 3) of the schlieren imaging system at the Fragmentation Simulation Facility before installation of the acoustical measurement system and light baffles

5 Analyzer portion (left side of Fig. 3) of the schlieren imaging system at the Fragmentation Simulation Facility before installation of the acoustical measurement system and light baffles

6 Flashlamp intensity over time

7 Illuminator section of the schlieren imaging system

8 Analyzer section of the schlieren imaging system

9 Kirana camera field of view (solid line) circumscribing the diameter of the parabolic mirrors (dashed line)

10 Frame from a schlieren image sequence highlighting the 1- and 10frame ghosting issue

11 Overhead flashlamps added to illuminate the projectile as it passed through the test section. The flashlamps are aimed at a white diffusing screen to reduce glare on the projectile. An additional light baffle blocked light from entering the optical path of the schlieren system

12 Additional flashlamps were placed on the floor aimed at the diffusor panel to provide further illumination

13 Projectiles were painted matte white to reduce further the contrast between the projectile and the background. The left shows a loaded .50 caliber M33 Ball round, while the right shows painted 500 Nitro Express and .50 caliber FSPs before loading

14 Peak sound pressure level, $L_{p k}$, vs. miss distance for a .50 caliber projectile for three velocities Mach 2 (solid curve), Mach 3 (dashed curve), and Mach 4 (dotted curve). The upper limit of a GRAS 4OBF $1 / 4$ " condenser microphone is shown as the red dashed line

15 Plan view of acoustical components in the experimental setup. The angle of array B with respect to the projectile trajectory is set to the Mach angle corresponding to the target projectile velocity. The nearest sensor, B1, is 6 in. perpendicular to the projectile trajectory. The sensing elements of the microphones in arrays $\mathrm{B}$ and $\mathrm{C}$ lie in the same plane as the projectile trajectory and optical axis, while Array A lies 6 in. below the trajectory. The LDV head is $1 \mathrm{in.} \mathrm{above,} \mathrm{and}$ perpendicular to, the projectile trajectory 
Figure

Page

16 Array A consists of eight PCB 113B28 high-frequency pressure transducers flush-mounted in an aluminum baffle plate

17 The underside of Array A showing the mounting position of the PCB 333B32 accelerometer

18 Array B consists of four PCB 113B28 high-frequency pressure transducers and four GRAS 40DP condenser microphones flushmounted in an aluminum baffle plate

19 The backside of Array B, showing the accelerometer mounting location and the condenser microphone holders

20 Array $\mathrm{C}$ consists of eight GRAS 40BF condenser microphones mounted in a uniform linear spacing of $10 \mathrm{~cm}$. The front of the array mounting hardware and other nearby surfaces were covered in acoustical foam to reduce the effects of reflections

21 The LDV measurement apparatus as configured. The first-surface mirror used as the reflective target is near at center, while the LDV head is visible in the background with the red protective cap covering the aperture

22 Connection diagram

23 Procedure for preparing a shot, adjusting the powder charge (left), and loading the cartridge (right)

24 Projectile velocity vs. shot number. Vertical gray lines indicate test days. Shots to the left of the vertical dashed line are considered test shots

25 Boxplots of measured Mach numbers for target Mach number 2.5

26 Boxplots of measured Mach numbers for target Mach number 1.1

27 A single frame of an image sequence of a .50 caliber M33 projectile traveling at Mach 2.5

28 Enlarged portion of a schlieren image sequence frame of a .50 caliber M33 projectile traveling at Mach 2.5

29 Example of acoustical data recorded for a single shot 40

30 An example N-wave recorded on microphone C-1 40

31 An example N-wave recorded on the Tektronix TDS2024b at sensor B-1

32 Recorded barometric pressure 42

33 Recorded relative humidity 42

34 Recorded temperature 43

35 Calculated sound speed 44 
1 All flashlamp setting combinations used for overhead front lighting of projectiles

2 Channel settings for Yokogawa recording oscilloscopes

3 Number of shots per projectile per target Mach number

A-1 Serial numbers of sensors and signal conditioners in Array A

A-2 Serial numbers of sensors, signal conditioners, and preamps in Array B'

A-3 Serial numbers of sensors and preamps in Array C

A-4 Sensor sensitivities

A-5 Sensor locations with respect to the origin at the intersection of the optical axis and the trajectory. $\mathrm{X}$ is positive uprange, $\mathrm{Y}$ is positive toward the illuminator section, $Z$ is positive upwards. $R$ is the distance to the sensor perpendicular to the trajectory

B-1 Shot Log 


\section{Preface}

This study was conducted for the U.S. Army under Program Element 06011102, "Protection Maneuver, Geospatial, Natural Sciences"; Project AB2, "Fundamental Mapping, Remote Sensing, Signature Physics and Terrain State Research"; Task SAB201, "Optical and Acoustical Separation and Identification of Ballistic Noise Signatures (OASIS)." The GRE technical monitor was Dr. Robert E. Davis, CEERD-RZT.

The work was performed by the Ecological Processes Branch, of the Installations Division, U.S. Army Engineer Research and Development Center, Construction Engineering Research Laboratory (ERDC-CERL), and by the Signature Physics Branch, of the Research \& Engineering Division, of Engineer Research and Development Center, Cold Regions Research and Engineering Laboratory (ERDC-CRREL). At the time of publication, Dr. Chris Rewerts was Chief of the Ecological Processes Branch and Ms. Michelle Hanson was Chief of the Installations Division. The Acting Director of ERDC-CERL was Dr. Kumar Topudurti. Mr. M. Andrew Niccolai was Chief of the Signature Physics Branch and Mr. Jimmy D. Horne was Chief of the Research \& Engineering Division. The associated Technical Director was Dr. Robert E. Davis, CEERD-RZT. The Deputy Director of ERDC-CRREL was David B. Ringelberg and the Director was Dr. Joseph L. Corriveau.

This experiment could not have been completed without Ricky Magee, Terry Smith, and Bill Heard (all associated with the Geotechnical and Structures Laboratory) at the Fragmentation Simulation Facility, and the authors are grateful for their assistance. The authors are also grateful for the contributions of Chris Donnelly (CRREL), who modified the schlieren setup and fabricated the sensor array baffles. The authors appreciate Gordon Ochi, Jesse Barr, and E. J. Vargas (all CERL) for their assistance in preparation for this experiment, including calibration of sensors, exploring software for image processing and annotation, and fabricating equipment mounts.

COL Teresa A. Schlosser was Commander of ERDC, and Dr. David W. Pittman was the Director. 
THIS PAGE INTENTIONALLY LEFT BLANK 


\section{Introduction}

\subsection{Background}

Supersonic motion of an object through air produces a prominent Nshaped wave, i.e., the ballistic shock wave, which requires nonlinear acoustics to explain the wave amplitude, shape, and propagation. Signal parameters from the ballistic shock wave are key elements in most acousticbased shooter localization devices that work at short range from the projectile path. Current methods of distinguishing ballistic shock from muzzle blast assume that the ballistic shock wave arrives at a sensor first, contains more high-frequency energy, and is composed of pressure peaks that are spaced a short duration apart (Sallai et al. 2013; Mäkinen and Pertilä 2010; Völgyesi et al. 2007).

These assumptions break down rapidly when implemented outside of ideal experimental conditions, which limits effectiveness in real environments. Figure 1 shows ideal and measured N-waves; a comparison of these two waves yields potentially useful information that is lost when an ideal Nwave is assumed. Performance of shooter localization devices suffers over longer distances from the line of fire because the ballistic shock wave encounters the rough ground surface and atmospheric turbulence, accumulating distortions until it becomes practically indistinguishable from muzzle blast. At farther distances along the line of fire, the ballistic shock becomes separated in time from the muzzle blast, requiring association.

Projectiles, whether moving at subsonic or supersonic velocity, also produce a turbulent wake. The turbulent wake behind a supersonic projectile contains stochastic flow in a region through which the ballistic shock wave has just swept. In the reference frame of the projectile, the deficit in fluid velocity produced by the wake flow is the inverse of a jet flow. The properties of the aeroacoustic wake, especially its spectrum, intensity, and Doppler rate, would lend opportunity to infer gun caliber and trajectory without constraints on Mach angle and without the requirement for supersonic motion. To our knowledge, the contribution of a projectile's aeroacoustic wake to its acoustic signature has never been conceptualized or explored in ballistics, although the wake itself is clearly visible in schlieren images. 
Figure 1. A measured (solid black line) N-wave produced by ballistic shock compared to an ideal (dashed red line) $\mathrm{N}$-wave.

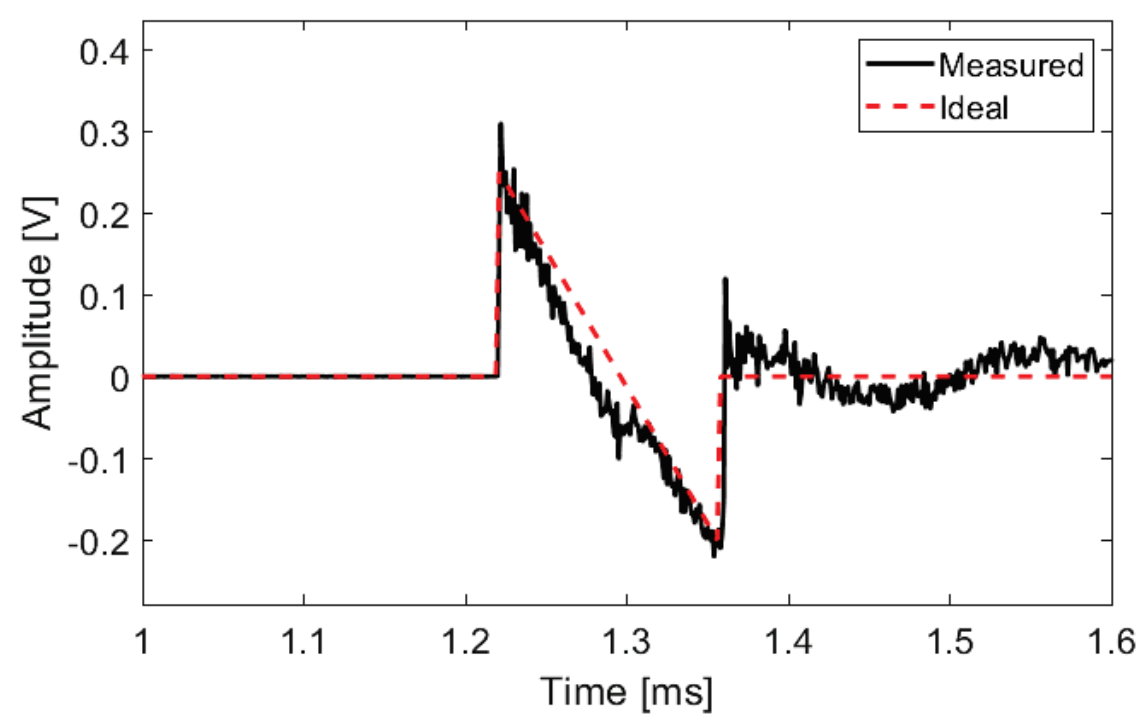

When visualized as a schlieren image, the perturbations in density produced by a supersonic projectile immediately elucidate the separate sound mechanisms. Consider Figure 2, which shows the schlieren image of a .50 caliber M33 Ball projectile traveling leftward at Mach 1.1. The bow shock is evident as the dark line on the left side of the image. Other features, such as the back shock and the turbulent wave behind the projectile, are also apparent.

Figure 2. A single frame from a schlieren image sequence showing a .50 caliber M33 Ball round traveling at Mach 1.1.

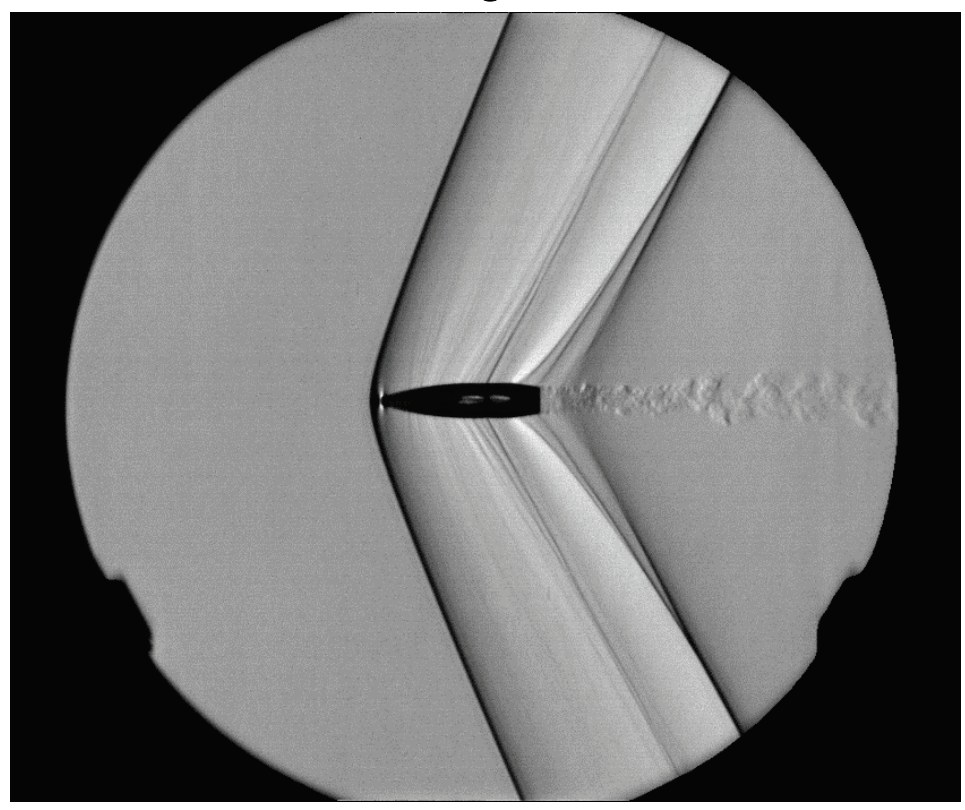


Experimentally identifying the specific mechanisms of ballistic sound generation requires simultaneous capture of acoustical and optical data. An array of audio microphones is placed in the near- and far-field with respect to the ballistic trajectory, as well as in the transition region, to capture the pressure disturbances caused by the projectile. A schlieren imaging system with a highspeed camera simultaneously captures the changes in light intensity caused by gradients in the index of refraction of the disturbed air, thus providing a visualization of the acoustic signatures generated by the projectile's motion.

This work was undertaken to collect optical and acoustical data of ballistic noise signatures of sufficient quantity and quality for further analysis. This report details the laboratory deployment of an integrated audio-visual measurement system, and documents the experimental collection of data, post-processing, and preliminary results.

\subsection{Objectives}

The objective of this work was to collect optical and acoustical data of ballistic noise signatures of sufficient quantity and quality for further analysis. A secondary objective was to investigate the use of an interferometer to transduce the axisymmetric pressure perturbation indirectly.

\subsection{Approach}

Optically and acoustically sensing the generation of sound near a projectile requires a controlled environment in which a variety of projectiles can be fired through a test section in a repeatable manner. The projectile must hit the target accurately and must also follow the same trajectory at a controlled velocity. To accomplish this task, an experiment was conducted at the Engineer Research and Development Center, Geotechnical and Structures Laboratory (ERDC-GSL), Fragmentation Simulation Facility in which schlieren images of the acoustic and aerodynamic density field produced by several projectile shapes over a range of Mach numbers synchronous with high-frequency acoustic pressure field sensors were recorded.

A Z-type schlieren imaging system was installed within this facility in which projectiles fired by a gun fixed uprange would pass directly through the center of its $317.5 \mathrm{~mm}$ test section aperture perpendicular to the optical axis. Folding mirrors were used to make the optical apparatus more compact, to fit the schlieren system within the width of the firing lane. A 
high-speed camera was used to record image sequences from the schlieren system at a rate of 1 million frames per second. As described previously, the sequences visualize the density gradients produced in the air by passage of the projectile.

In addition to the schlieren imaging system, measurements were made of the time rate of change of the optical phase shift induced in a laser interferometer beam directed toward the nominal projectile trajectory. This measurement, achieved through use of a laser Doppler vibrometer, is similarly related to the inhomogeneity in refractive index produced by the projectile passage.

Schlieren illumination and acquisition of data from all systems, including the high-speed camera, were triggered by a velocity trap system included in the camera itself. Two pairs chronograph light screens were located uprange from the experimental instrumentation. The farther downrange pair of these light screens, which each send a rising-edge signal when their sensing plane is broken by a solid object, were connected to the trigger inputs for the camera. By providing the camera software with the distance between the light screens and the approximate projectile velocity, the camera hardware extrapolates the user-defined downrange position of arrival and sends a trigger signal to all other systems at the corresponding instant. In this way, firing the projectile itself served to trigger the experimental measurement.

To study the influence of projectile shape on sensed acoustic signature, five different projectiles were tested. Two common military projectiles, the .50 caliber M33 and $7.62 \mathrm{~mm}$ M80 which are specified by Army Technical Manual (TM) 43-0001-27 (HQDA 1994), have a typical ogival head and allow the effect of scaling to be investigated. Two large-bore hunting rounds, the 500 Jeffery and 500 Nitro Express, are similar in shape with different noses, round and flat, respectively. The .50 caliber fragment simulating projectile (FSP) specified by MIL STD 46593B (DoD 2008) is a short projectile with non-axisymmetric geometry.

\subsection{Safety and security plan}

All work associated with this experiment was conducted under the guidance and supervision of Fragmentation Simulation Facility engineers. The facility is purpose-built for safe testing of high-caliber armament projectiles and their impact on a wide range of target materials. As such, the entire facility 
is designed to safely contain projectiles, shrapnel, and any high-speed fragments. Furthermore, personnel are protected from not only the intended line of fire, but also any fragments that may be produced.

During the experimental setup, whenever possible, long lengths of cable were used to locate equipment and instrumentation behind a row of $80-\mathrm{ft}$ high heavy steel barriers. These barriers formed the left side of the firing lane and were covered in a layer of rubber designed to stop and trap fragments. This way, if any misfires occurred, the resulting ricochets and/or fragments would damage the least amount of equipment possible.

When firing projectiles, the facility operational procedure was carefully followed. First, hearing protection for all personnel was required before all shots. Second, all personnel gathered in a protected control room, which permits viewing of the firing lane while remaining separate from the actual test area. When all present were ready, the external facility alarm was activated, which alerted anyone outside the facility to ensure no one would be startled by the firing, or would attempt to enter during the test. The shot was then triggered remotely, and once the shot was complete, the alarm was deactivated. To maintain a safe air quality in the test area, several large high-efficiency particulate air (HEPA) filtration systems were run continuously during days when firing occurred.

This facility also contains a purpose-built secured room for storage of ammunition, projectiles, propellant, and any other hazardous materials. For safety and security, the facility engineers held sole access to this room and locked away all materials at the end of each day.

\subsection{Scope}

This report documents the experimental data collection task of the project. Subsequent post-processing, data analysis, and findings will be documented in another technical report and/or peer-reviewed journal publications. 


\section{Schlieren Imaging System}

To visualize the various mechanisms of ballistic sound, high-speed sequences of schlieren images were taken of supersonic projectiles. A folded Z-type schlieren imaging system (Settles and Hargather 2017) was modified from an existing system developed for Dr. Hart's ongoing geospatial research engineering (GRE) Basic Research project, "Nonlinear acoustic propagation in periodic and aperiodic arrays of scatterers." High-speed schlieren image sequences were captured using a Kirana camera system at the Fragment Simulation Facility at ERDC-GSL on the ERDC-Vicksburg campus.

In its most basic form, a schlieren system collimates broadband light from a small extended source, usually an optical slit, and projects it through a test section toward a knife-edge cutoff. Without disturbances, light rays in the collimated beam are approximately parallel. Although the cutoff blocks a portion of these rays, the projected image will maintain uniform intensity. However, when a disturbance in density is introduced within the test section, the gradients in refraction index deflect rays away from their originally parallel configuration. At the cutoff, these rays are diverted either away from or onto the cutoff, depending on the direction of the gradient. By adjustment of the cutoff position, the sensitivity and orientation can be tuned for the phenomenon of interest.

Schlieren images, which are projected beyond the cutoff position in the analyzer section, are a consequence of the proportionality between the index of refraction of light $\mathrm{n}$ and the air density $\rho$, according to the GladstoneDale relation, $n-1=G \rho$, where $G$ is the Gladstone-Dale coefficient, about $0.23 \mathrm{~cm} 3 / \mathrm{g}$ for air. A schlieren image shows the derivative of the index of refraction, corresponding to the derivative of the density field. For a ballistic shock such as that shown in Figure 2, the derivative of the density is large in magnitude so that schlieren imaging reveals the shock wave's position and structure. Weaker disturbances, such as shocks caused by boundary-layer dynamics or the turbulent wake of the projectile, can also be visualized through schlieren imaging.

In a Z-type schlieren system, the collimation of light is achieved through two matched, parabolic field mirrors. The extended source and cutoff are 
placed at focal points for opposing mirrors, forming the respective illuminator and analyzer sections of the schlieren. The optical axis of both mirrors must be angled away from the centerline joining them, so that the other optics do not obstruct the collimated light, which forms a "Z" shape in a plan view. While this can introduce off-axis optical aberrations, the advantage to using parabolic mirrors is that, unlike lenses, they do not need correction for chromatic aberrations.

\subsection{System design}

To constrain degrees of freedom of all optical elements while providing a more flexible, field-ready optomechanical solution, the entire schlieren system was built around sections of slotted aluminum extrusion, which was used as an optical rail. By attaching standard optomechanical mounts, posts, and post holders to sliding linear bearings, optics could be freely positioned along the axis of each mirror while maintaining a fixed off-axis angle. Matching this angle on the illuminator and analyzers sections is critical for minimizing coma, an off-axis aberration.

Due to the limited space in the ballistic testing area, the traditional Z-type schlieren setup was "folded" using flat high-quality first-surface mirrors to move the sensitive illumination and analyzer equipment away from the ballistic trajectory. Optically, neglecting losses from the reflective surface, the resulting system is identical to the original unfolded configuration. Geometrically, the folding mirrors introduced several additional degrees of freedom that were constrained both by mechanical design and systematic setup and alignment, by predetermining, marking, and matching the folding angle, elevation, and surface normal of the mirrors. Custom hardware components were built to permit the optical rail to be broken into sections and folded at the same point as the folding mirror surface.

The folded Z-type schlieren imaging system (Figure 3) was located $2.81 \mathrm{~m}$ downrange of the infrared light screens that were used to trigger data acquisition. Figures 4 and 5, respectively SHOW the illuminator and analyzer sections. Sections 2.2 and 2.3 discuss their components in detail. 


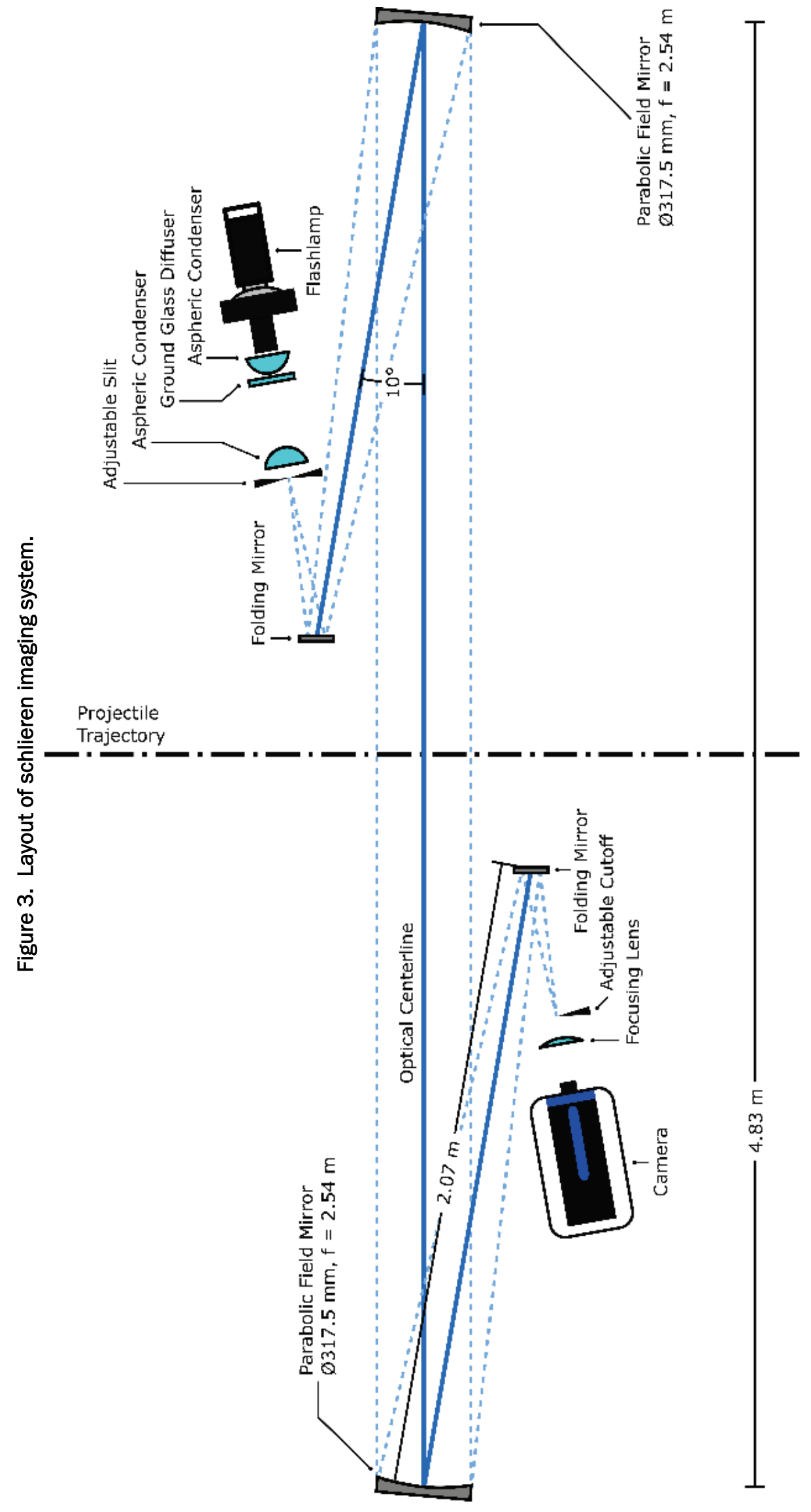


Figure 4. Illuminator portion (right side of Fig. 3) of the schlieren imaging system at the Fragmentation Simulation Facility before installation of the acoustical measurement system and light baffles.

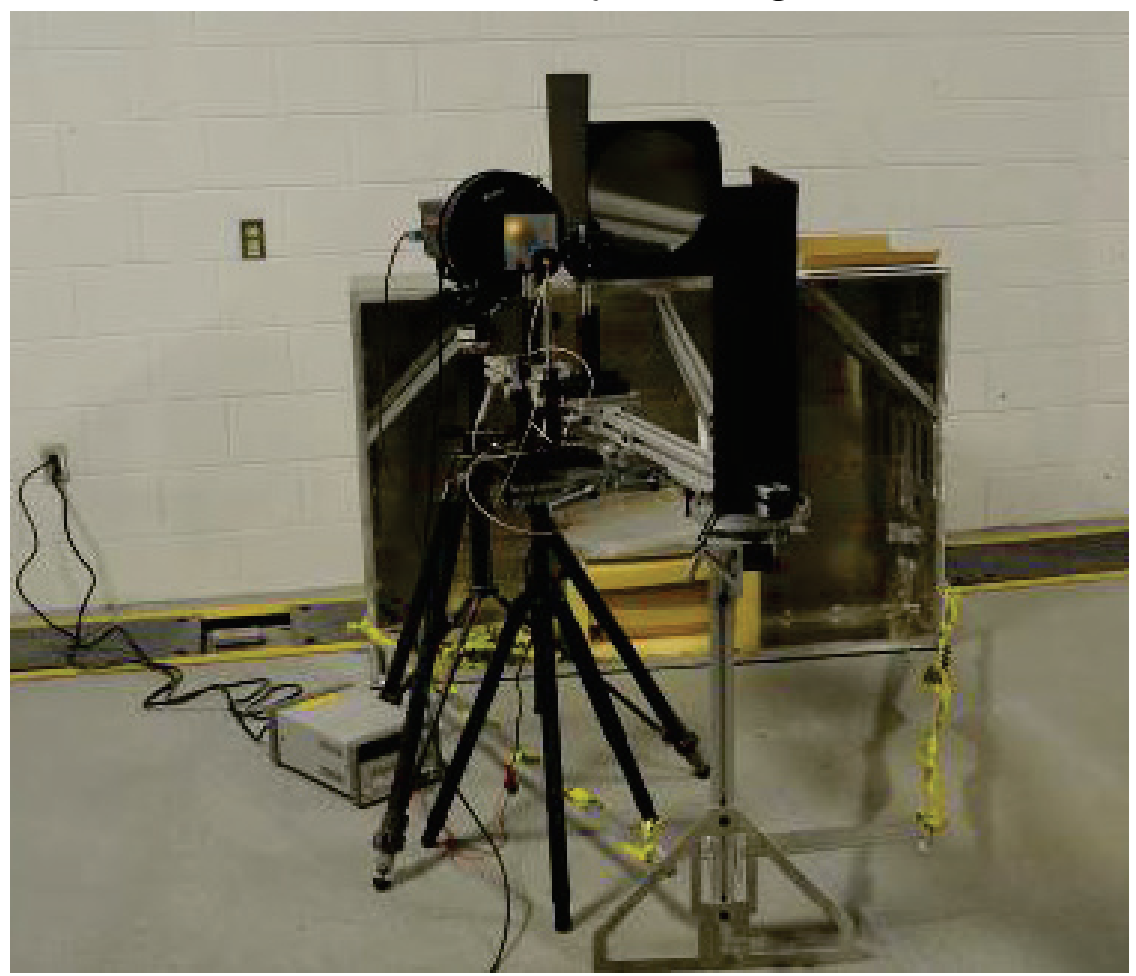

Figure 5. Analyzer portion (left side of Fig. 3) of the schlieren imaging system at the Fragmentation Simulation Facility before installation of the acoustical measurement system and light baffles.

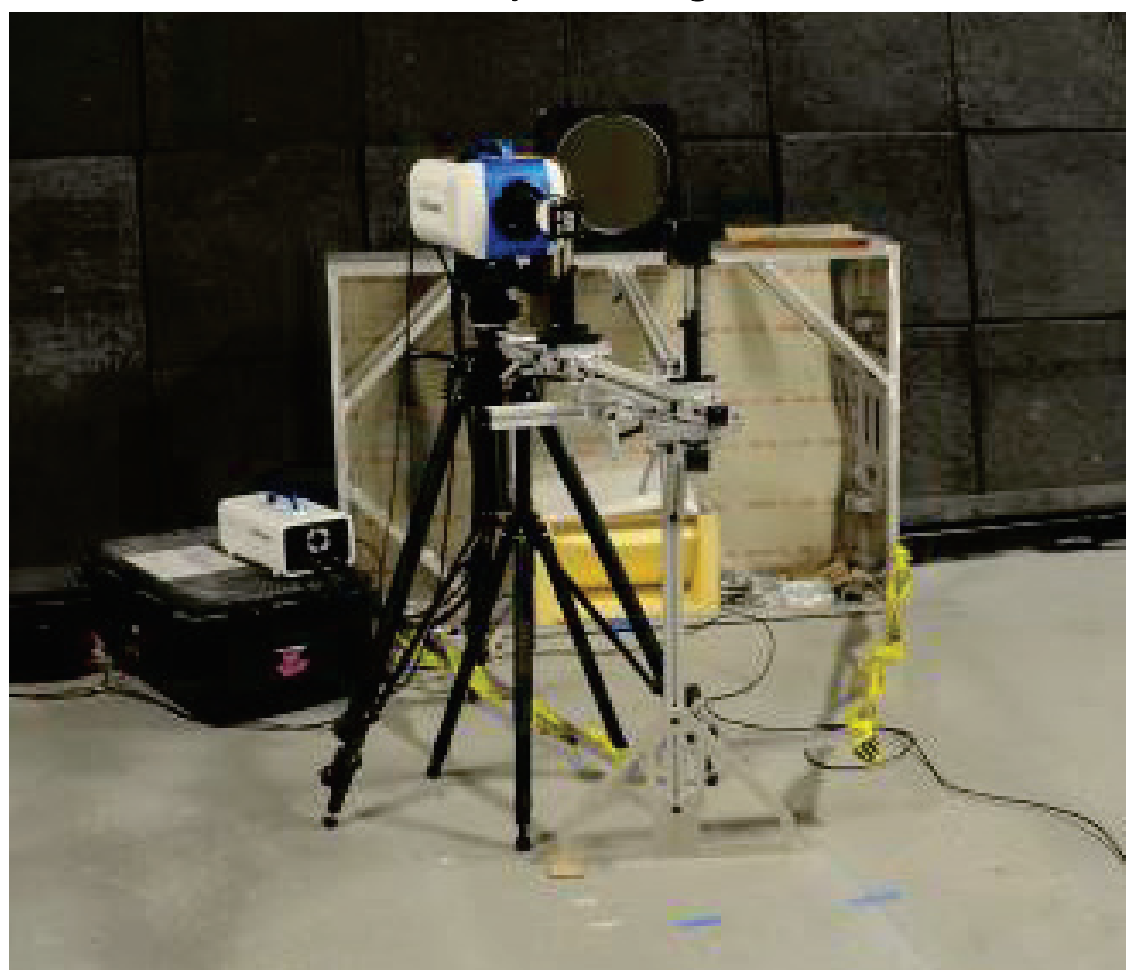




\subsection{Illuminator section}

Figure 7 shows the illuminator section of the schlieren setup. The lighting source was a Photogenic PL2500DR flashlamp, which was triggered by the Kirana high-speed camera using its velocity trap feature, described in detail below. A pair of aspheric condenser lenses on either side of a ground glass diffuser were used to condition and focus the light on the adjustable slit to produce an effectively uniform spatial illumination. For the PL250oDR, the rise-time of the irradiance from the initial trigger depends strongly on the illumination f-stop setting. In the range of f-stop settings used, 200 to 250 , the rise-time was approximately 300 microseconds. A Thorlabs SMo5PD2A photodiode sensing element was used to tune the delay time between the camera and the flashlamp such that the peak light intensity occurred as the camera was acquiring data. Figure 6 shows the output of the photodiode and the camera trigger signal.

Figure 6. Flashlamp intensity over time.

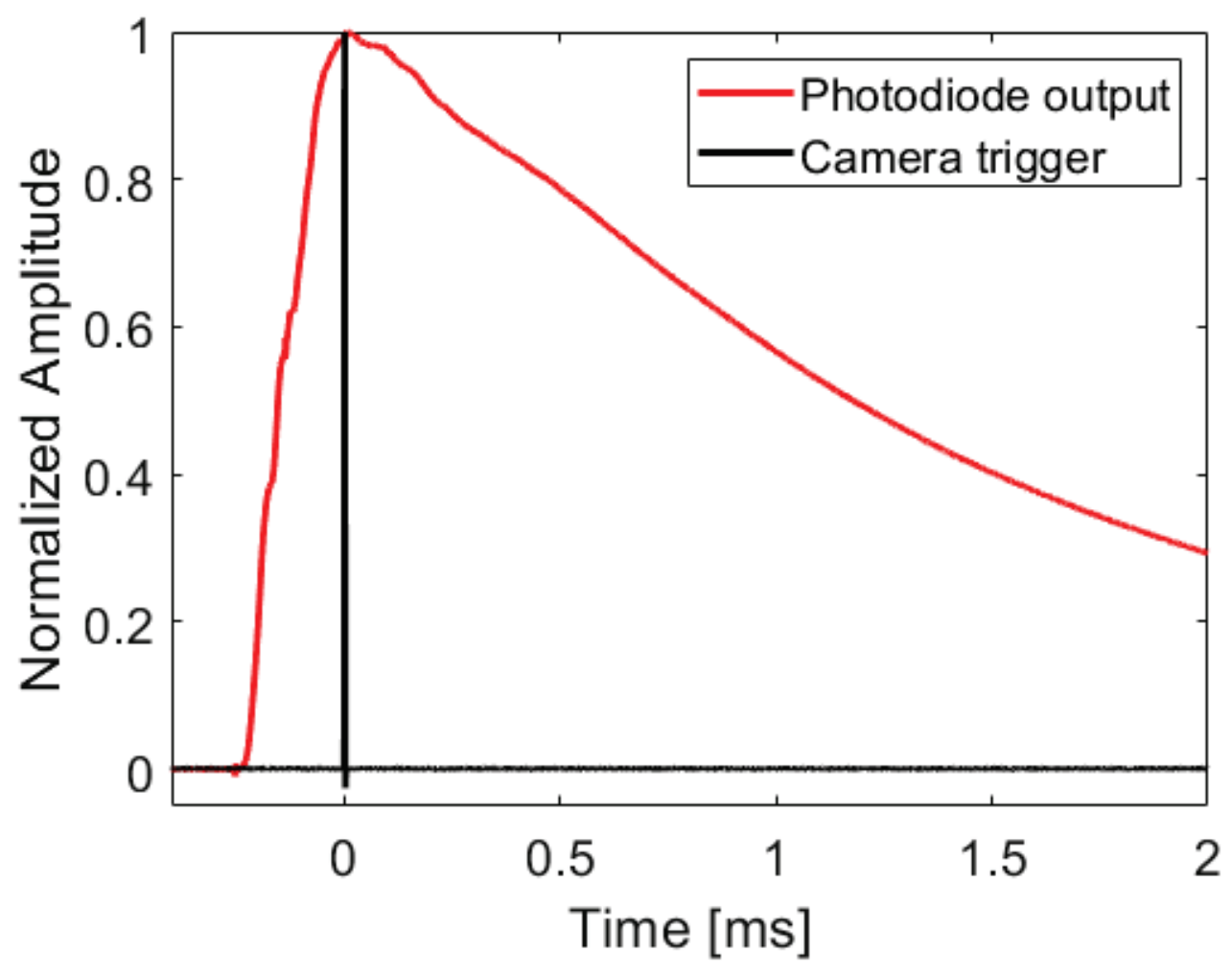


Figure 7. Illuminator section of the schlieren imaging system.

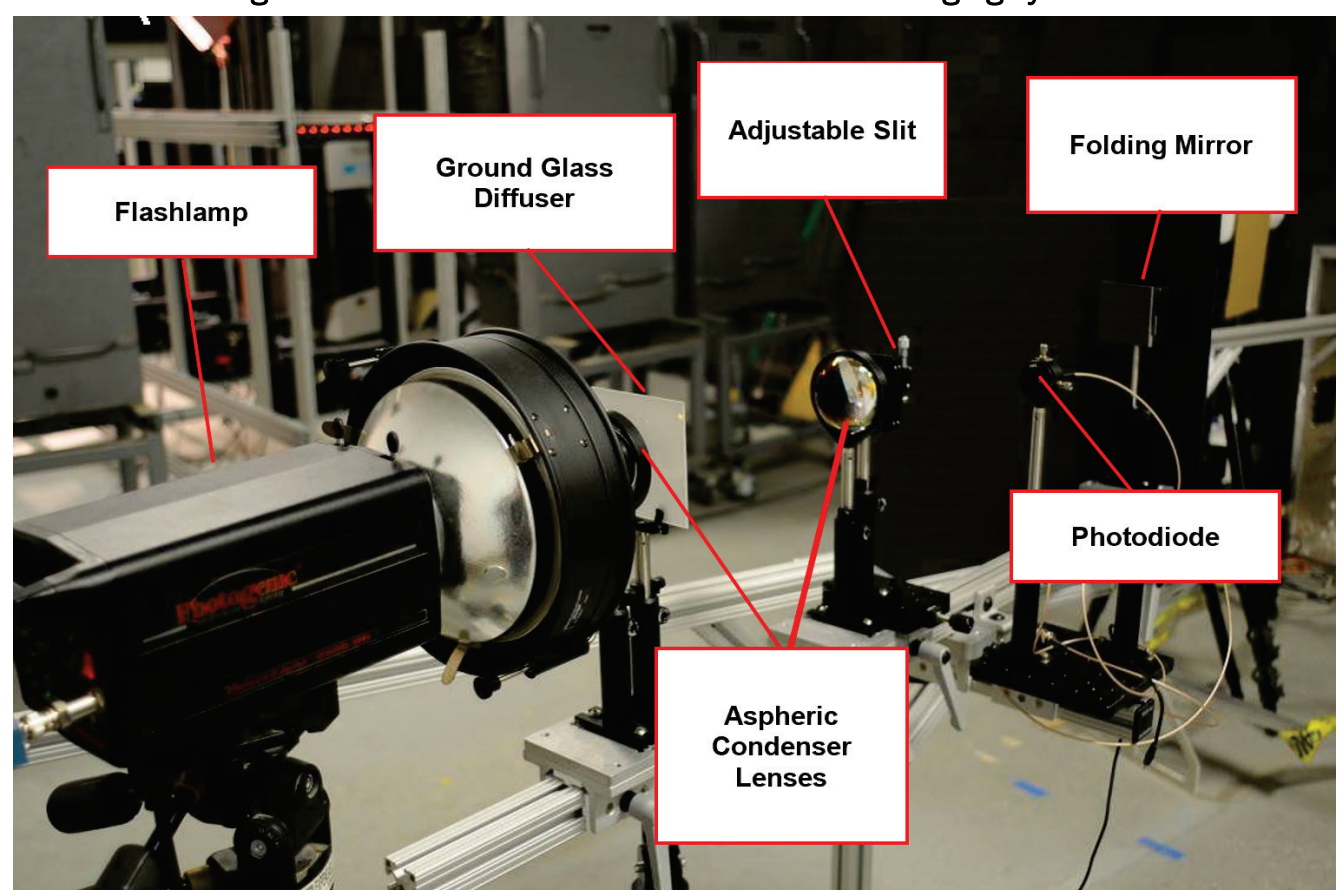

The conditioned light radiates from the slit to the first folding mirror, where it is then reflected onto the first parabolic mirror. The adjustable slit is positioned precisely at the focal point of the parabolic mirror, after accounting for the folding mirror, such that the light is collimated through the test section.

\subsection{Analyzer section}

The analyzer section (Figure 8) consists of an adjustable cutoff (a vertically mounted razor blade) positioned at the second field mirror focal point, a focusing lens, and a camera. In this configuration, the razor edge was adjusted to cut off precisely half of the vertical slit image at the analyzer focal point. When the parallel light rays in the test section encounter a disturbance in density, the light is diverted either away from or onto the cutoff, depending on the direction of the gradient. In this way, a schlieren system projects an image related to the gradient of density transverse to the cutoff edge onto the camera's sensing element.

The focusing lens was used to ensure a sharp focus on objects at the midpoint between field mirrors, through which the projectile was fired. By placing a small opaque object at this position with fine edge details, in this case a small threaded bolt attached to a tripod stand, the camera focus was finely adjusted by sliding the lens along the rail assembly to produce high-quality images. 
Figure 8. Analyzer section of the schlieren imaging system.

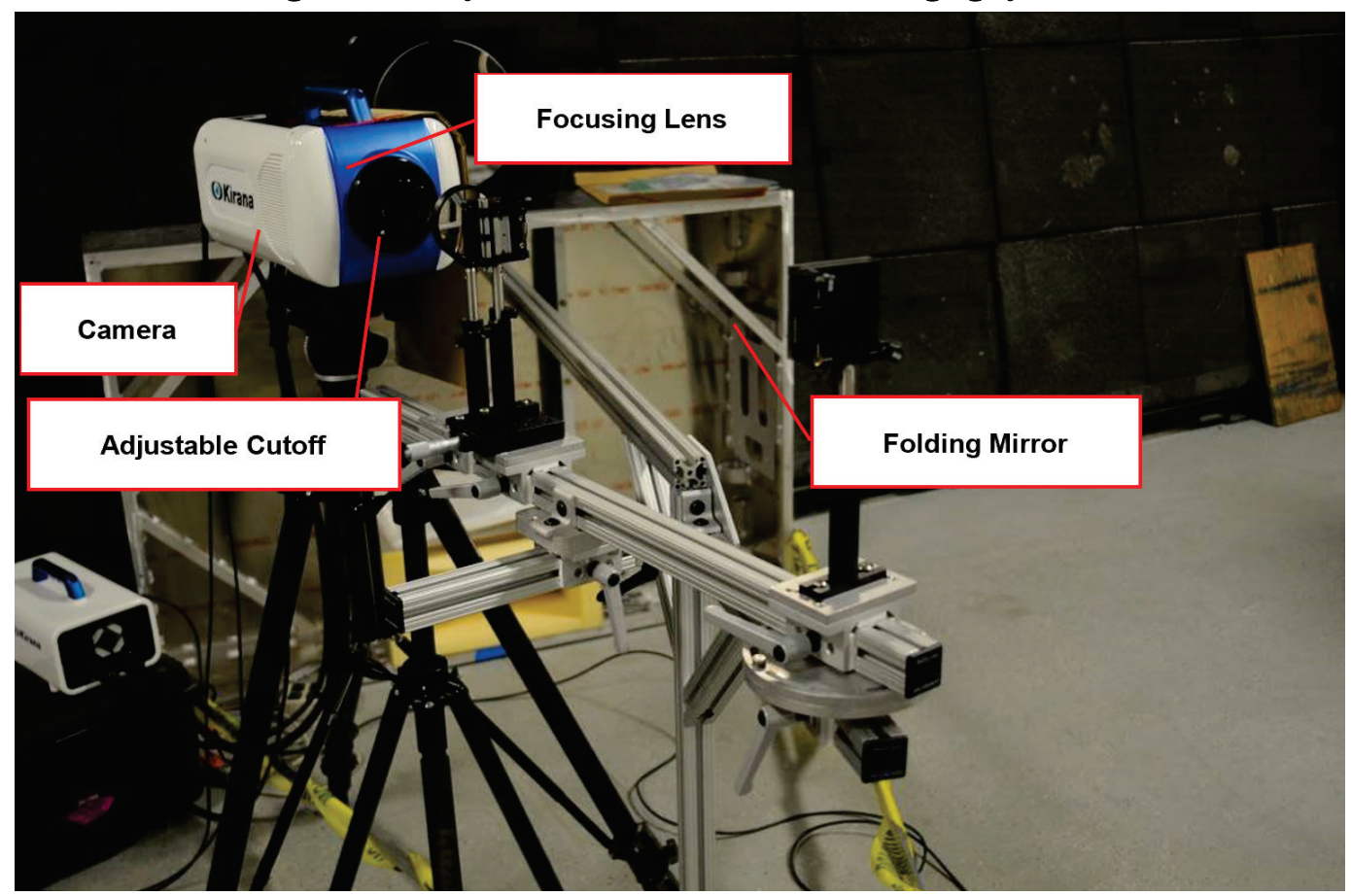

\subsection{Camera and timing}

Image sequences of ballistic pressure disturbances were acquired with a highspeed camera (Specialised Imaging, Kirana SIL-7000-00-Ho1). The sensing element is a charge-coupled device (CCD) that measures $28 \mathrm{~mm}$ in width and $23 \mathrm{~mm}$ in height. Each pixel is approximately $30 \mu \mathrm{m}$ square, translating into an image resolution of $924 \times 768$ pixels (1.2:1 ratio). Acquisition speeds range from 1,000 to 5,000,000 frames per second, with a dynamic range of 10 bits per frame. Minimum camera exposure is $200 \mathrm{~ns}$. Before each image sequence capture, the camera must be manually armed. The camera features dual trigger inputs for operating in a "velocity trap" mode, and contains up to four auxiliary outputs for instrument synchronization and flash triggering. Up to 180 frames can be acquired per image sequence. Section 2.5 further details the camera capture controls, i.e., frame rate and exposure.

To image as much of the acoustic perturbation as possible, the camera field of view ideally circumscribes the schlieren field mirrors. Figure 9 illustrates such a scenario. In practice, the parabolic mirrors were approximately circumscribed, due to the focusing lenses that were available. This was accomplished by placing a focusing lens (Thorlabs, LB1917-A, $300 \mathrm{~mm}$ focal length biconvex lens) between the camera and schlieren cutoff (knife-edge). 
Figure 9. Kirana camera field of view (solid line) circumscribing the diameter of the parabolic mirrors (dashed line).

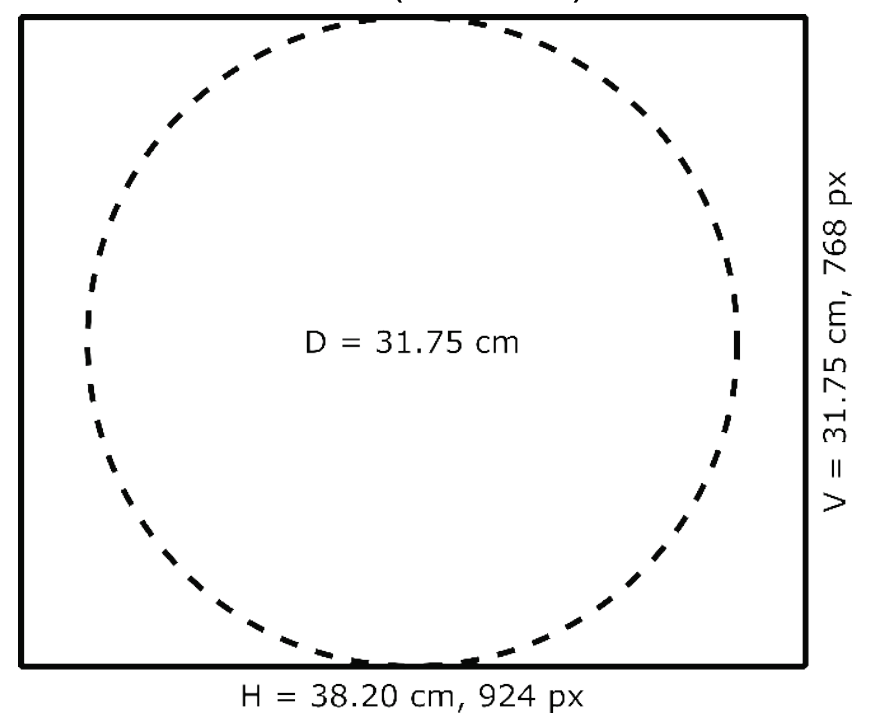

Operating the camera in its "velocity trap" mode provided timing control for image sequence capture, and flashlamp triggering. As a projectile crosses a pair of infrared light screens (Oehler, Model 57) in the chronograph, a rising-edge output is sent from each to the Kirana camera. Given a fixed distance of $0.762 \mathrm{~m}$ between the two planar parallel light screens, the time delay between two rising edges is used to calculate the projectile speed. These rising edges are used directly by the Kirana camera to conduct its own velocity estimation. Provided a distance from the downrange light screen to a point in the camera's field of view, the estimated velocity is used to internally determine the time delay such that the image sequence captures the projectile at a specific point in the field of view. Section 2.5 provides further details regarding timing control via the velocity trap mode.

\subsection{System operation}

Image acquisition with the high-speed camera requires settings for both image capture and timing control. Image capture settings include camera frame rate and image exposure. Timing control was facilitated by operating the camera in a velocity trap mode. Operating in a velocity trap mode requires an initial estimate of the projectile velocity, the distance between two infrared light screens that provide trigger inputs to the camera, and a distance from the downrange light screen to the desired position in space at which image sequence capture begins. Furthermore, in this mode a flash trigger can be sent from the camera to a flashlamp, given a time delay to the first image frame. 
Considerations for camera frame rate are based on the following factors: flight distance in the image sequence, and the number of acceptable frames. Initially, it was decided to image projectile flights across the whole diameter of the schlieren field mirrors. Practically, the first 30 frames are discarded due to pixel bleed (improper spatial binning within a single image) and other oscillatory artefacts, which leaves 150 acceptable frames. Given a projectile velocity, the upper frame rate is computed as

$$
F_{u}=\frac{N_{k} V}{D},
$$

where

$$
\begin{aligned}
F_{u} & =\text { the upper frame rate } \\
N_{k} & =\text { the number of frames to keep (150) } \\
V & =\text { the projectile velocity } \\
D & =\text { the schlieren field mirror diameter }(0.3175 \mathrm{~m}) .
\end{aligned}
$$

Under the circumstances of the test, the upper frame rate was computed to be $145,843,178,252$, and 405,118 frames per second, for projectile velocities of Mach 0.9, 1.1, and 2.5, respectively. During initial tests, it was determined that these frame rates were incompatible with the required exposure setting due to image ghosting and camera noise (based on communications with Specialised Imaging, the camera noise is minimal when the frame rate is set to the reciprocal of the exposure time). It was decided that it would better serve the objectives of the test to improve the image quality so the frame rate was set to $1,000,000$ frames per second.

The required camera exposure is based on the need to freeze projectile flight in a frame such that its displacement is at the sub-pixel level. The time it would take for a projectile to traverse a single pixel is simply the ratio of the distance corresponding to the horizontal breadth of the camera's field of view, and the projectile velocity (see Figure 9). For example, given a velocity of Mach 2.5, the time to travel across a single pixel is $445 \mathrm{~ns}$. Since the closest preset value for the Kirana camera is 500 ns, this exposure was selected.

As mentioned above, the velocity trap mode requires input regarding the distance from the second infrared light screen to the point at which image capture begins. Based on the revised frame rate, it was decided that the 
image sequence capture, after the $30^{\text {th }}$ frame, should begin when the projectile tip meets the optical axis along the two schlieren field mirrors. This distance is computed in the following manner,

$$
L=A-\frac{N_{d} V}{F},
$$

where

$$
\begin{aligned}
A= & \text { the distance from the second light screen, parallel to the } \\
& \text { projectile path, to a point that intersects the optical axis along } \\
& \text { the two schlieren field mirrors }(2.7392 \mathrm{~m}) \\
N_{d} \quad=\text { the number of frames to discard }(30) & \\
F= & \text { the frame rate }(1,000,000 \text { frames } / \mathrm{s}) .
\end{aligned}
$$

In addition to this input to the velocity trap mode, the time delay in sending a flash trigger was required. This time delay was largely a function of the schlieren illuminator flashlamp f-stop setting. Since the illumination time history was a function of f-stop setting, it was necessary to inspect the output of a photodiode, which measured the flashlamp output, along with the gated exposure output of the camera on a digital oscilloscope. The necessary time delay was set such that the maximum illumination occurred during the gated camera exposure. For the nominal f-stop setting of 233, the optimal time delay was found to be 300 microseconds. This value was used for the duration of the experiment.

In the course of aligning and configuring the schlieren system, a series of test shots were used to refine both the slit width and flashlamp irradiance, which are related to the measurement range and sensitivity, respectively, for a linear photoelectric detector such as the Kirana camera (Vasil'ev 1971). These adjustments were made by observing the histogram of camera pixel intensities. Both settings were adjusted iteratively to produce a distribution of pixel intensities that nearest approached the bright and dark limits of the camera without over- or under-ranging, to fully use the dynamic range of the camera.

However, it was found that certain weak features of interest, particularly acoustic radiation from the turbulent projectile wake, were difficult to resolve with these settings. Therefore, the measurement range was decreased, and sensitivity increased, to deliberately create a small degree of 
overranging in the portion of the front shock nearest to the projectile. After this final adjustment, the slit width was found to be $2 \mathrm{~mm}$. The optimal schlieren illuminator flashlamp f-stop was found to be projectile- and velocity-dependent, and was adjusted slightly between 200 and 250 over the course of testing. Most significantly, the increase in the ballistic shock Mach angle with decreasing projectile velocity caused the pressure gradient component in the direction of the trajectory (and perpendicular to the schlieren cutoff) to be greater at the lower Mach number test point, despite the decrease in overall pressure perturbation magnitude.

An important procedure to follow when using the Kirana camera is the recording of a session black image sequence. Even when no light is incident on the camera sensor, weak artefacts in the image sequences can be seen. For this reason, the camera software uses a reference sequence of dark images for a post-correction step. Whenever any camera setting was changed, including frame rate and exposure settings, the camera aperture was blocked with a lens cap, and a new session black sequence was acquired according to the software procedure.

A practical issue that arose in testing of the Kirana camera with the schlieren system was that of so-called 1- and 10-frame ghosting. This is an artefact particular to the Kirana camera architecture in which images 1 and 10 frames before a recorded sequence are "ghosted" into the current image. The resulting effect is that of "doubling" or even "tripling" the actual recorded object in obvious error. Figure 10 shows an example of this artefact and its impact on a recorded sequence. For the chosen frame rate, magnification, and projectile velocity, the 10-frame ghosting effect is much more pronounced.

While this effect cannot be entirely eliminated, it was reduced significantly through two modifications. First, the frame rate was increased from an initial setting of 400,000 frames per second to the final 1,000,000 frames per second. Second, the contrast from the dark silhouette of the projectile against the schlieren background was reduced by introducing front lighting. Four additional Photogenic PL250oDR flashlamps were used to illuminate projectiles from the front (i.e., the analyzer side of the schlieren) with diffuse indirect light, by redirecting their flash with white diffusor panels shown in Figures 11 and 12. Stray light entering the schlieren system or camera aperture without first reflecting from the projectile was sys- 
tematically identified and eliminated with a series of light baffles. Projectiles were also painted white with a matte finish (Figure 13) both to improve illumination and reduce glare from specular reflection.

As described previously, the illumination time history from a PL250oDR flashlamp is a function of f-stop setting. The higher the f-stop setting, the more quickly the lamp reaches full illumination after receiving a trigger. Because the front-lighting lamps were operated at a much higher f-stop than the schlieren lamp, it was necessary to correct for the difference in optimal illumination rise times through an additional delay. Again, through use of a photodiode and oscilloscope, it was found that the flashlamps at their highest f-stop of 1000 setting reached full illumination in only 184 microseconds. Since the schlieren flashlamp was triggered by the camera 300 microseconds (for an f-stop of 233) before the image sequence capture, a BNC 577 pulse generator was used to introduce a 116 microsecond delay from this signal to trigger the four front-lighting flashlamps.

In the course of testing, it was found that different projectiles required different levels of front lighting, and so the f-stop settings of the two overhead flashlamps shown in Figure 10 were regularly adjusted to illuminate each type of projectile as much as possible without overranging the image due to glare on the projectile surface. Table 1 lists all combinations of $\mathrm{f}-$ stop settings used for these two flashlamps. The lower two front-lighting flashlamps shown in Figure 11 were set to an f-stop of 1000 and left at this setting for the duration of the experiment.

Table 1. All flashlamp setting combinations used for overhead front lighting of projectiles.

\begin{tabular}{|l|l|l|l|l|l|l|l|l|l|}
\hline Left f-stop & 660 & 707 & 707 & 758 & 758 & 812 & 871 & 933 & 1000 \\
\hline Right f-stop & 660 & 707 & 758 & 707 & 758 & 812 & 871 & 933 & 1000 \\
\hline
\end{tabular}

While front lighting of the projectile did reduce the ghosting artefacts, it introduced a new issue in the form of diffuse stray light entering the schlieren optical system. The most intense stray light was blocked with baffles as described above, but it was impossible to eliminate all ray paths. The schlieren images after the front-light modification suffered from a weak background illumination that was greatest in the upper right image corner.

Since this background was weak enough so that it did not contribute significantly to image overranging, and since it was repeatable from shot to shot, a 
series of background-only images without the schlieren illuminator flashlamp can be used to simply subtract this weak unwanted background. To record such sequences, the four front-lighting flashlamps were triggered in sequence with the camera, but the schlieren flashlamp was disabled. A set of five image sequences were recorded for each of the nine pairs of overhead flashlamp f-stop settings listed in Table 1, so that non-deterministic random electronic noise could be averaged out of the background sequences. Backgrounds were taken both with the edge of the Array B baffle plate occluding part of the schlieren test section, as was the case for all Mach 2.5 projectile shots, and with the edge removed, as was true for the Mach 1.1 shots.

Instead of firing a projectile to trigger these sequences, the BNC 577 pulse generator was reconfigured to act as a "virtual" set of chronograph light screens. The travel time for a Mach 2.5 projectile between the two screens, which were displaced by $762 \mathrm{~mm}$, was calculated to be 889 microseconds. The timing generator was then programmed to send two rising-edge signals with this delay to the camera trigger inputs, which then triggered all four front-lighting flashlamps at their optimal 184 microsecond delay before the image sequence capture.

Similarly, a set of schlieren backgrounds was taken for each schlieren flashlamp f-stop used, still using the pulse generator as a virtual light screen velocity trap trigger. In this configuration, the front lighting was disabled and the pre-sequence delay was returned to the 300 microsecond value used for the schlieren lamp throughout testing. For each f-stop setting, a set of 10 identical background sequences were taken, in this case both for averaging electronic noise and any inhomogeneity in the image due to temperature fluctuations in the room. These sequences can be used to correct for any systematic non-uniformity in the schlieren test section illumination itself, such as the slight fading at the aperture edges. 
Figure 10. Frame from a schlieren image sequence highlighting the 1- and 10 -frame ghosting issue.

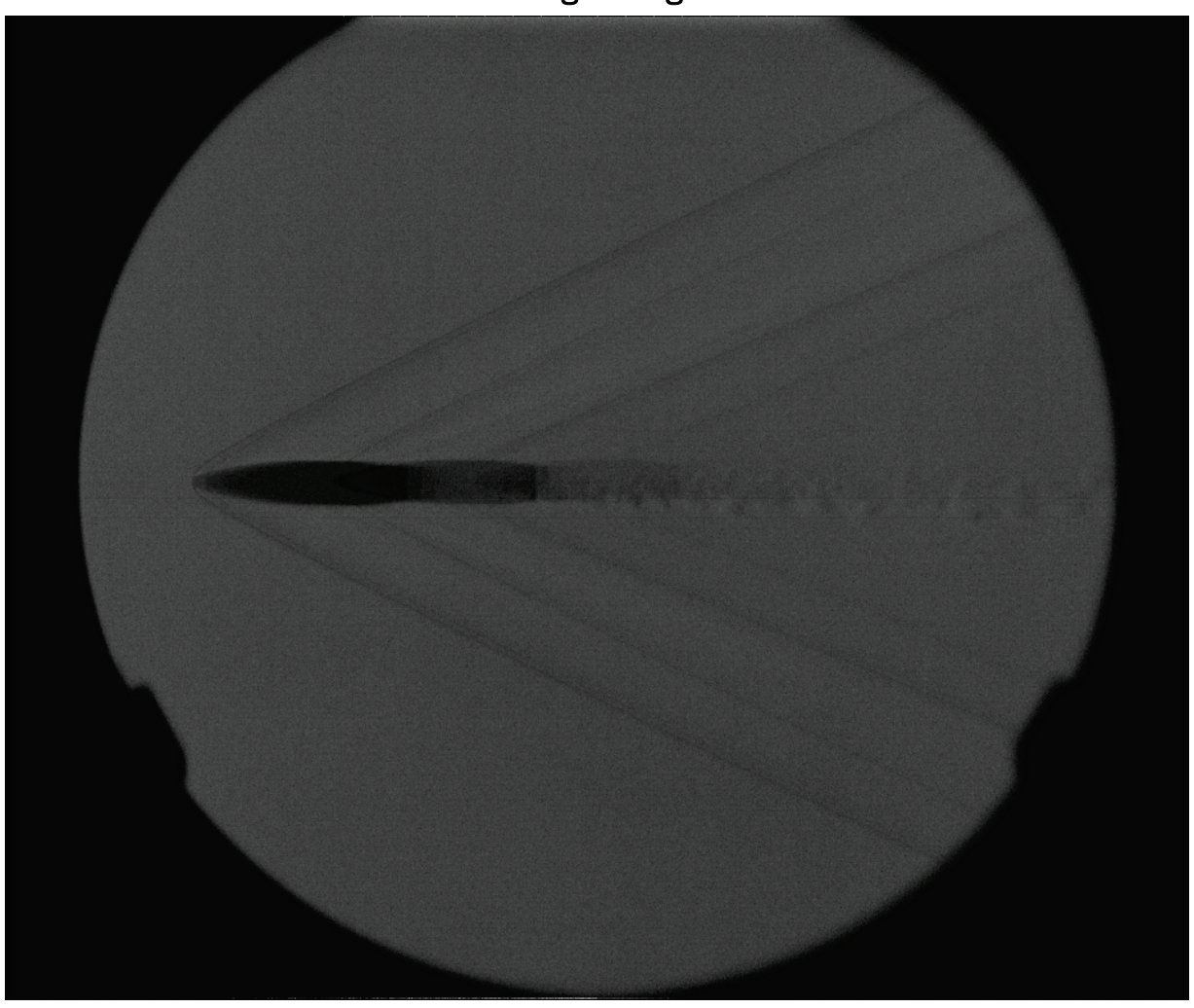

Figure 11. Overhead flashlamps added to illuminate the projectile as it passed through the test section. The flashlamps are aimed at a white diffusing screen to reduce glare on the projectile. An additional light baffle blocked light from entering the optical path of the schlieren system.

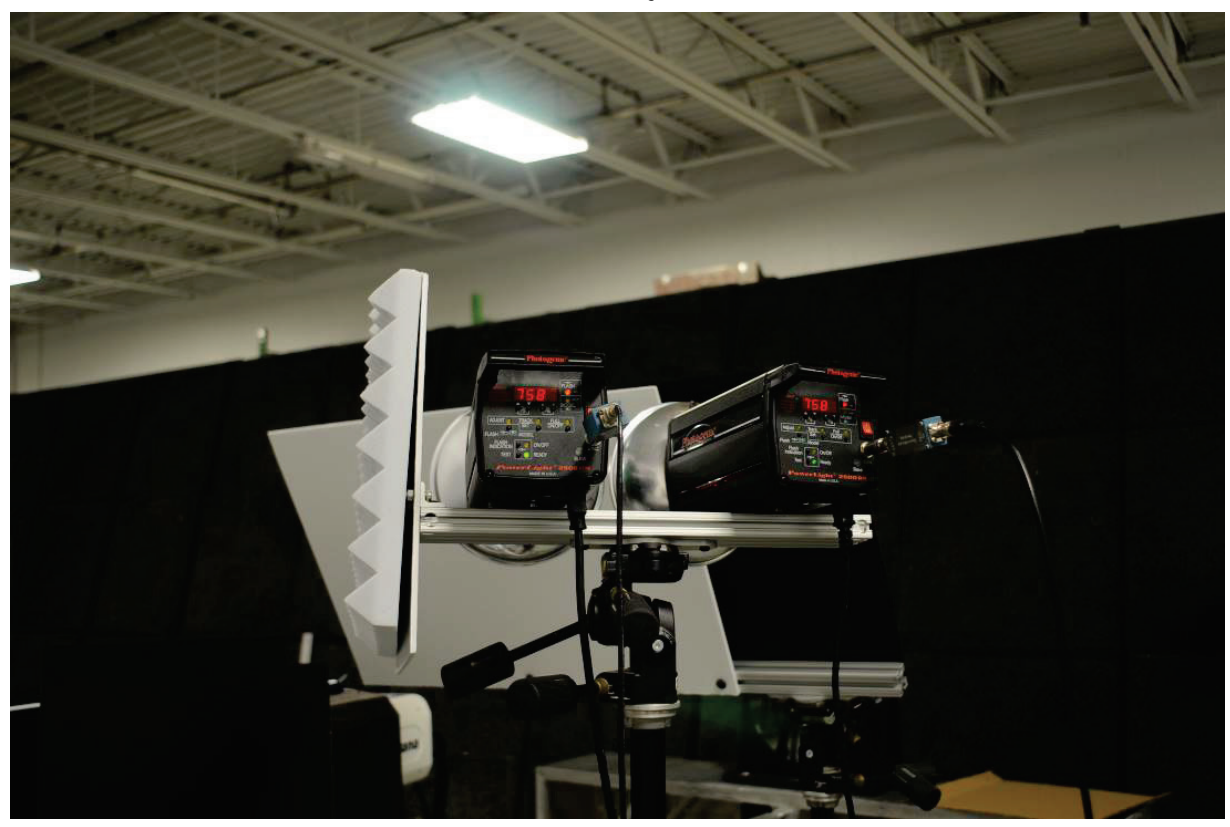


Figure 12. Additional flashlamps were placed on the floor aimed at the diffusor panel to provide further illumination.

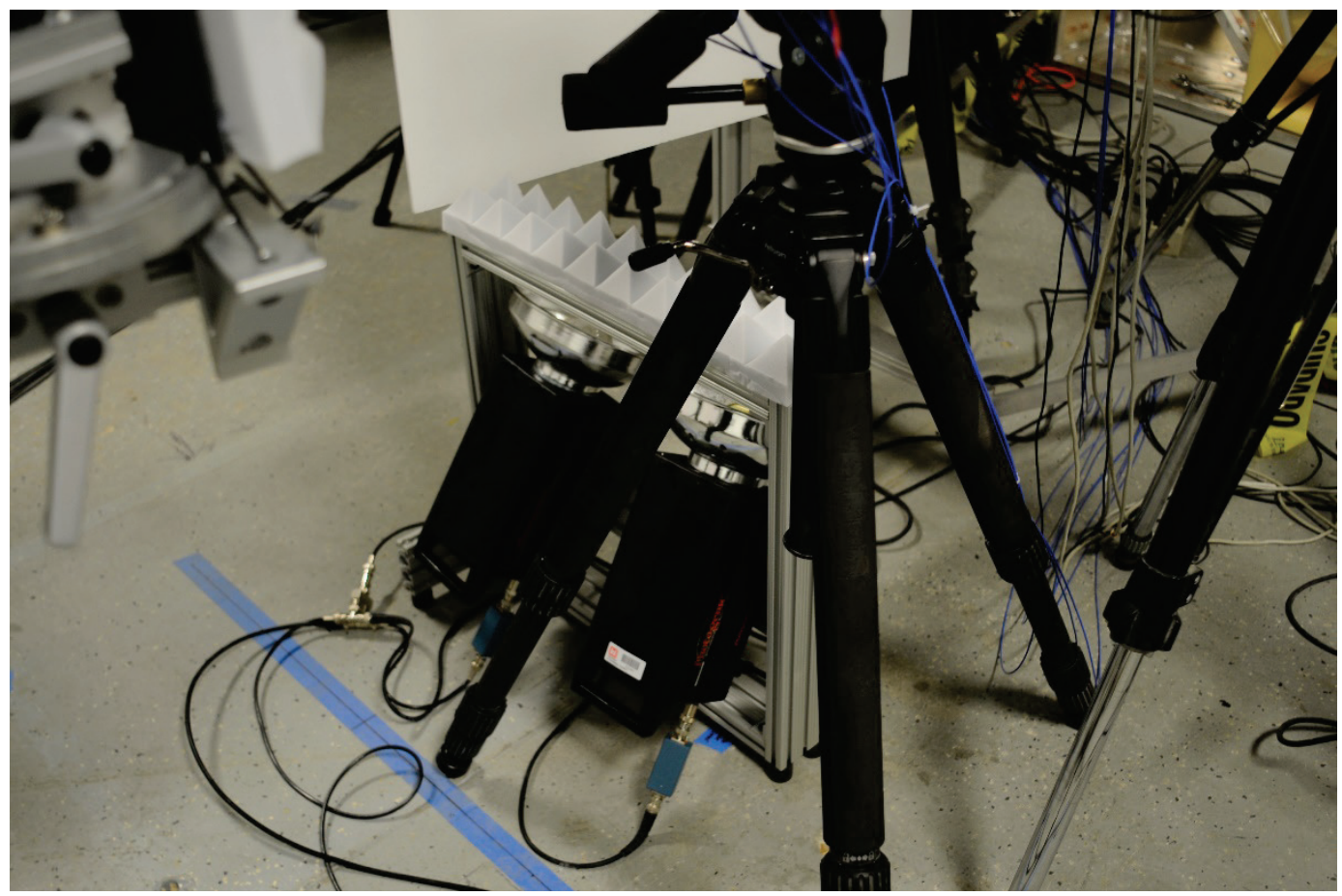

Figure 13. Projectiles were painted matte white to reduce further the contrast between the projectile and the background. The left shows a loaded .50 caliber M33 Ball round, while the right shows painted 500 Nitro Express and .50 caliber FSPs before loading.

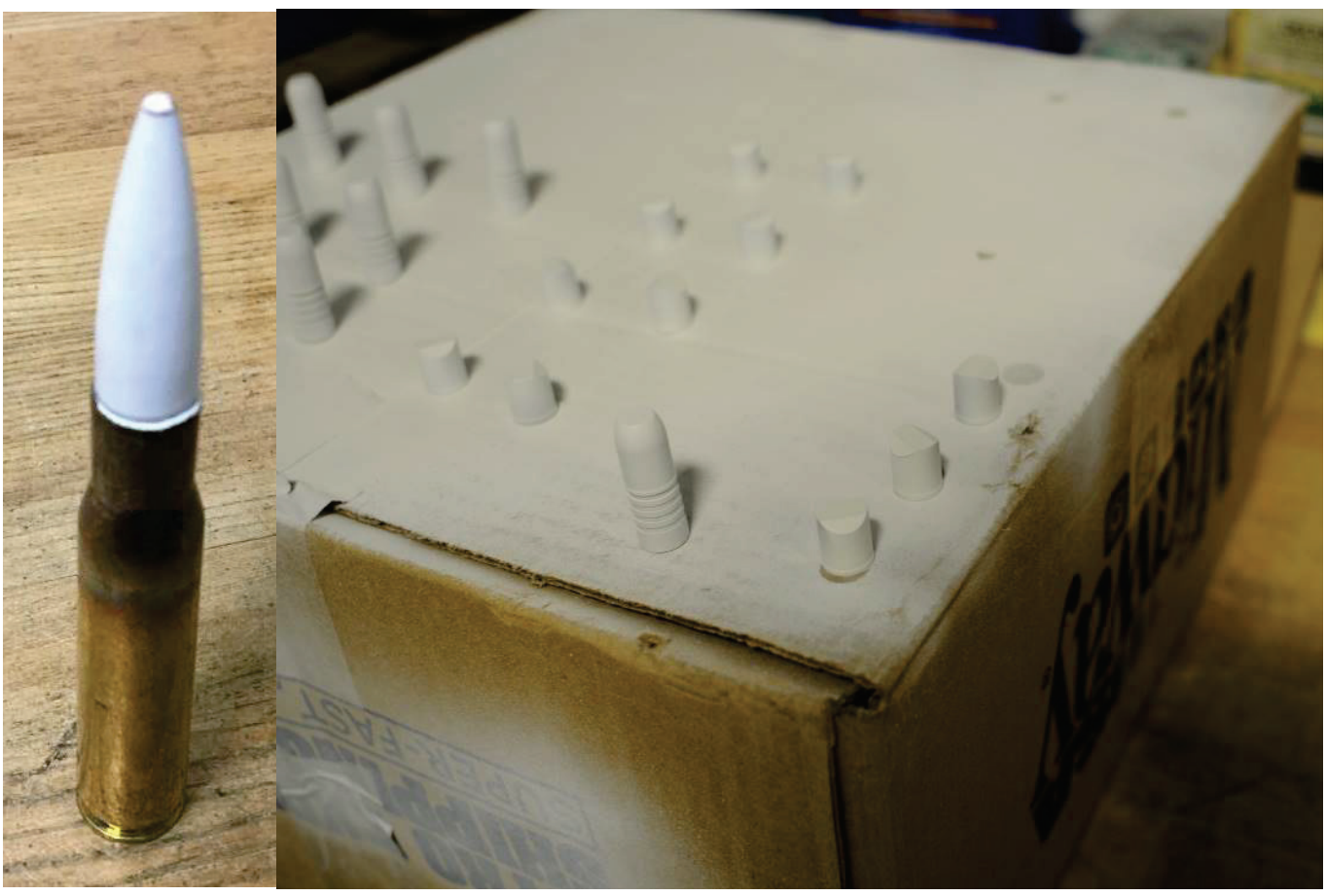




\section{Acoustic Sensors}

\subsection{System design}

Several types of transducers were used to sense the acoustic pressure disturbances caused by supersonic projectile motion. High-frequency pressure transducers were used close to the ballistic trajectory to capture the generation of shocks near the projectile surface. Conventional condenser microphones were used to capture the propagation and coalescence of the shocks into acoustical signatures. A laser doppler vibrometer (LDV) was used to indirectly record the axisymmetric pressure perturbation by encoding the optical path difference due to variation in the refraction index as the velocity of a fictitious vibrating surface.

Due to the high peak overpressures caused by the ballistic shock, special care was taken to ensure that the condenser microphones did not overrange. The equation for the peak pressure amplitude, $p_{\max }$, of a projectile of length $l$ and diameter $d$ traveling at Mach $M$ a distance $b$ from the trajectory is given as (Stoughton 1997)

$$
p_{\text {max }}=\frac{0.53 P_{0}\left(M^{2}-1\right)^{1 / 8}}{b^{3 / 4}} \frac{d}{l^{1 / 4}},
$$

where $P_{0}$ is the ambient pressure.

Assuming a .50 caliber projectile with a length of $58.4 \mathrm{~mm}$, Figure 14 shows the peak pressure amplitude as a function of distance from the trajectory for velocities of Mach 2, 3, and 4.

The fast rise times expected from ballistic shocks necessitated transducers capable of sensing very high frequency. For this task, 1/8-in.condenser microphones and high-frequency pressure transducers were employed close to the projectile trajectory. $\mathrm{PCB}$ 113B28 high-frequency pressure transducers were used in Arrays A and B, as shown in Figure 15, due to their high dynamic range, up to $689.4 \mathrm{kPa}$, and high resonant frequency, $\geq 500 \mathrm{kHz}$. GRAS $40 \mathrm{DP}$ condenser microphones, capable of sensing sound up to $140 \mathrm{kHz}$ at \pm $2 \mathrm{~dB}$, were flush-mounted in a baffle, Array B, with their grid caps removed. Farther from the source, GRAS 4OBF microphones were used in Array C. 
Figure 14. Peak sound pressure level, $L_{p k}$, vs. miss distance for a .50 caliber projectile for three velocities Mach 2 (solid curve), Mach 3 (dashed curve), and Mach 4 (dotted curve). The upper limit of a GRAS 4OBF 1/4" condenser microphone is shown as the red dashed line.

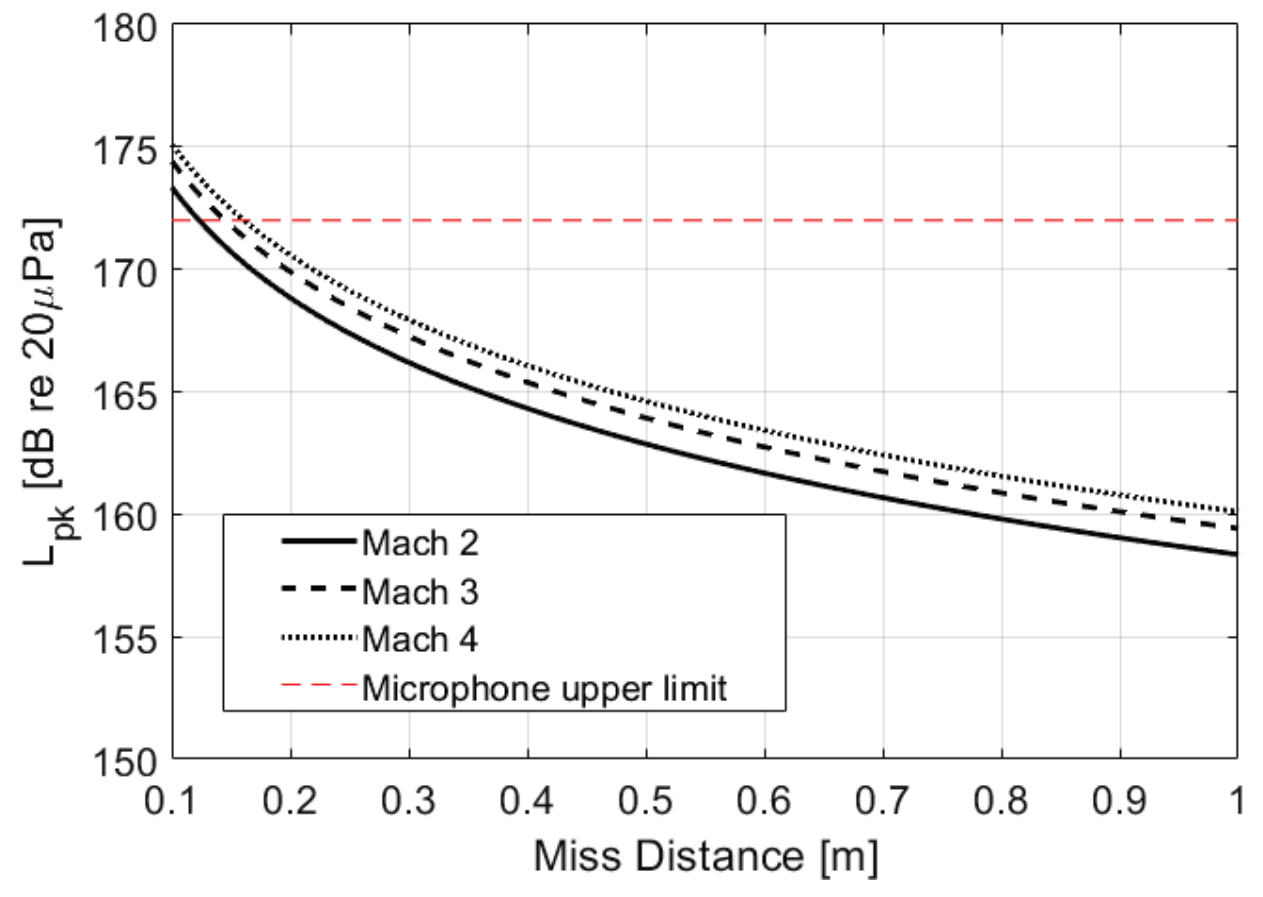

Figure 15. Plan view of acoustical components in the experimental setup. The angle of array $B$ with respect to the projectile trajectory is set to the Mach angle corresponding to the target projectile velocity. The nearest sensor, B1, is 6 in. perpendicular to the projectile trajectory.

The sensing elements of the microphones in arrays $B$ and $C$ lie in the same plane as the projectile trajectory and optical axis, while Array A lies 6 in. below the trajectory. The LDV head is 1 in. above, and perpendicular to, the projectile trajectory.

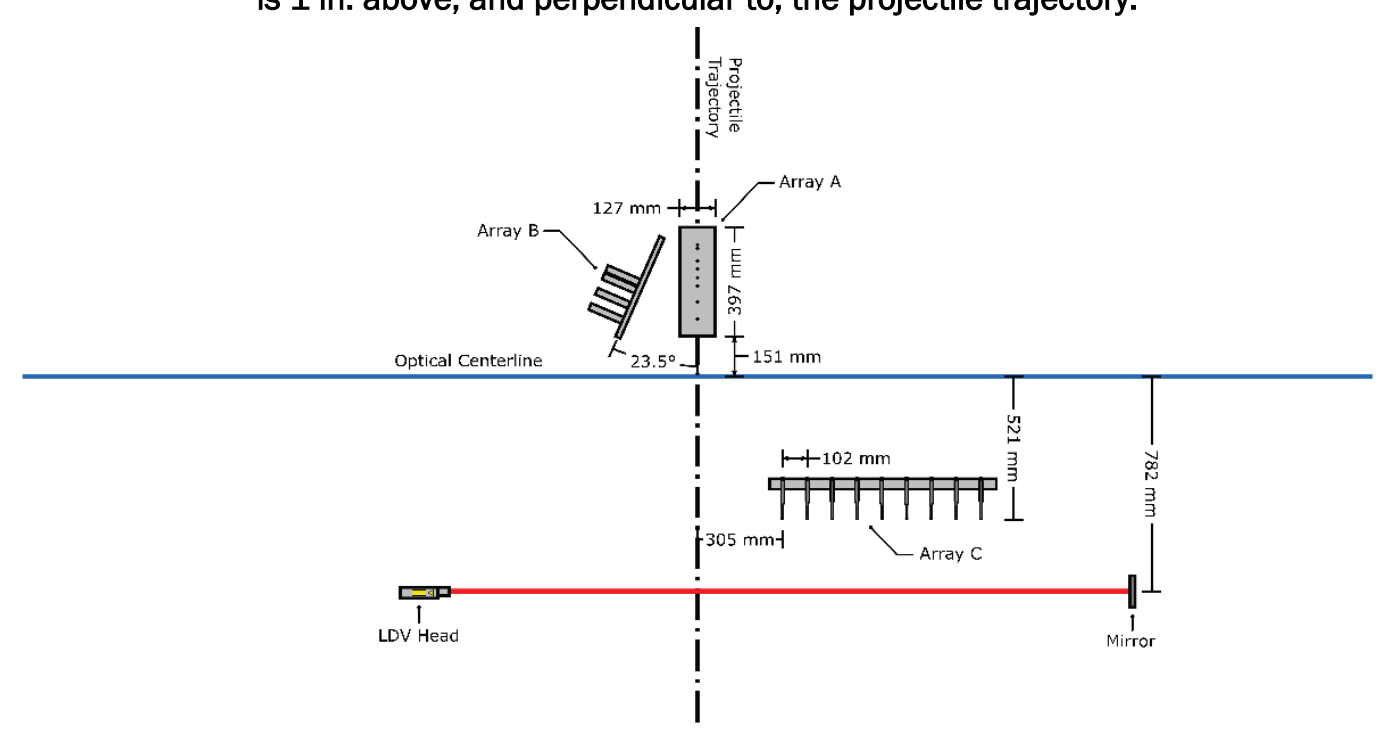


Figure 15 shows the arrangement of acoustical sensors used in the experiment. Arrays A and B were mounted as close as possible to the ballistic trajectory to capture the generation of sound by the projectile. Array A was mounted parallel to the trajectory while array B was angled such that the Mach cone of a projectile traveling at the target velocity would be parallel to the array. Array $\mathrm{C}$ was located uprange of Arrays A and B and was oriented perpendicular to the ballistic trajectory to measure acoustic quantities as a function of radial distance from the trajectory. The LDV is oriented 1 in. above, and perpendicular to, the trajectory slightly uprange of Array C.

\subsection{Array A}

Array A consists of eight PCB 113B28 high-frequency pressure transducers flush-mounted in an aluminum baffle (see Figure 16). Appendix A lists the sensor and signal conditioner serial numbers. in. The sensors are arranged in a Minimally Redundant Array (MRA) configuration. This configuration was chosen to maximize resolution and uniformly sample the spatial-frequency spectrum (Moffet 1968). Based on a preliminary estimate of the vortex shedding frequency for a .50 caliber projectile traveling at Mach 2, the minimum array spacing is set to $1.5 \mathrm{~cm}$.

Since the high-frequency pressure sensors were mounted in a baffle with finite stiffness, some degree of vibration induced by the impinging ballistic shock wave was expected. To capture this vibration, a PCB 333B32 accelerometer was affixed to the bottom of the baffle plate using hot glue (Figure 17). The output of the accelerometer was recorded on one of the Yokogawa DL750 recording oscilloscopes through a 701275 acceleration and voltage input module at a sampling rate of $100 \mathrm{kHz}$. The data from the accelerometer enables the degree to which the vibration of the baffle plate may have affected the high-frequency pressure transducers to be assessed. 
Figure 16. Array A consists of eight PCB 113B28 high-frequency pressure transducers flushmounted in an aluminum baffle plate.

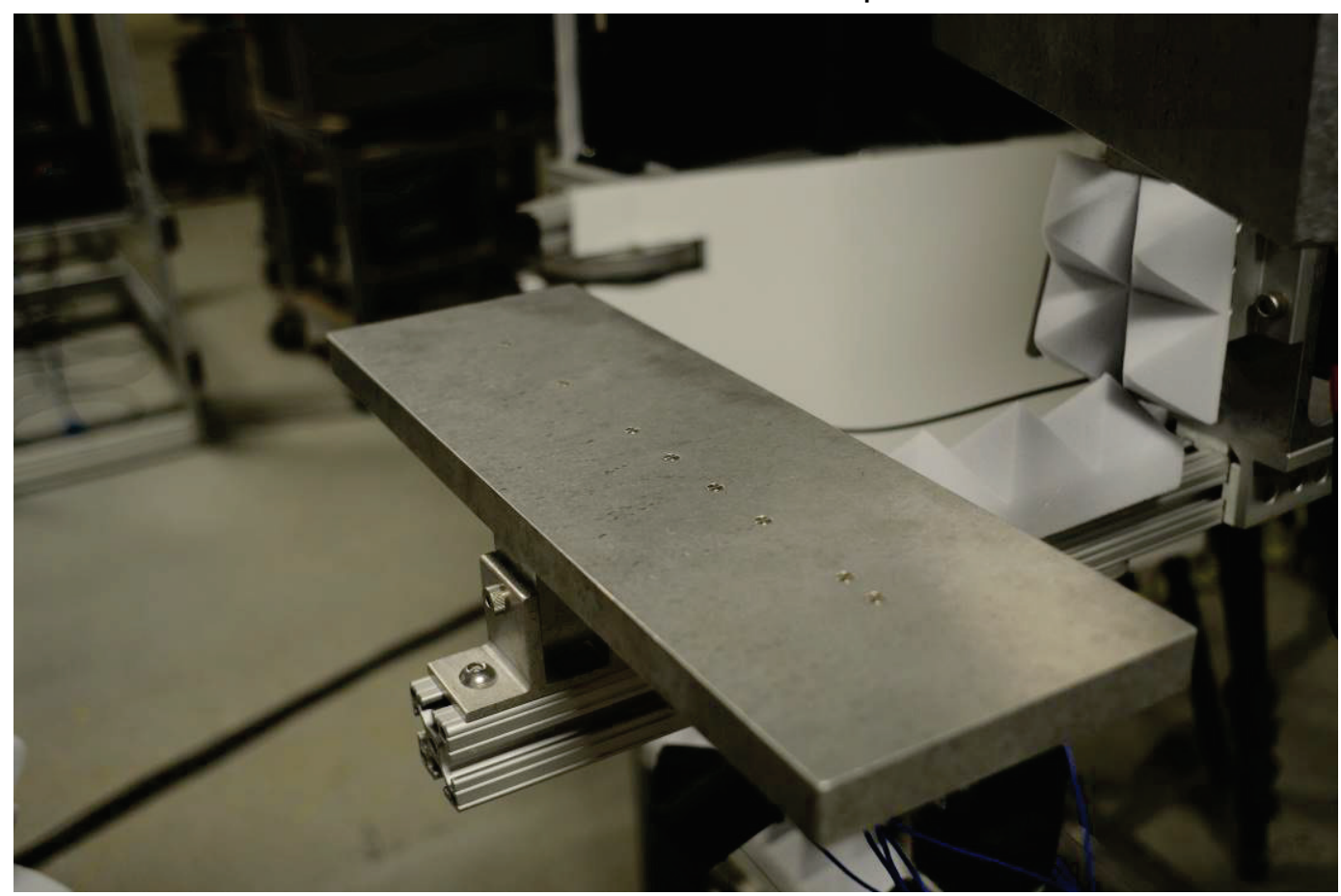

Figure 17. The underside of Array A showing the mounting position of the PCB $333 \mathrm{~B} 32$ accelerometer.

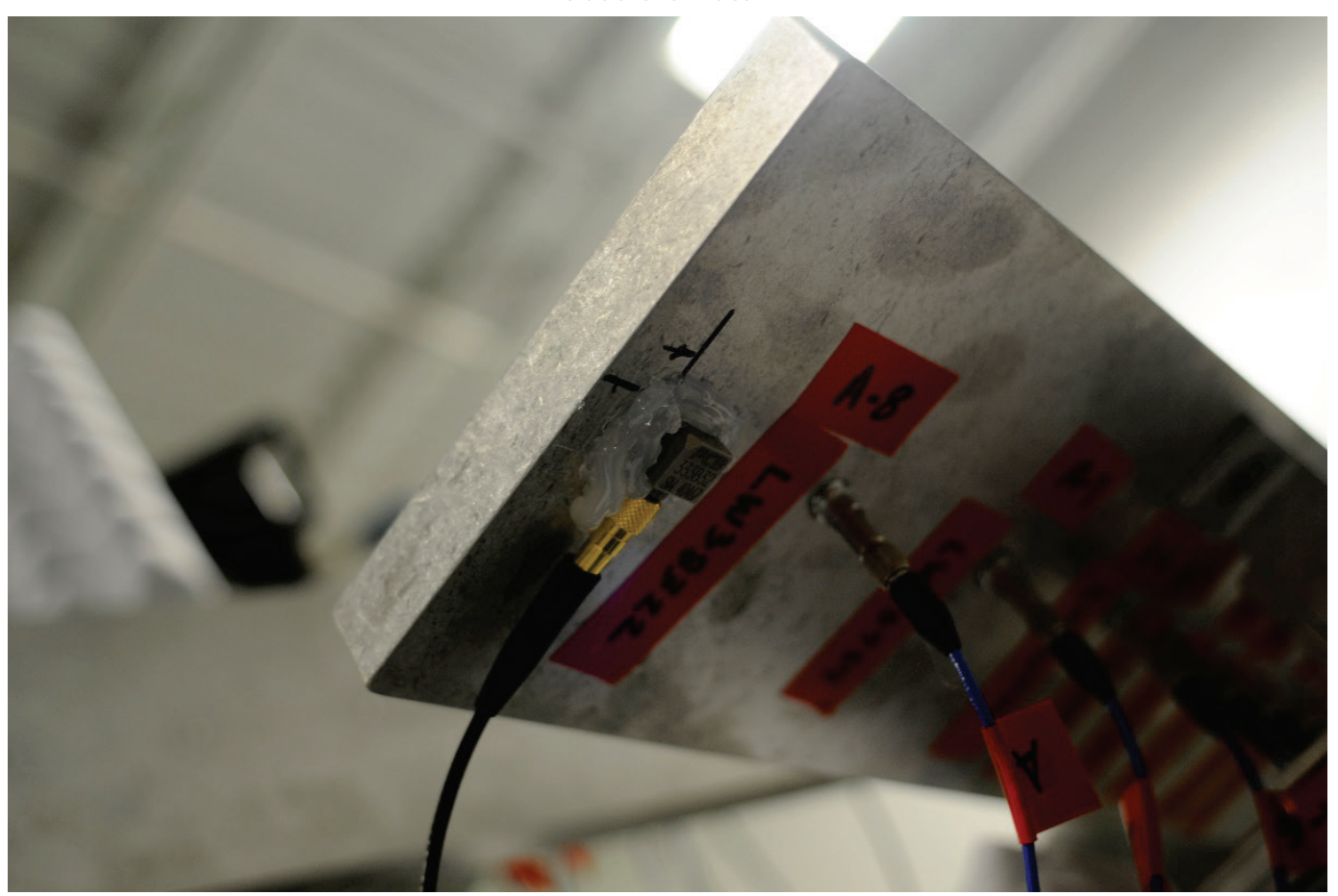




\subsection{Array B}

Array B is similar to Array A, and differs only in its orientation and choice of sensors (compare Figures 16 and 17 to Figures 18 and 19). Array B is mounted at an angle relative to the projectile trajectory such that the ballistic shock wave of a projectile traveling at a nominal velocity of Mach 1.1 or Mach 2.5 is sensed by the array at broadside incidence. Additionally, the changes in the sensed waveform (e.g., the decay of the peak amplitude, elongation of the waveform, and coalescence of the intermediate shocks) can be noted by comparing the output of the sensors at different distances from the projectile trajectory, but at nearly the same instance in time.

The sensors in positions B-5 through B-8 (see Figure 19 and Table A-2) are GRAS model 4ODP 1/8-in condenser microphones with Brüel and Kjær (B\&K) Type 2639 preamplifiers. These condenser microphones are located farthest from the projectile trajectory due to their higher sensitivity and lower maximum dynamic range than the high-frequency pressure transducers used in the other array positions. The output is fed into a B\&K Type 2829 4-channel microphone power supply, then into Yokogawa 701251 ana$\log$ voltage modules of the DL750 recording oscilloscope. Channels B-1 through B-4 were also split after the signal conditioner and fed into a secondary recording oscilloscope for more accurate measurement of the risetime of the signal. The Tektronix $2024 \mathrm{~b}$ is capable of sampling up to $2 \mathrm{GS} / \mathrm{s}$, but sacrifices amplitude resolution by only recording at 8 bits per sample.

Similar to Array A, a PCB 333B32 accelerometer was affixed to the baffle plate of Array B (Figure 19). The accelerometer was placed on the side of the baffle plate closest to the projectile trajectory. 
Figure 18. Array $B$ consists of four PCB 113B28 high-frequency pressure transducers and four GRAS 4ODP condenser microphones flush-mounted in an aluminum baffle plate.

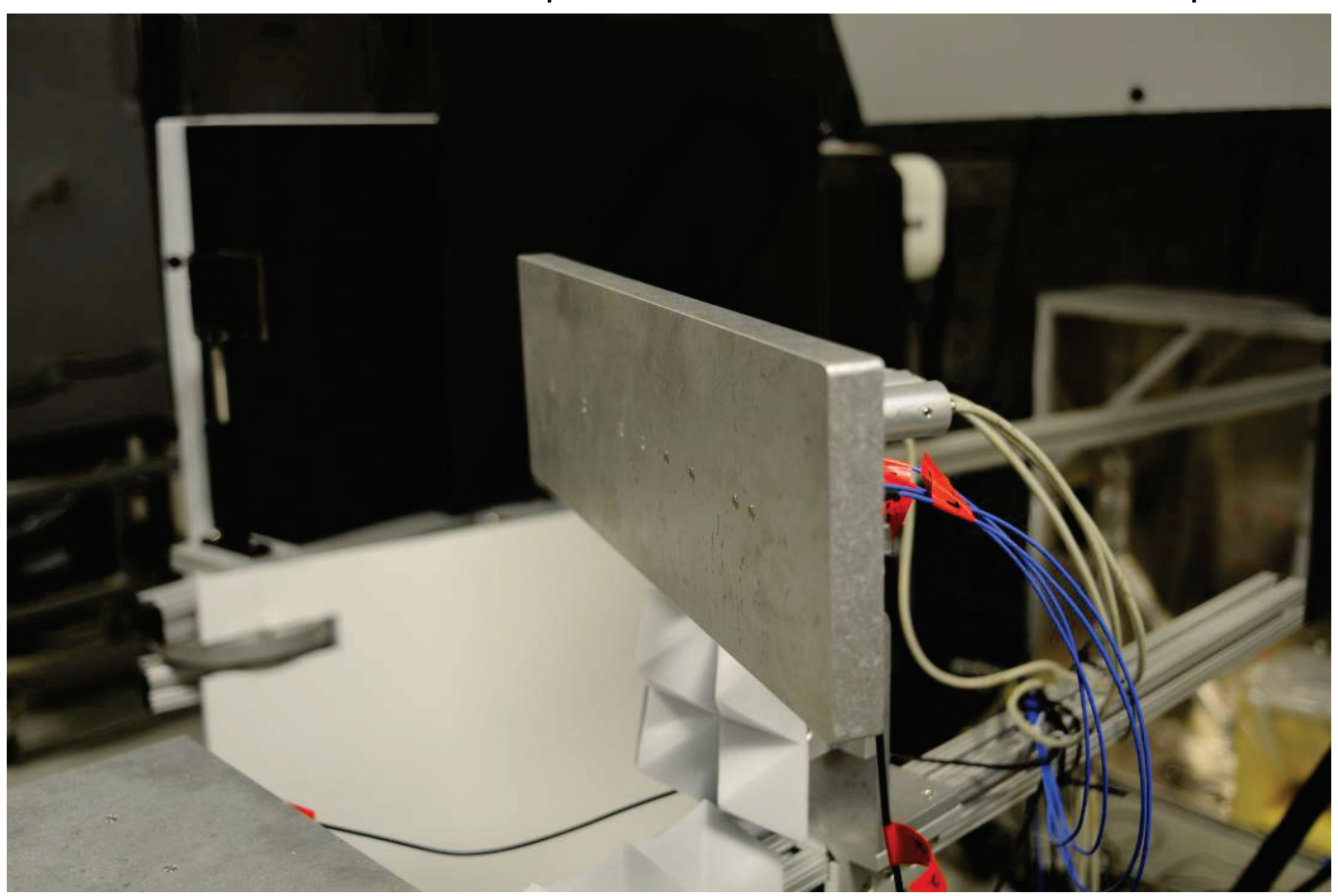

Figure 19. The backside of Array B, showing the accelerometer mounting location and the condenser microphone holders.

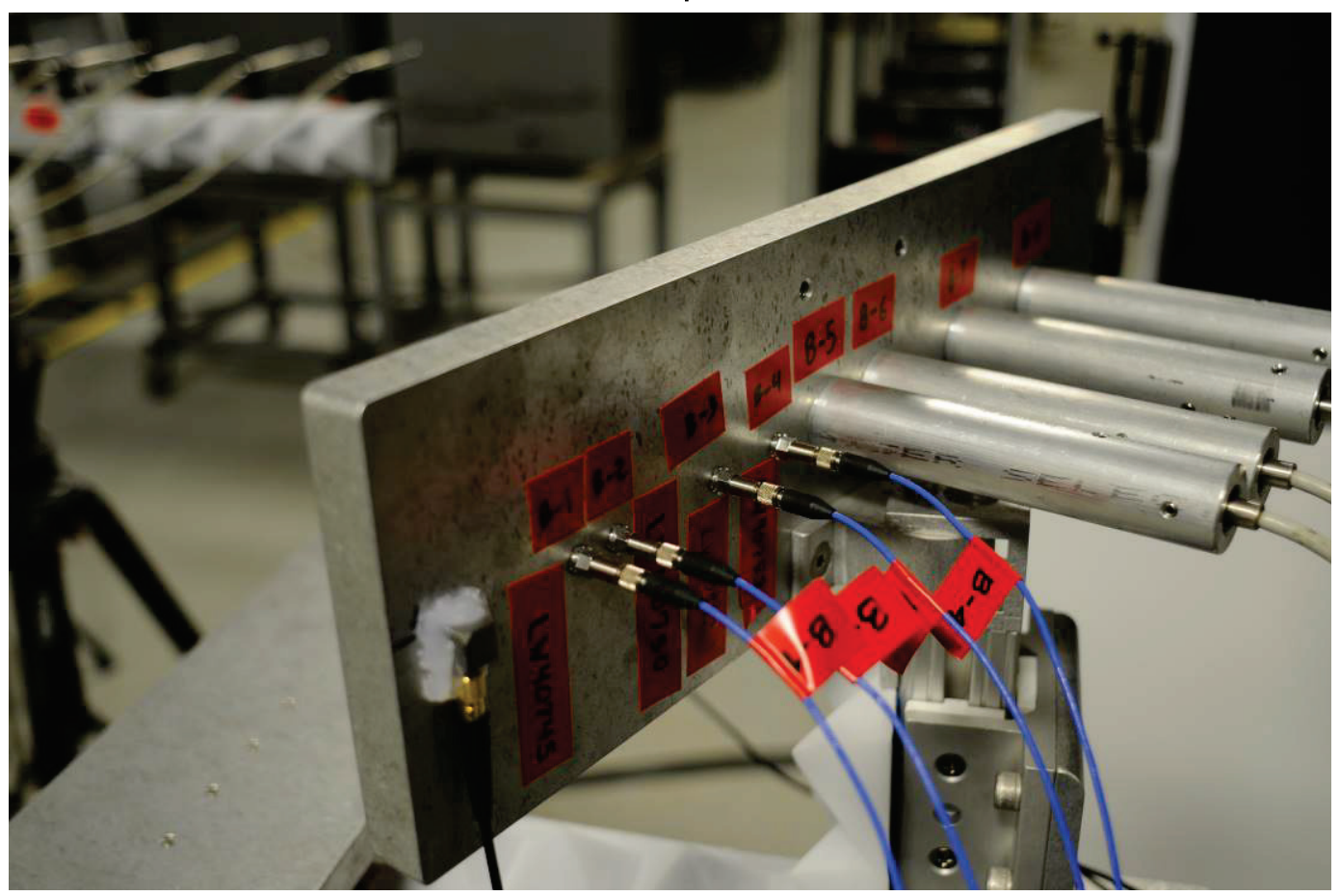




\subsection{Array C}

Array C consists of eight GRAS 4OBF 1/4-in. condenser microphones with B\&K Type 2639 preamplifiers. Table A-3 lists the serial numbers of the microphones and preamplifiers used in the experiment. Their output is connected to a B\&K 2811 8-channel multiplexer that provides the external polarization voltage and feeds the output to the Yokogawa 701251 analog voltage modules of the DL750 recording oscilloscope.

The sensors are mounted in a uniform linear array (ULA) configuration with a spacing of $10 \mathrm{~cm}$ (Figure 20).

Figure 20. Array $C$ consists of eight GRAS 40BF condenser microphones mounted in a uniform linear spacing of $10 \mathrm{~cm}$. The front of the array mounting hardware and other nearby surfaces were covered in acoustical foam to reduce the effects of reflections.

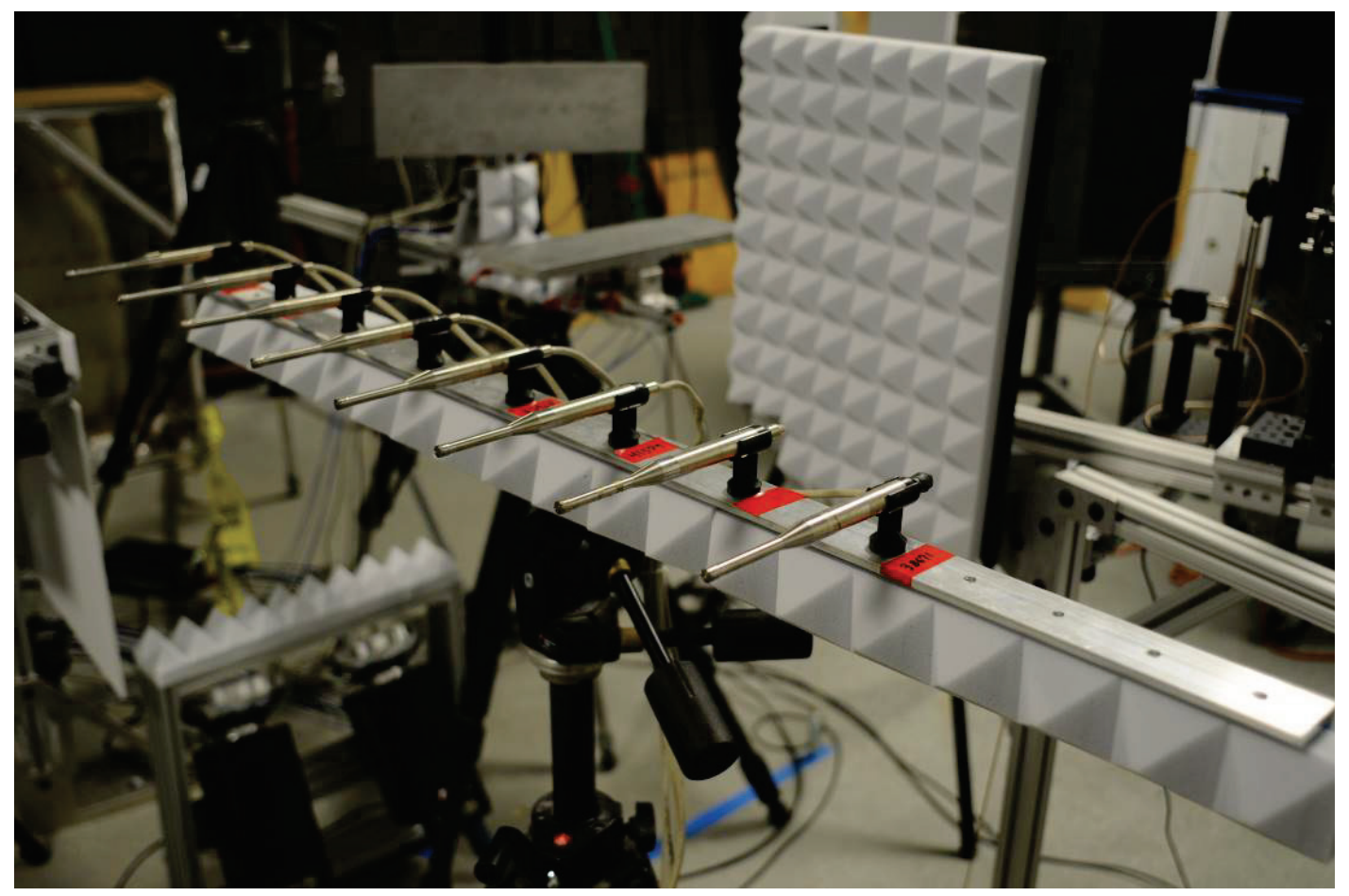

\subsection{Laser Doppler Vibrometer (LDV)}

A secondary objective of this experiment was to use an LDV as an interferometric measurement of the optical phase shift caused by perturbations in 
refraction index induced by the ballistic shock wave. The purpose of this measurement was twofold:

1. The velocity decoder from the LDV, from which the recording was made, has a frequency response with less than $2 \mathrm{~dB}$ attenuation up to approximately $3 \mathrm{MHz}$, which is more suitable than any microphone or pressure sensor used to obtain the sub-microsecond front-shock rise-time.

2. The unique distributed measurement principle can be done at an arbitrary standoff, up to the limit of the laser beam coherence, which makes it an interesting sensing modality for further study.

The principle of measurement is not unlike schlieren, where the ray-path integral of any ray-normal gradient of refractive index is proportional to the ray deflection. In the case of optical phase shift $\varphi$ produced by an inhomogeneous field, for a ray parallel with the z-axis,

$$
\varphi(x, y) \approx k_{0} \int_{z_{1}}^{z_{2}} n(x, y, z) d z
$$

Where

$$
\begin{aligned}
k_{0} & =\text { the optical wavenumber } \\
n & =\text { the inhomogeneous refractive index (Vasil'ev 1971). }
\end{aligned}
$$

In air, the refractive index perturbation induced by an acoustic field is proportional to the pressure $p$, according to

$$
n-1=\frac{G}{c_{0}^{2}} p
$$

where $c_{0}$ is the sound speed (Yuldashev et al. 2015).

In this way, a measurement of the optical phase difference produced in a laser beam near to the passage of the ballistic projectile is intrinsically related to the pressure field.

A Polytec NLV-2500 LDV was used in this experiment to measure the first derivative of time-dependent optical phase shift along a single ray path, which is in fact a modified Mach-Zehnder interferometer. ${ }^{*}$ In its intended

\footnotetext{
* Polytec Inc. 2008. Operating Instructions: Compact Laser Vibrometer NLV-2500-2. Manufacturer's Product Instruction Manual,
} 
use, the optical phase shift is related to the displacement of a reflective target. In this case, the target is motionless, and the optical phase shift registered and decoded by the LDV is instead due to the refractive inhomogeneity in the air along the beam path produced by the ballistic shock. The velocity decoder output from the LDV can be related directly to the time rate of change of the acoustical optical phase shift,

$$
v(t)=\frac{1}{k_{0} n_{0}} \frac{d \varphi}{d t}
$$

where $n_{0}$ is the index of refraction of the ambient air (Torras-Rosell et al. 2012).

By assuming the ballistic shock to be axisymmetric, this field will be inverted for the pressure by use of an inverse Abel transform (Vasil'ev 1971).

Figure 15 shows a plan view of the experimental configuration. The LDV head was placed $890 \mathrm{~mm}$ away from the projectile trajectory in the horizontal, and $782 \mathrm{~mm}$ away from the optical axis of the schlieren system (Figure 21). The LDV beam was oriented perpendicular with the trajectory in a horizontal plane raised $25.4 \mathrm{~mm}$ above the trajectory itself. The actual angle made with the trajectory deviated by less than $0.1^{\circ}$ from perpendicular, with the point of reflection being $3 \mathrm{~mm}$ nearer to the schlieren optical axis than the LDV head. The reflective target was a protected silver firstsurface mirror with one-eighth wavelength surface flatness at $633 \mathrm{~nm}(\approx$ $80 \mathrm{~nm}$ peak-to-valley) mounted on a tripod $2.45 \mathrm{~m}$ away from the LDV head in the horizontal. The reflected beam was carefully directed back to the LDV head by use of a fine adjustment optomechanical mirror mount. Care was taken to minimize the spot size at the point of reflection.

Records of the velocity decoder were made at the $100 \frac{\mathrm{mm}}{\mathrm{s}} / \mathrm{V}$ setting to maximize the high-frequency response. Noise was found to be minimal relative to the ballistic shock signal due to the high quality of the reflector used. Once collected, these voltage records can be converted to velocity by applying the instrument sensitivity, which are subsequently converted to the time derivative of optical phase shift through the above equation. 
Figure 21. The LDV measurement apparatus as configured. The first-surface mirror used as the reflective target is near at center, while the LDV head is visible in the background with the red protective cap covering the aperture.

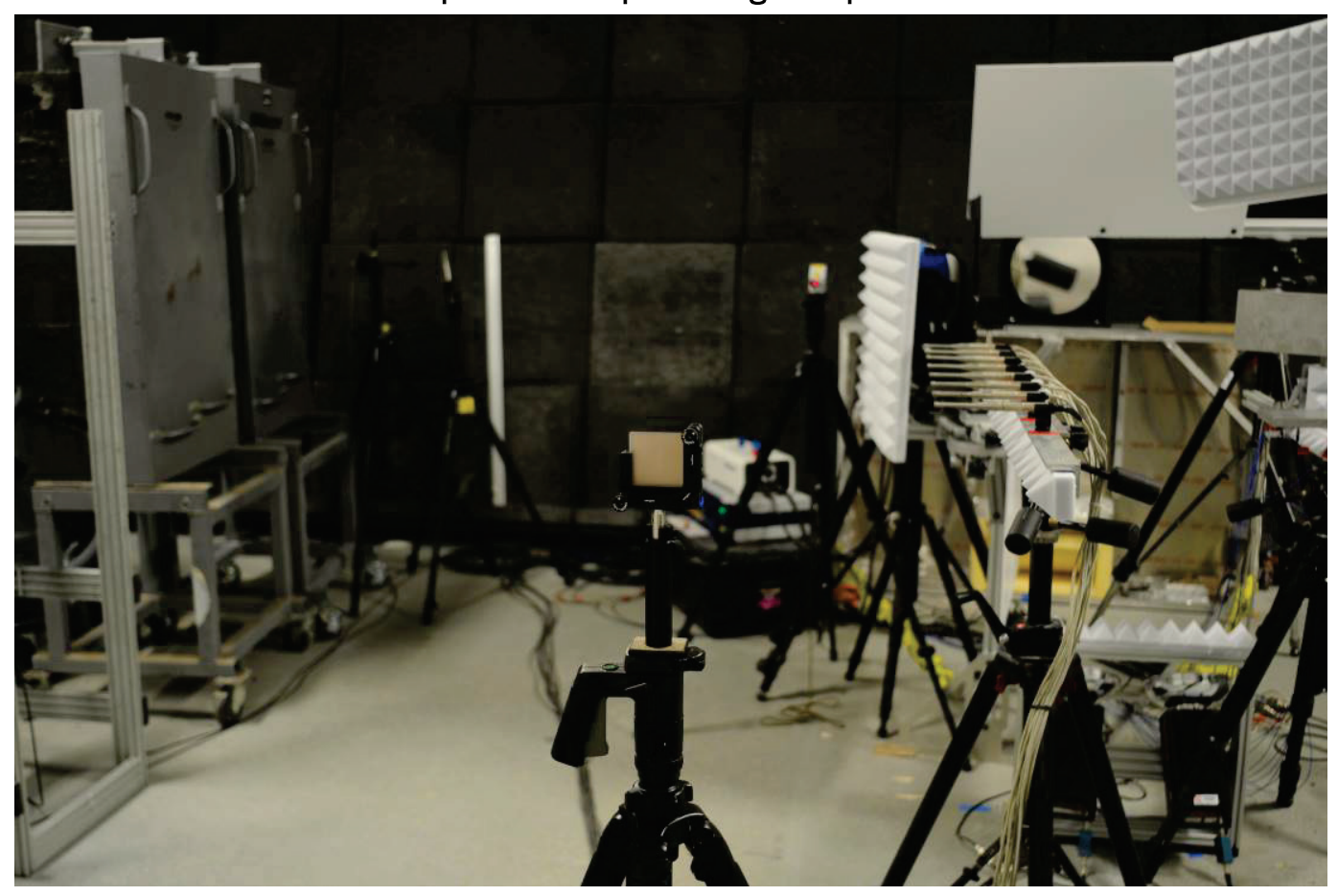

\subsection{Data acquisition}

Two Yokogawa model DL750 recording oscilloscopes and a Tektronix TDS2024b were used to record the data. Figure 22 shows the connections between the sensors and data acquisition units. 
Figure 22. Connection diagram.
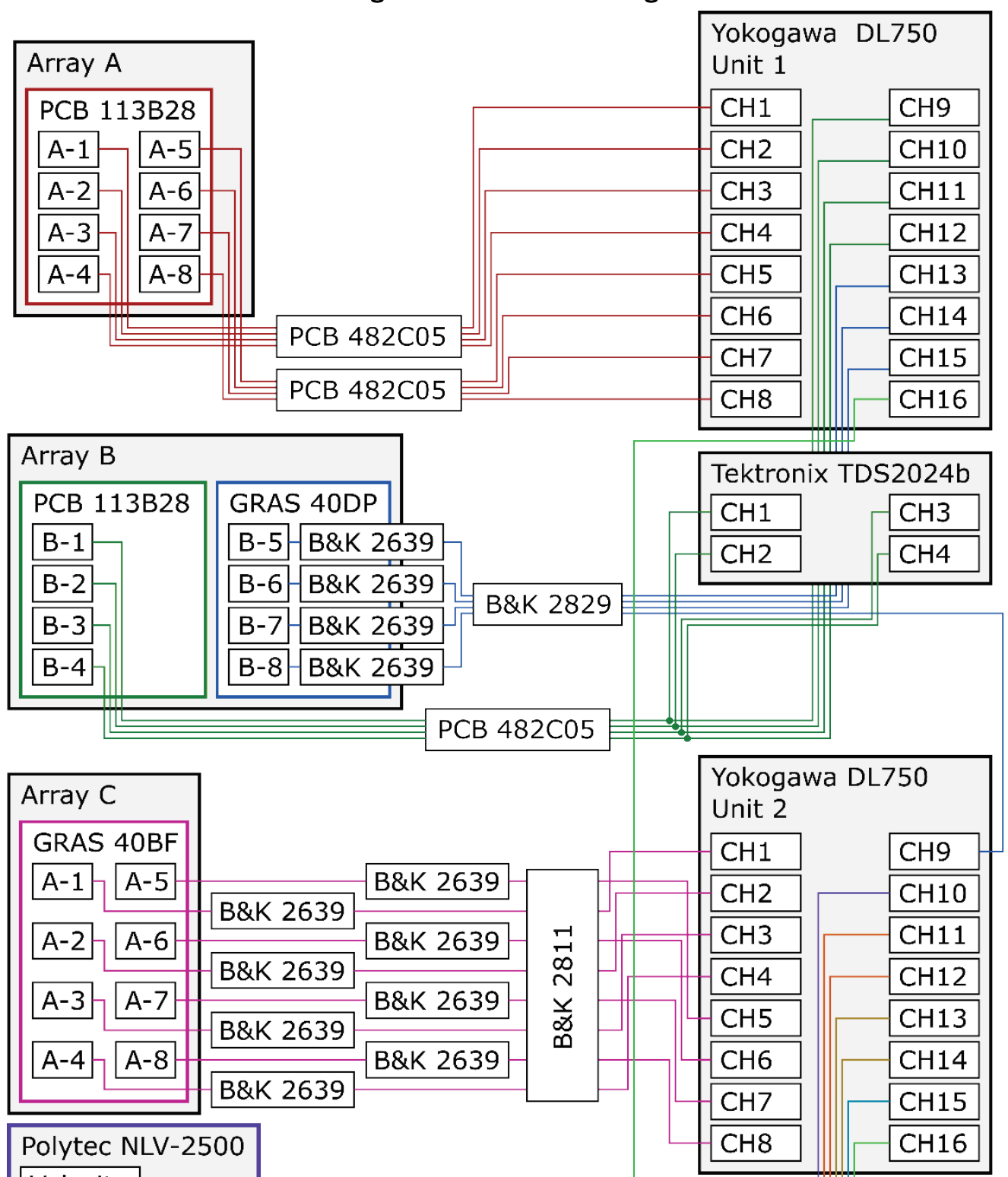

\begin{tabular}{|l|}
\hline Polytec NLV-2500 \\
Velocity \\
\hline
\end{tabular}

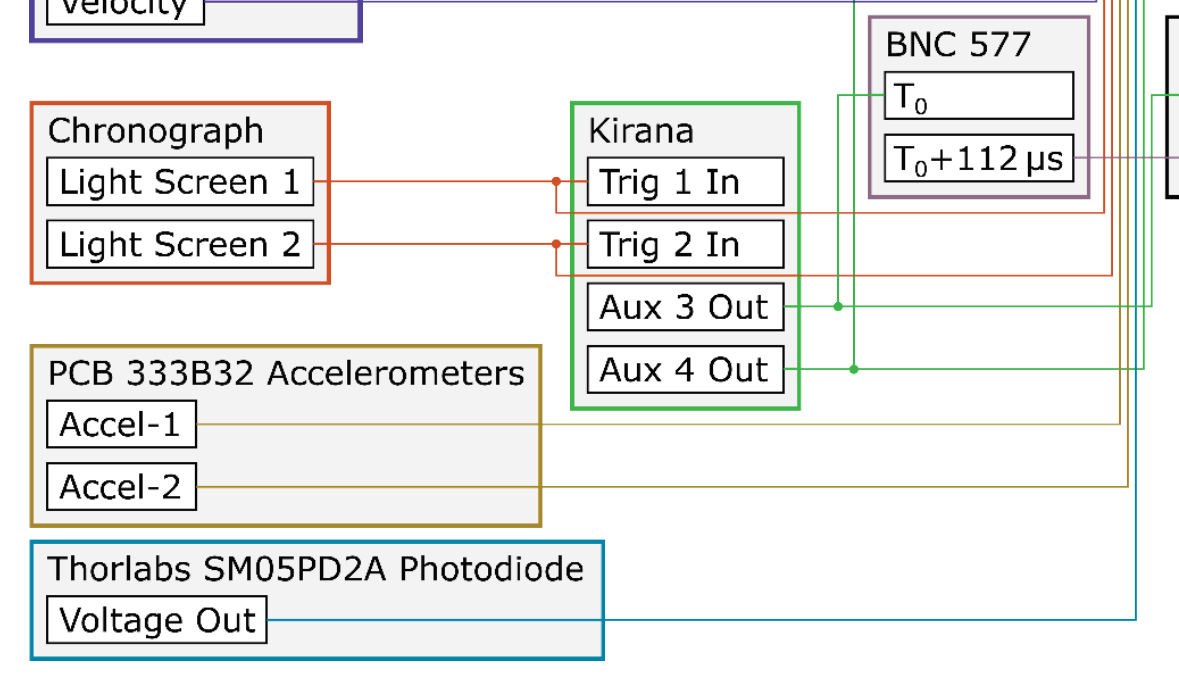

Flashlamps Schlieren Front Light 
Both of the Yokogawa digital oscilloscopes were triggered on a rising-edge signal emitted from Auxiliary Output 4 from the Kirana camera at the start of image sequence acquisition (Table 2). A pre-trigger of 0.5 seconds and a 1-second total acquisition time ensured adequate capture of the background noise and the signal of interest.

Table 2. Channel settings for Yokogawa recording oscilloscopes.

\begin{tabular}{|c|c|c|c|c|c|c|}
\hline \multirow[b]{2}{*}{$\begin{array}{c}\text { Sample Rate } \\
\text { Horizontal Scale }\end{array}$} & \multicolumn{3}{|c|}{ Yokogawa 1} & \multicolumn{3}{|c|}{ Yokogawa 2} \\
\hline & $\begin{array}{c}1 \mathrm{MS} / \mathrm{s} \\
100 \mathrm{~ms} / \mathrm{div} \\
\text { Sensor }\end{array}$ & Vertical Scale & Coupling & $\begin{array}{c}1 \mathrm{MS} / \mathrm{s} \\
100 \mathrm{~ms} / \mathrm{div} \\
\text { Sensor }\end{array}$ & Vertical Scale & Coupling \\
\hline $\mathrm{CH} 1$ & $A-1$ & $50 \mathrm{mV} / \mathrm{div}$ & $\mathrm{AC}$ & C-1 & $5 \mathrm{~V} / \mathrm{div}$ & $\mathrm{AC}$ \\
\hline $\mathrm{CH} 2$ & $\mathrm{~A}-2$ & $50 \mathrm{mV} / \mathrm{div}$ & $A C$ & $\mathrm{C}-2$ & $5 \mathrm{~V} / \mathrm{div}$ & AC \\
\hline $\mathrm{CH} 3$ & $\mathrm{~A}-3$ & $50 \mathrm{mV} / \mathrm{div}$ & $\mathrm{AC}$ & $\mathrm{C}-3$ & $5 \mathrm{~V} / \mathrm{div}$ & $\mathrm{AC}$ \\
\hline $\mathrm{CH} 4$ & $\mathrm{~A}-4$ & $50 \mathrm{mV} / \mathrm{div}$ & $\mathrm{AC}$ & C-4 & $2 \mathrm{~V} / \mathrm{div}$ & $\mathrm{AC}$ \\
\hline $\mathrm{CH} 5$ & $A-5$ & $50 \mathrm{mV} / \mathrm{div}$ & $A C$ & $\mathrm{C}-5$ & $2 \mathrm{~V} / \mathrm{div}$ & $\mathrm{AC}$ \\
\hline $\mathrm{CH} 6$ & $A-6$ & $50 \mathrm{mV} / \mathrm{div}$ & $A C$ & $\mathrm{C}-6$ & $2 \mathrm{~V} / \mathrm{div}$ & $\mathrm{AC}$ \\
\hline $\mathrm{CH} 7$ & $A-7$ & $50 \mathrm{mV} / \mathrm{div}$ & $A C$ & $\mathrm{C}-7$ & $2 \mathrm{~V} / \mathrm{div}$ & AC \\
\hline $\mathrm{CH} 8$ & A-8 & $50 \mathrm{mV} / \mathrm{div}$ & $\mathrm{AC}$ & $\mathrm{C}-8$ & $2 \mathrm{~V} / \mathrm{div}$ & $\mathrm{AC}$ \\
\hline $\mathrm{CH} 9$ & B-1 & $50 \mathrm{mV} / \mathrm{div}$ & $\mathrm{AC}$ & B-8 & $2 \mathrm{~V} / \mathrm{div}$ & $\mathrm{AC}$ \\
\hline $\mathrm{CH} 10$ & B-2 & $50 \mathrm{mV} / \mathrm{div}$ & $A C$ & LDV & $500 \mathrm{mV} / \mathrm{div}$ & $\mathrm{DC}$ \\
\hline $\mathrm{CH} 11$ & B-3 & $50 \mathrm{mV} / \mathrm{div}$ & $\mathrm{AC}$ & Trig-1 & $2 \mathrm{~V} / \mathrm{div}$ & $\mathrm{DC}$ \\
\hline $\mathrm{CH} 12$ & B-4 & $50 \mathrm{mV} / \mathrm{div}$ & $A C$ & Trig-2 & 200 mV/div & $\mathrm{DC}$ \\
\hline $\mathrm{CH} 13$ & B-5 & $2 \mathrm{~V} / \mathrm{div}$ & $\mathrm{AC}$ & Accel-1 & $100 \mathrm{~m} / \mathrm{s}^{2} / \mathrm{div}$ & Accl \\
\hline $\mathrm{CH} 14$ & B-6 & $2 \mathrm{~V} / \mathrm{div}$ & $\mathrm{AC}$ & Accel-2 & $100 \mathrm{~m} / \mathrm{s}^{2} / \mathrm{div}$ & Accl \\
\hline $\mathrm{CH} 15$ & $\mathrm{~B}-7$ & $2 \mathrm{~V} / \mathrm{div}$ & $\mathrm{AC}$ & Photodiode & $10 \mathrm{mV} / \mathrm{div}$ & $\mathrm{DC}$ \\
\hline $\mathrm{CH} 16$ & AUX 4 & $1 \mathrm{~V} / \mathrm{div}$ & $\mathrm{DC}$ & AUX 4 & $1 \mathrm{~V} /$ div & $\mathrm{DC}$ \\
\hline
\end{tabular}

\subsection{Calibration}

The condenser microphones were calibrated before and after the experiment using a B\&K model 4228 pistonphone calibrator. The instrument provides a steady reference tone of $250 \mathrm{~Hz}$ at $124 \mathrm{~dB}$ re $20 \mu \mathrm{Pa}$. Each microphone recorded the calibration signal in as close to in-situ conditions as possible. The same preamplifiers, signal conditioners, and data acquisition channels that were used during the experiment were used in calibration. The sensitivity value $(K)$ used to determine the measured acoustic pressure were given in millivolts per Pascal by

$$
K=1000 \times \frac{\widetilde{V}_{p r e}+\widetilde{V}_{\text {post }}}{2 \tilde{P}},
$$


where

$$
\begin{aligned}
& \tilde{V}_{\text {pre }} \text {, and } \tilde{V}_{\text {post }} \text { are the average root mean square (RMS) voltage of } \\
& \text { the pre- and post- experiment calibration signals, respectively. } \\
& \tilde{P}=\text { the reference RMS acoustic pressure, } \tilde{P}=2 \times 10^{-5} \times \\
& 10^{\frac{124}{20}}[\mathrm{~Pa}] .
\end{aligned}
$$

Calibration certificates for the newly purchased PCB 113B28 high frequency pressure sensors were provided by the manufacturer, and the sensitivity values were used to determine the measured acoustic pressure. Similarly, the sensitivity values for the two $\mathrm{PCB} 333 \mathrm{~B} 32$ accelerometers were taken from the most recent laboratory calibration certificates and were used to determine the acceleration of the baffle plates on Arrays A and B. 


\section{Data Collection}

The experiment was conducted $18-29$ March 2019 at the Geospatial and Structures Laboratory's Fragmentation Simulation Facility on ERDC's Vicksburg campus. The first week of the experiment was dedicated to equipment setup, testing, and calibration. Week 2 was dedicated to collecting data and tearing down equipment.

\subsection{Choreography}

Over the course of the experiment, each team member's roles and responsibilities necessary to collect data were solidified. The procedure was tuned into a kind of choreography that was executed for each shot. While many of the tasks were completed simultaneously, they are explained sequentially in the following paragraphs.

Before firing a shot, the projectile was prepared by adjusting the powder charge according to the projectile weight, target velocity, and measured velocity of any previous shots of the same projectile. The projectile was then loaded into a primed cartridge. Figure 23 shows the procedure and equipment used in preparing the shot.

Figure 23. Procedure for preparing a shot, adjusting the powder charge (left), and loading the cartridge (right).

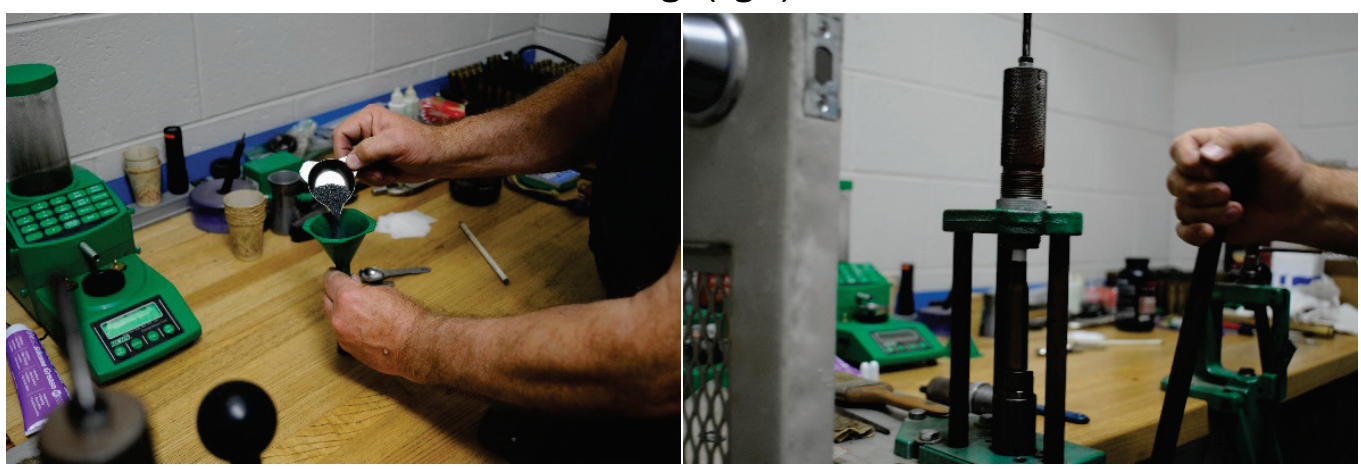

Immediately before each shot, the data acquisition systems were armed. The two Yokogawa DL750 units were set to trigger on a signal from Auxiliary Output 4 on the Kirana camera. The Tektronix TDS2024b was set to trigger on a rising-edge signal. Section 2.4 discusses how the Kirana Control software uses its velocity trap mode. As a precautionary measure, the digital delay used to time the flashlamps front-lighting the projectile was also reset before each shot. 
After arming the equipment and verifying the aim of the gun using a target located on the theoretical trajectory, team members retreated to the control room. The control room was sealed and an alarm was sounded indicating that firing was imminent. After ensuring that the chronograph light screens were armed and that each team member had proper hearing protection, the gun was loaded and a visual signal was given to fire. After a short countdown, the shot was fired.

Immediately following the shot, the gun was made safe and the alarm was switched off. Team members began a number of tasks that occurred simultaneously. The shot log (see Table B-1 in Appendix B) was updated with the time of the shot, and the output from the chronograph. Two mobile air filtration systems to remove smoke from the air, one located near the gun and another downrange, were started.

At the experiment apparatus, if any shrapnel was seen, the target and/or barriers were moved or otherwise modified to prevent shrapnel damage from subsequent shots. The floor area was swept to facilitate identification of any new shrapnel. The sensitive optical components were visually inspected for damage. A tripod with a target was placed on the theoretical trajectory to assist in verifying the aim for the next shot.

Meanwhile, schlieren image sequences were downloaded as *.SVFR files and inspected for any issues, such as overranging or projectile illumination. Corresponding adjustments were made to the slit opening in the analyzer section of the schlieren system or the f-stop values of the flashlamps. The velocity calculated from the Kirana camera's velocity trap mode was manually recorded in the shot log.

The data from the two Yokogawa DL750s were downloaded as *.WVF files and transferred to an external hard drive via a D-Link DSS-8+ Ethernet switch. The data from the Tektronix 2024b oscilloscope in *.CSV files were transferred via USB to the same hard drive. The readings of temperature, pressure, and relative humidity from the Vaisala PTU300 were manually recorded in the shot log.

The procedure outlined in the above paragraphs was carried out for each of the 125 shots taken during the experiment. Deviations from this procedure and any significant adjustments to the acoustical and optical systems were documented in the test notes. 


\subsection{Test shots}

The first set of test shots with the schlieren system in place was made on Thursday, 21 March. The test shots served to tune the schlieren setup as well as to begin the process of dialing in the projectile velocity. The first shot was a .50 caliber M33 round with a standard factory powder charge. The measured velocity was $913 \mathrm{~m} / \mathrm{s}$, indicating that subsequent shots required a smaller powder charge. The target velocity was reached by weighing the projectiles and incrementally adjusting the powder charge.

The system was considered ready for data collection when the schlieren and acoustic systems were functioning properly. The image sequences were evaluated to ensure sufficient resolution to visualize small details in the turbulent wake structure, and minimal ghosting. Minor adjustments to the illumination and position of the projectile in the field of view were made throughout data collection but did not significantly impact the quality of the resulting image sequences. The acoustic data acquisition systems were evaluated to ensure sufficient headroom so that the channels were not over-ranged. The delineation between test shots and experimental data collection is indicated by the vertical dashed line in Figure 24.

Figure 24. Projectile velocity vs. shot number. Vertical gray lines indicate test days. Shots to the left of the vertical dashed line are considered test shots.

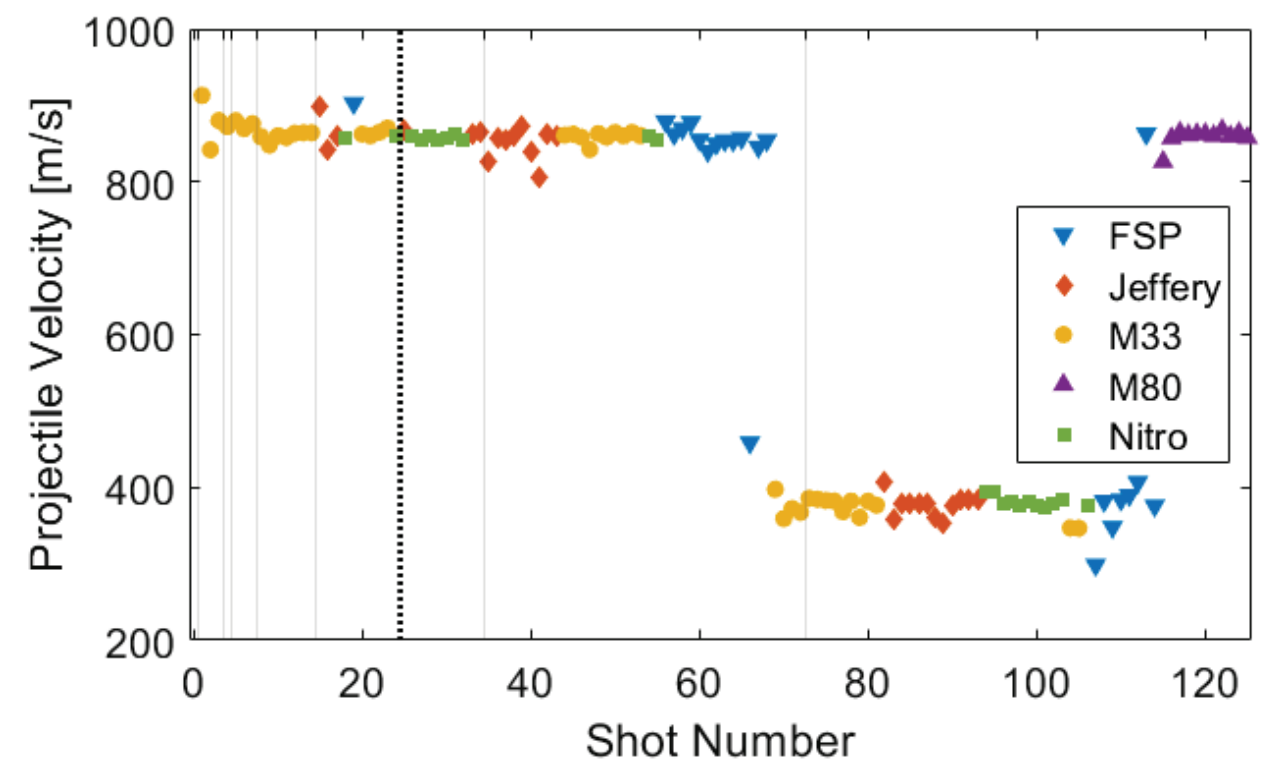




\subsection{Test matrix}

For each of the three primary projectiles of interest (M33, 500 Jeffery, and 500 Nitro), a minimum of 10 shots per target Mach number were required. For the secondary projectiles (FSP and M80), at least eight shots per target Mach number were required. Table 3 lists the actual number of shots per projectile per target Mach number. For the M8o, it was not feasible to reach a target Mach number below 2.5. It was also not feasible to capture subsonic projectiles accurately with the experimental setup. Data collection was therefore limited to Mach 1.1 and 2.5 for the three primary projectiles and the FSP, and to only Mach 2.5 for the M80.

Table 3. Number of shots per projectile per target Mach number

\begin{tabular}{|l|c|c|c|}
\hline & $\begin{array}{c}\text { Subsonic, } \\
\mathbf{M}=\mathbf{0 . 9}\end{array}$ & $\begin{array}{c}\text { Transonic, } \\
\mathbf{M}=\mathbf{1 . 1}\end{array}$ & $\begin{array}{c}\text { Supersonic, } \\
\mathbf{M}=\mathbf{2 . 5}\end{array}$ \\
\hline .50 Caliber M33 (point) & 2 & 13 & 28 \\
\hline 500 Jeffery (round) & 0 & 12 & 15 \\
\hline 500 Nitro Express (flat) & 0 & 11 & 11 \\
\hline .50 Caliber FSP (complicated) & 0 & 8 & 14 \\
\hline 7.62 mm M80 (small point) & 0 & 0 & 11 \\
\hline
\end{tabular}

While great care was taken to achieve the target Mach number, there was some unavoidable variability in the measured velocities due to the stochastic nature of combustion in internal ballistics. Figures 25 and 26 show the distribution of projectile Mach numbers measured using the Kirana camera's velocity trap grouped by projectiles for target Mach number 2.5 and 1.1 , respectively.

Figure 25. Boxplots of measured Mach numbers for target Mach number 2.5.

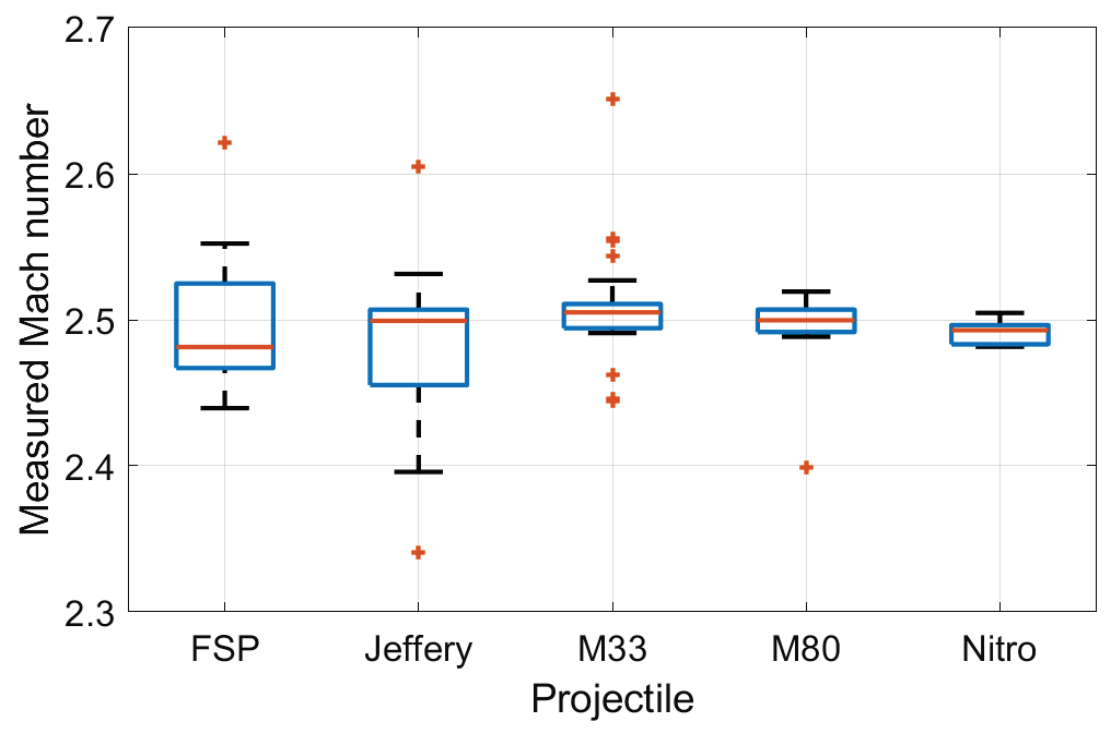


Figure 26. Boxplots of measured Mach numbers for target Mach number 1.1.

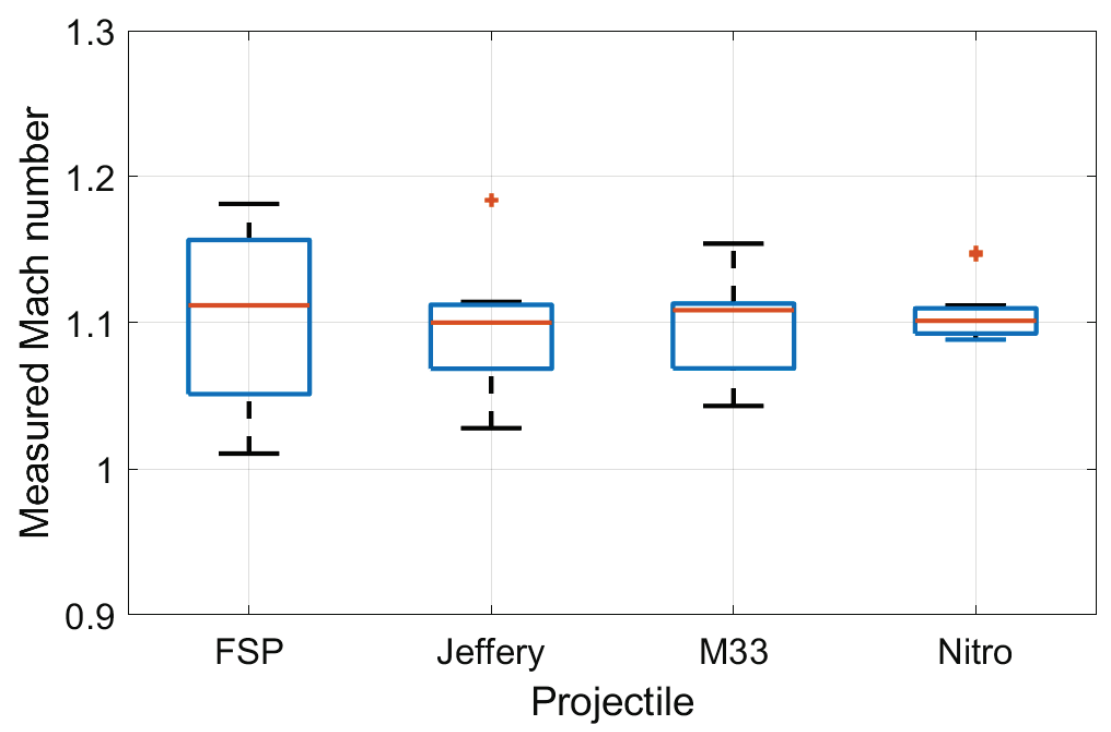

\subsection{Optical data}

In total, 125 schlieren image sequences were taken, including test shots. Each image sequence consists of 180 grayscale frames at $768 \times 964$ pixels and 10-bit resolution. Figure 27 shows a typical image sequence frame.

Figure 27. A single frame of an image sequence of a .50 caliber M33 projectile traveling at Mach 2.5.

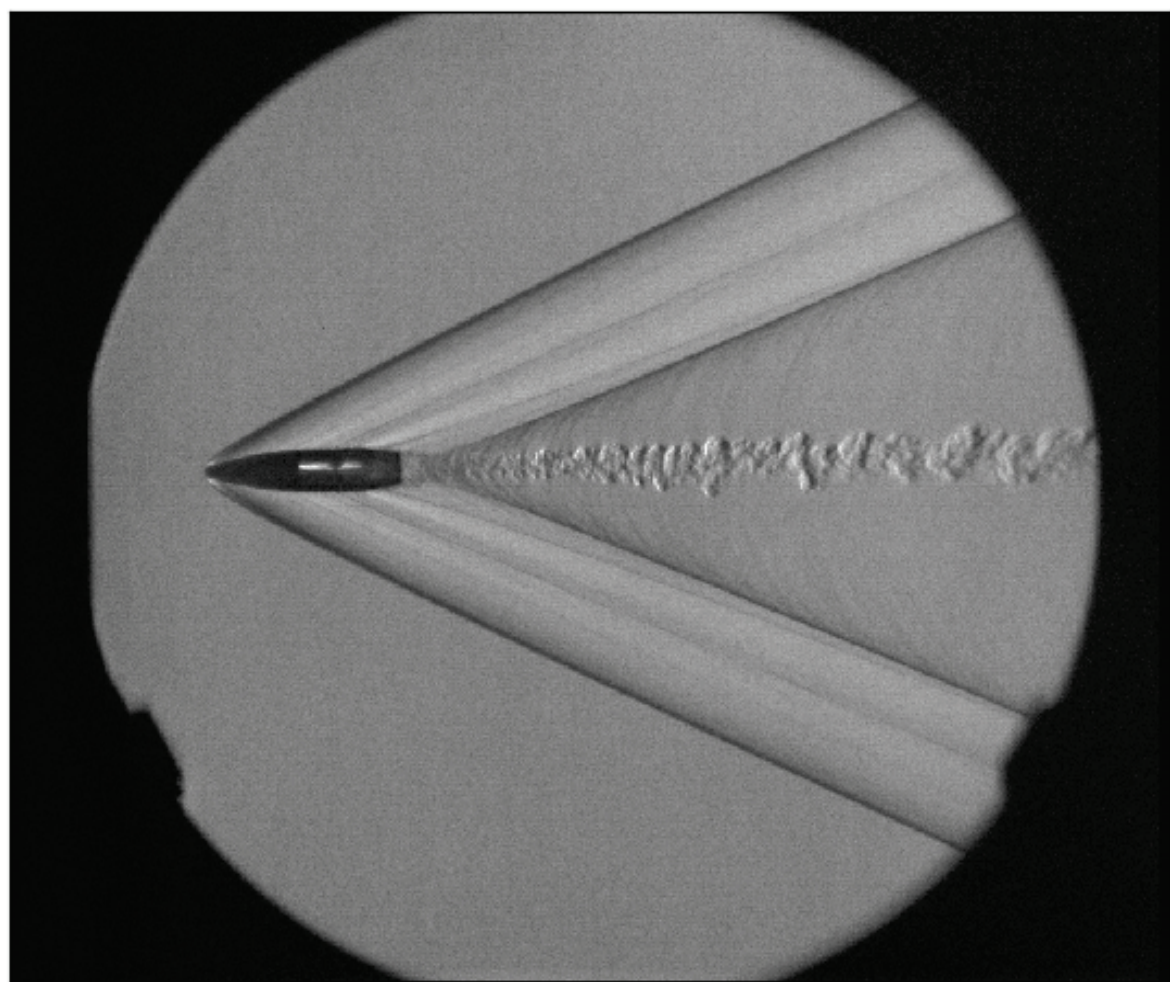


The schlieren image sequences reveal significant detail of the shock structure near the projectile and its turbulent wake, as shown in the enlarged portion of an image sequence in Figure 28.

Figure 28. Enlarged portion of a schlieren image sequence frame of a .50 caliber M33 projectile traveling at Mach 2.5.

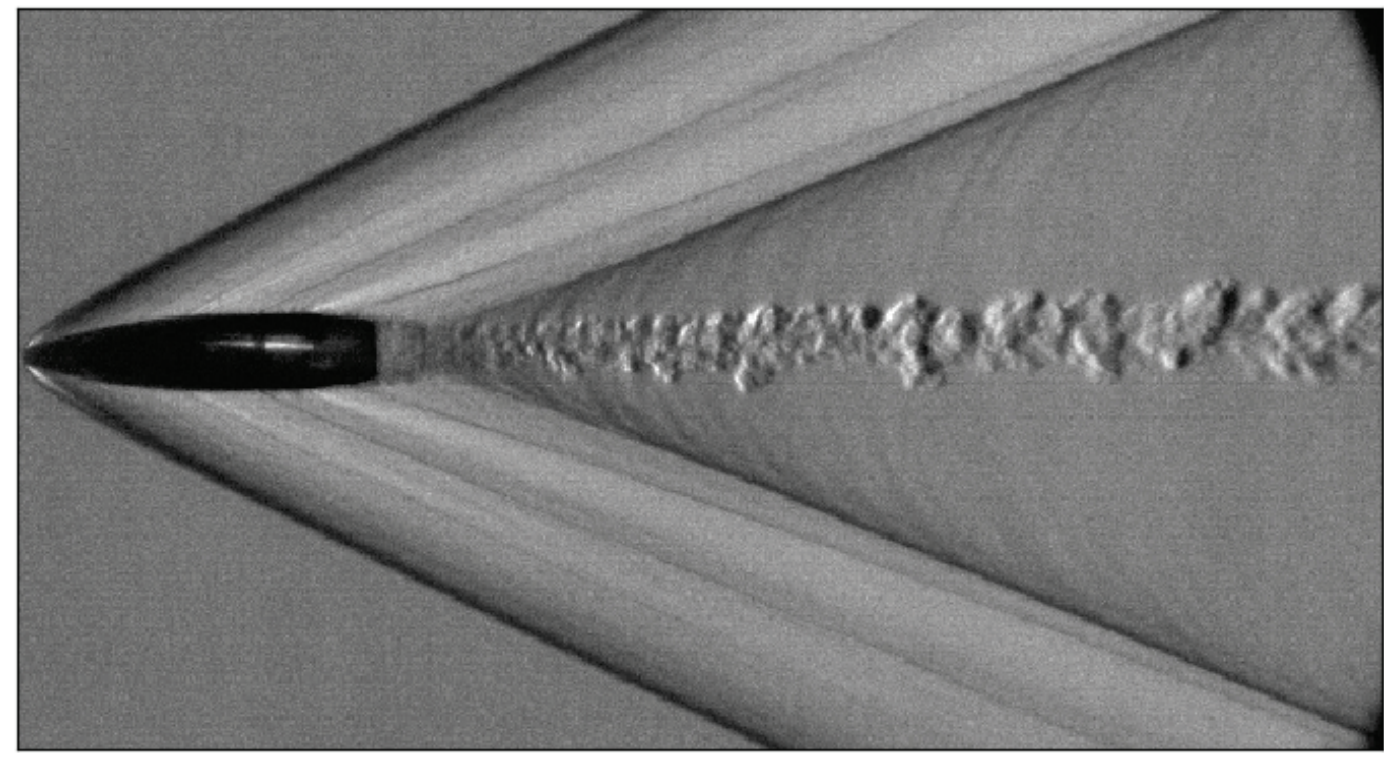

Further details are revealed when the schlieren image sequences are played as movies. For example, the rotation of the projectile, and what may be a corresponding rotation in the turbulent wake, are readily visible in the movies, but are not apparent at all in the still frames. The acoustic radiation from the turbulent structures along the trajectory behind the projectile is also visible.

\subsection{Acoustical data}

Acoustical data collection began after the schlieren system was in place and roughly tuned; hence the first five test shots do not have recorded acoustical data. A total of 120 shots have both a schlieren image sequence and acoustical data. For each of those 120 shots, 16 channels of acoustical data were recorded on the Yokogawa DL750 data acquisition units (Figure 29). 
Figure 29. Example of acoustical data recorded for a single shot.

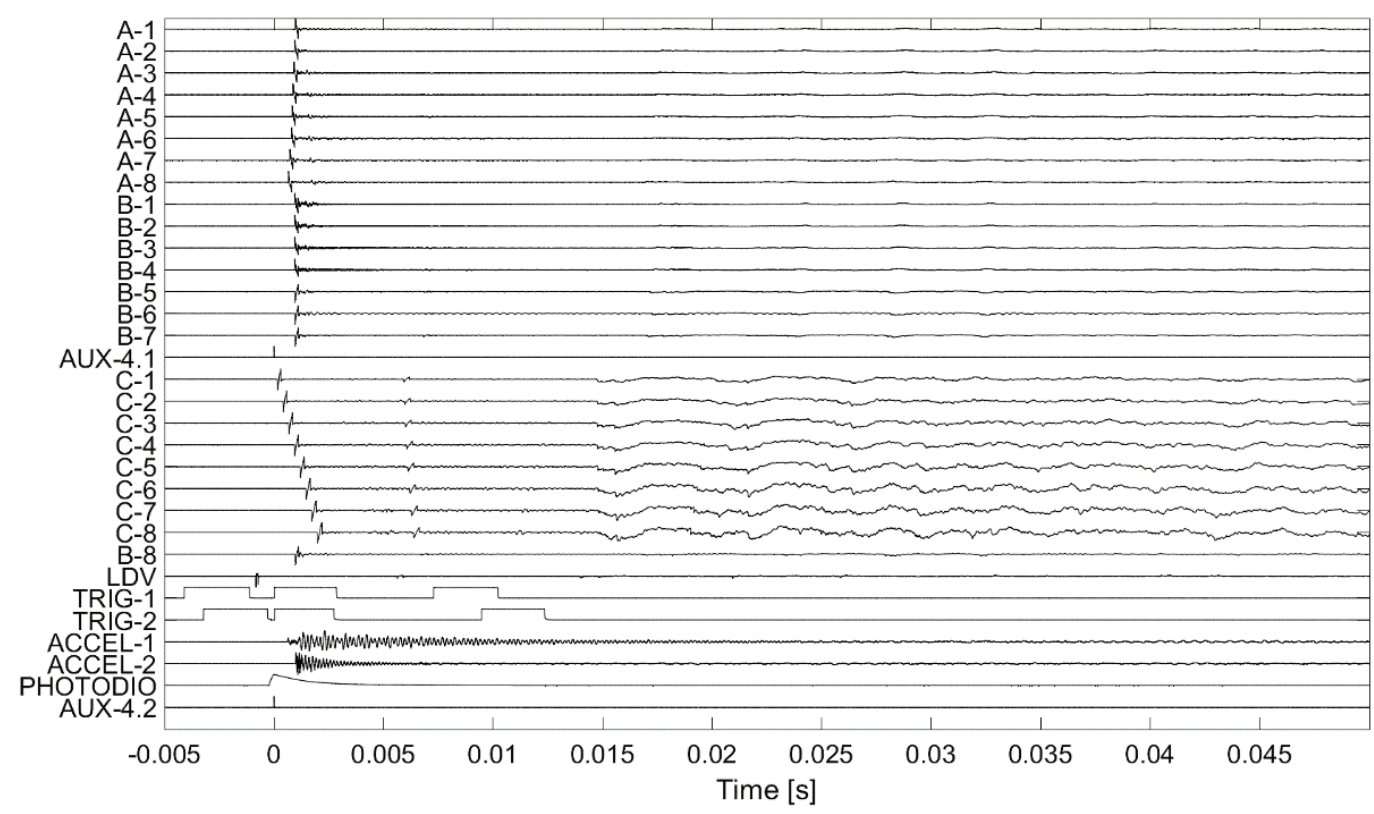

Each channel was recorded at a sampling rate of $1 \mathrm{MHz}$ for a duration of 1 second. At this sampling rate, the limiting factor for resolving high frequency signal components is the frequency response of the sensor. Figure 30 shows an example of a portion of a recorded waveform showing the $\mathrm{N}$-wave from a projectile.

Figure 30. An example N-wave recorded on microphone C-1.

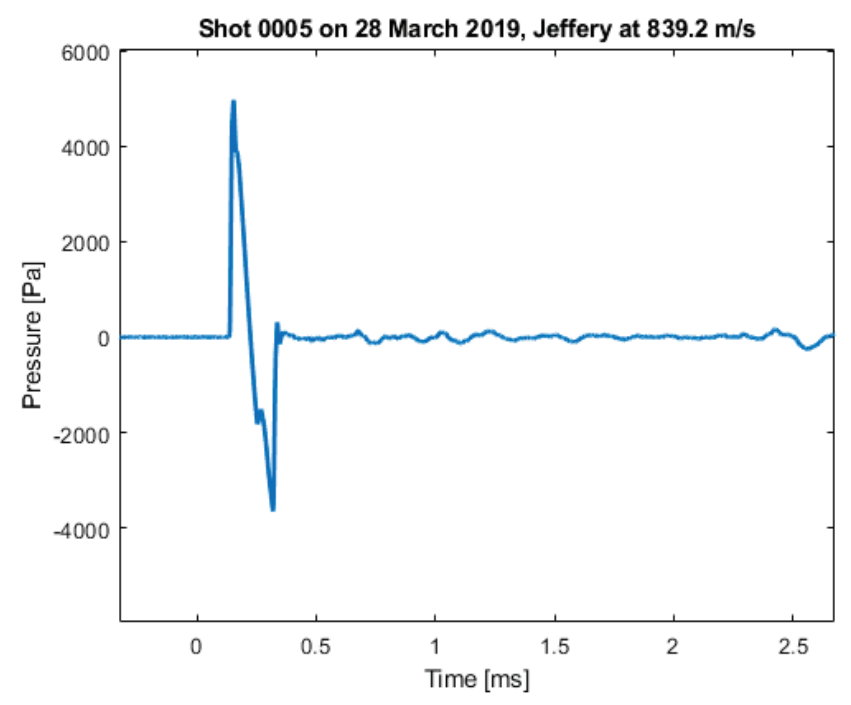

Data recorded on the Tektronix TDS2024b were inteded to capture the rise-time of the signal. Recording was triggered on a rising-edge of the signal from sensor B-1. Figure 31 shows an example $\mathrm{N}$-wave recorded at a 
sampling rate of $5 \mathrm{MHz}$. The signal appears to be binned in the vertical scale due to the 8-bit sample encoding used by the Tektronix TDS2024b. Another issue is the apparent high frequency oscillations in the waveform that were possibly caused by increased capacitance on the input of the signal conditioner due to long cable runs. The sampling rate and triggering mode were explored during the experiment to alleviate this issue, but no solution was found.

Figure 31. An example N-wave recorded on the Tektronix TDS2024b at sensor B-1.

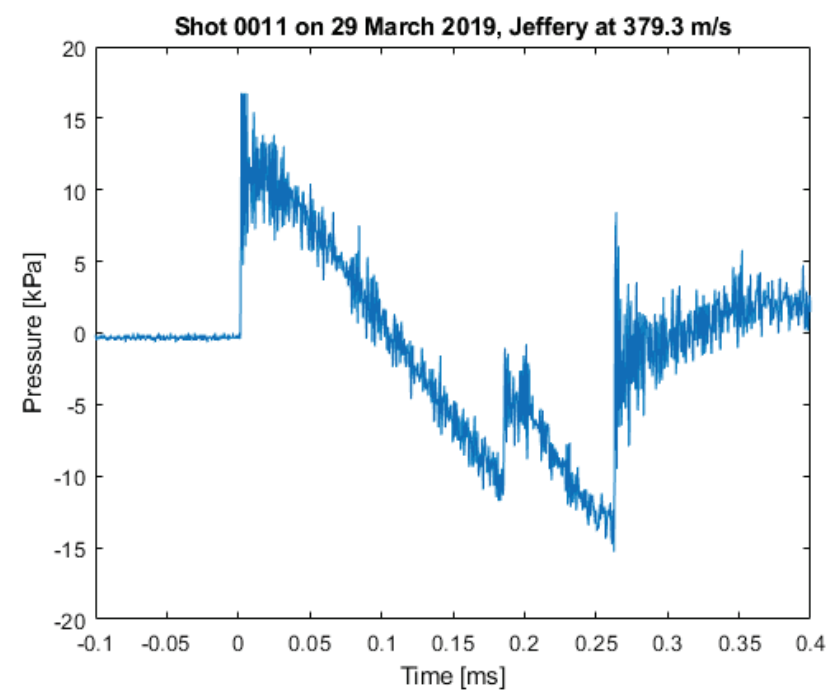

\subsection{Supporting data}

In addition to the optical and acoustical data collected during the experiment, supporting data were also recorded, including ambient air conditions, triggering outputs, and quantities used in ballistics calculations.

A Vaisala PTU300 sensor was deployed near the data acquisition units to read and display the barometric pressure, relative humidity, and temperature. These quantities were manually recorded immediately following each shot. Figures 32 to 34 show boxplots of the daily recorded barometric pressure, relative humidity, and temperature, respectively. 
Figure 32. Recorded barometric pressure.

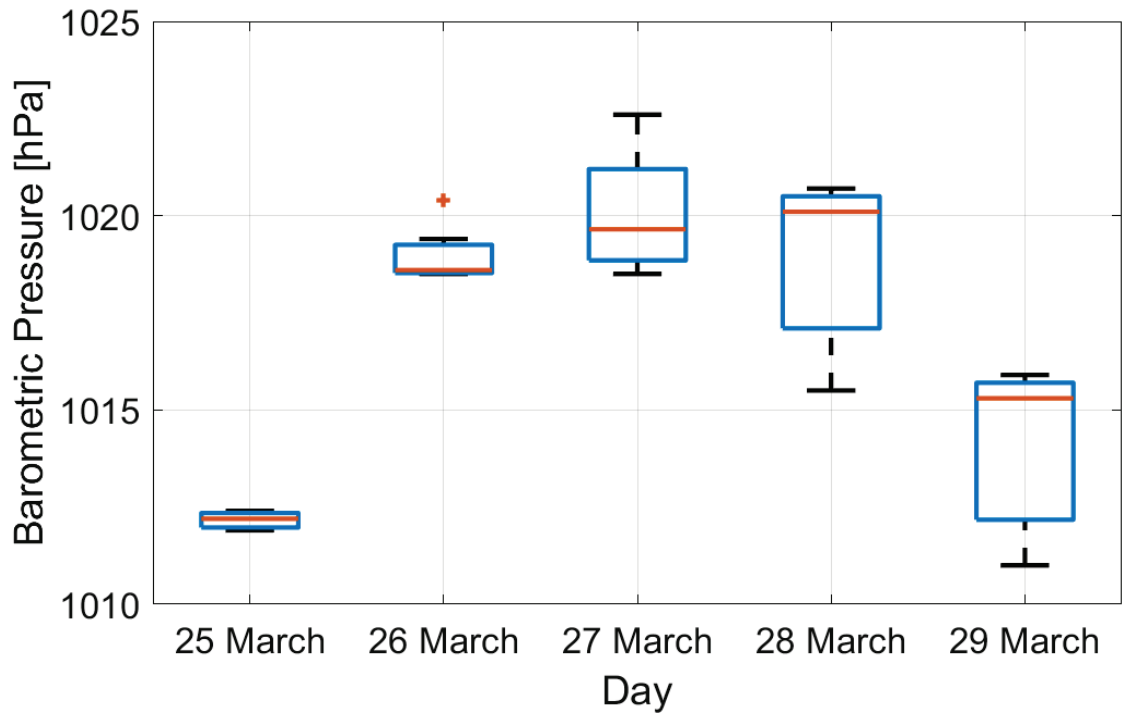

Figure 33. Recorded relative humidity.

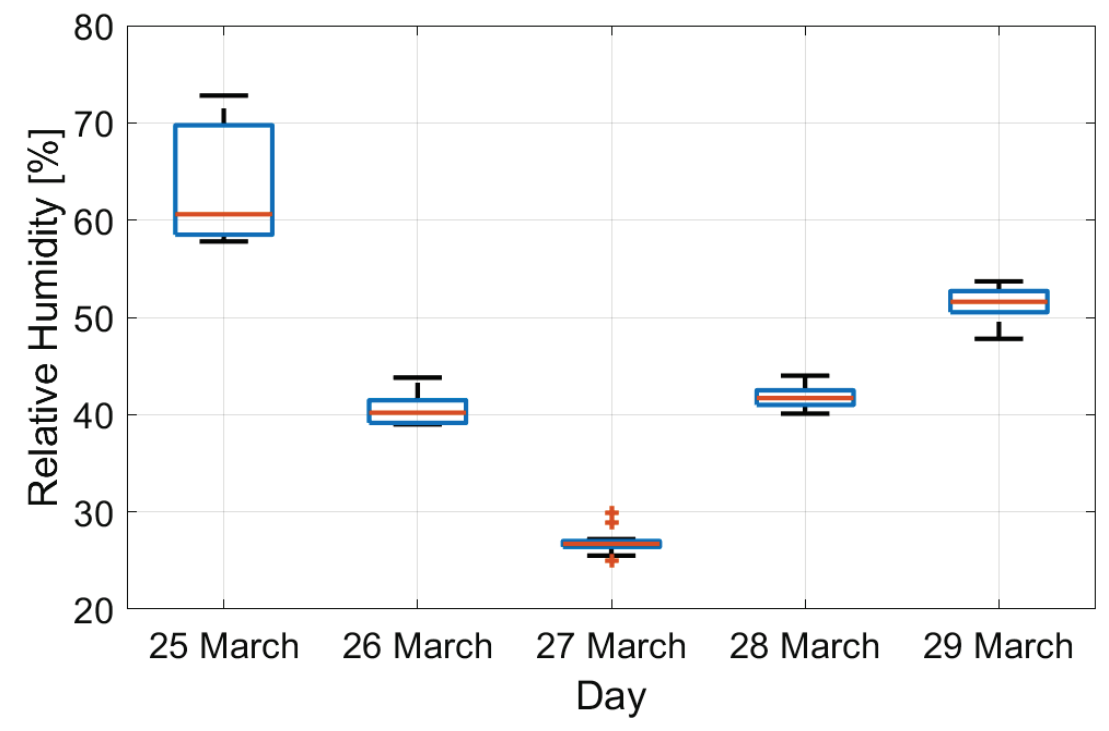


Figure 34. Recorded temperature.

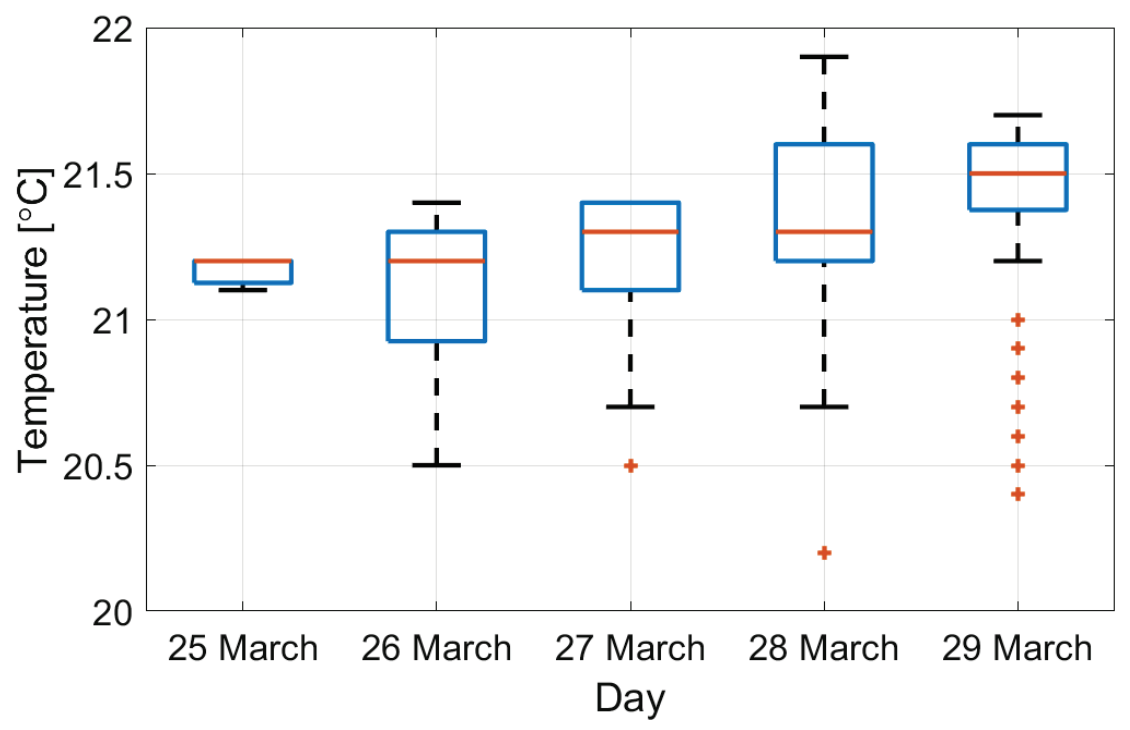

The speed of sound in air increases slightly with temperature and relative humidity. The speed of sound immediately following each shot is calculated as:

$$
c=[1+0.16 h]\left[331+0.6 T_{c}\right],
$$

where

$$
\begin{aligned}
& T_{c}=\text { temperature in degrees Celsius } \\
& h=\text { the fraction of } \mathrm{H}_{2} \mathrm{O} \text { molecules in air, which is given by } \\
& \qquad h=\frac{10^{-2}(R H) p_{v p}(T)}{p},
\end{aligned}
$$

where

$R H=$ the percent relative humidity

$$
\begin{aligned}
p_{v p}(T) & =\text { the vapor pressure of water at temperature } T \\
p & =\text { the ambient barometric pressure (Pierce 1994). }
\end{aligned}
$$

Figure 35 shows the speed of sound corrected for relative humidity and temperature plotted for each day. 
Figure 35. Calculated sound speed.

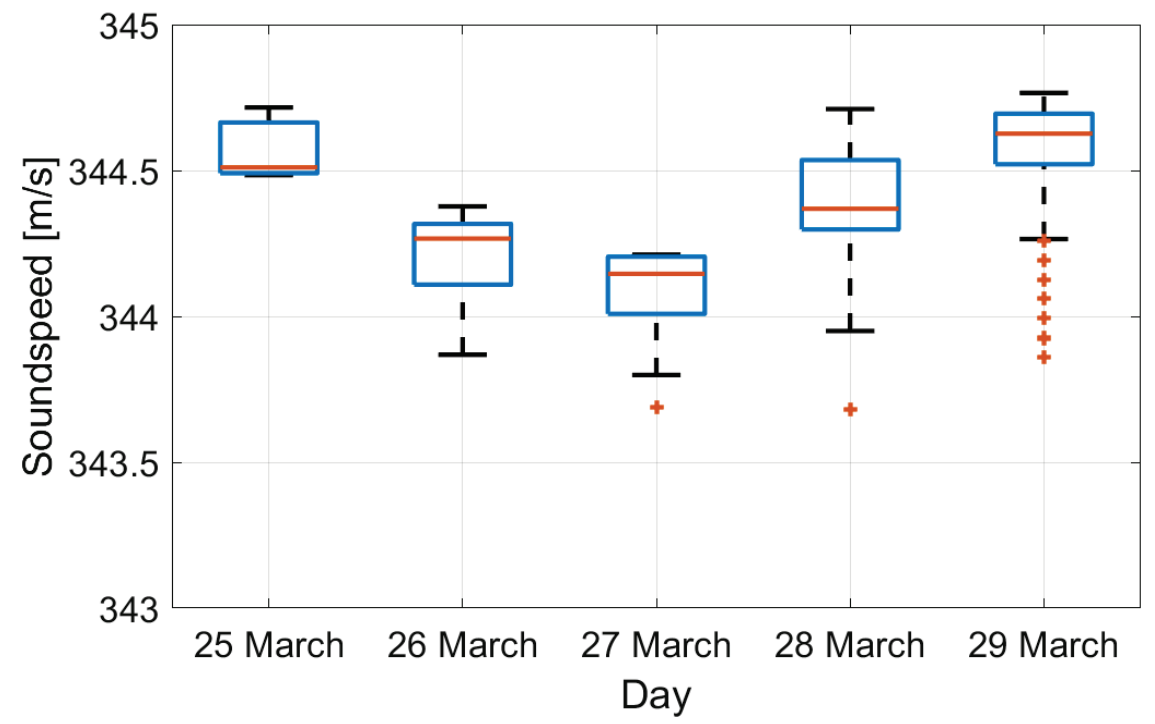

The mean sound speed across all 5 days of testing was $344.4 \mathrm{~m} / \mathrm{s}$ with a standard deviation of $0.27 \mathrm{~m} / \mathrm{s}$. The small differences in sound speed are negligible compared to the differences in projectile velocity.

Two sources of projectile velocity were recorded during the experiment. The Oehler Model 57 light screens that were used to trigger the Kirana camera also fed directly into an Oehler Model 36 chronograph. The chronograph output was displayed on a computer in the control room, and manually recorded after each shot. The velocity trap mode of the Kirana camera displays the velocity of the projectile in the Kirana Control software, and embeds the value in each image sequence file. The value was also manually recorded in the shot log. 


\section{Conclusion}

This work collected optical and acoustical data of ballistic noise signatures by recording schlieren images of the acoustic and aerodynamic density field synchronous with high-frequency acoustic pressure field sensor data. A modified Mach-Zehnder interferometer was used to transduce the axisymmetric pressure perturbation indirectly. Several projectile shapes over a range of Mach numbers were tested. Nominally, pointed, round, and flat nosed projectiles were tested in the main experiment at Mach numbers of 2.5 and 1.1. Further experiments tested a complicated projectile shape, the FSP, and a pointed projectile of a smaller caliber, $7.62 \mathrm{~mm} \mathrm{M80}$.

The data gathered in this experiment will be useful in determining the contributions of specific mechanisms on the projectile body to a sensed acoustic signature. Using the schlieren images, the generation, propagation, and coalescence of aerodynamically generated acoustic waves will be visible. The simultaneously captured acoustic data will describe these properties in three dimensions of space, and in time. For example, the canelure on the M33 and M80 projectiles, as well as the ridges on the 500 Jeffery and 500 Nitro, produce attached shock waves that coalesce and appear as an intermediate shock in the $\mathrm{N}$-waves captured by the acoustic sensors. Using the data gathered in this experiment, the process of its generation, the rate and mode of its coalescence, and its ultimate acoustic signature can be fully described.

With the aid of modern image processing techniques, including convolutional neural networks, similar features from the schlieren image sequences will be extracted for further study. Likewise, advanced techniques in array processing and time-reversal will be used to separate, identify, and study specific aspects of the acoustic signatures. The results of these techniques will be combined to form scaling relationships to describe the evolution of the acoustic waveform. 


\section{References}

DoD (U.S. Department of Defense). 2008. Projectile, Calibers .22, .30, .5O and 20MM Fragment-Simulating. (Revision B Notice 2 - Validation). MIL STD 46593B. Washington, DC: DoD.

HQDA (Headquarters, Department of the Army). 1994. Army Ammunition Data Sheets for Small Caliber Ammunition. Army Technical Manual (TM) 43-0001-27. Washington, DC: HQDA.

Mäkinen, Toni, and Pasi Pertilä. 2010. "Shooter Localization and Bullet Trajectory, Caliber, and Speed Estimation Based on Detected Firing Sounds." Applied Acoustics 71 (10):902-913. https://doi.org/10.1016/j.apacoust.2010.05.021.

Moffet, A. 1968. "Minimum-Redundancy Linear Arrays." IEEE Transactions on Antennas and Propagation 16 (2):172-75. https://doi.org/10.1109/TAP.1968.1139138.

Pierce, Allan D. 1994. Acoustics: An Introduction to Its Physical Principles and Applications. Melville, NY: American Institute of Physics.

Sallai, János, Péter Völgyesi, Ákos Lédeczi, Ken Pence, Ted Bapty, Sandeep Neema, and James R. Davis. 2013. "Acoustic Shockwave-Based Bearing Estimation.” In Proceedings of the 12th International Conference on Information Processing in Sensor Networks - IPSN '13, 217. Philadelphia, PA: ACM Press. https://doi.org/10.1145/2461381.2461409.

Settles, Gary S., and Michael J Hargather. 2017. "A Review of Recent Developments in Schlieren and Shadowgraph Techniques." Measurement Science and Technology 28(4):042001. https://doi.org/10.1088/1361-6501/aa5748.

Stoughton, Roland. 1997. "Measurements of Small-Caliber Ballistic Shock Waves in Air." Journal of the Acoustical Society of America 102(2):781-787. https://doi.org/10.1121/1.419904.

Torras-Rosell, Antoni, Salvador Barrera-Figueroa, and Finn Jacobsen. 2012. "Sound Field Reconstruction Using Acousto-Optic Tomography." Journal of the Acoustical Society of America 131(5):3786-3793. https://doi.org/10.1121/1.3695394.

Vasil'ev, Lev Aleksandrovich. 1971. Schlieren Methods. 1st ed. Israel Program for Scientific Translations. New York: Keter Inc.

Völgyesi, Péter, Gyorgy Balogh, Andras Nadas, Christopher B. Nash, and Ákos Lédeczi. 2007. "Shooter Localization and Weapon Classification with Soldier-Wearable Networked Sensors." In Proceedings of the 5th International Conference on Mobile Systems, Applications and Services - MobiSys 'o7, 113. San Juan, PR: ACM Press. https://doi.org/10.1145/1247660.1247676.

Yuldashev, Petr, Maria Karzova, Vera Khokhlova, Sébastien Ollivier, and Philippe BlancBenon. 2015. "Mach-Zehnder Interferometry Method for Acoustic Shock Wave Measurements in Air and Broadband Calibration of Microphones." Journal of the Acoustical Society of America 137(6):3314-3324. https://doi.org/10.1121/1.4921549. 


\section{Acronyms and Abbreviations}

\begin{tabular}{|l|l|}
\hline Abbreviation & Term \\
\hline CCD & Charge-Coupled Device \\
\hline ERDC & Engineer Research and Development Center \\
\hline FSP & Fragment Simulating Projectile \\
\hline GRE & Geospatial Research and Engineering \\
\hline$\underline{\underline{\text { GSL }}}$ & Geotechnical and Structures Laboratory \\
\hline LDV & Laser Doppler Vibrometer \\
\hline MRA & Minimally Redundant Array \\
\hline ULA & Uniform Linear Array \\
\hline B\&K & Brüel and Kjær \\
\hline HEPA & High-Efficiency Particulate Air \\
\hline RMS & Root Mean Square \\
\hline
\end{tabular}




\section{Unit Conversion Factors}

\begin{tabular}{|l|c|l|}
\hline Multiply & By & To Obtain \\
\hline atmosphere (standard) & 101.325 & kilopascals \\
\hline bars & 100 & kilopascals \\
\hline degrees (angle) & 0.01745329 & radians \\
\hline feet & 0.3048 & meters \\
\hline inches & 0.0254 & meters \\
\hline microns & $1.0 \mathrm{E}-06$ & meters \\
\hline square feet & 0.09290304 & square meters \\
\hline square inches & $6.4516 \mathrm{E}-04$ & square meters \\
\hline
\end{tabular}




\section{Appendix A: Tables}

Table A-1. Serial numbers of sensors and signal conditioners in Array A.

\begin{tabular}{|c|c|c|c|c|}
\hline Position Label & Sensor Model & Serial \# & Signal Conditioner Model & Signal Conditioner Serial \# \\
\hline A-1 & PCB 113B28 & LW40679 & PCB 482C05 & LW011060 \\
\hline A-2 & PCB 113B28 & LW40680 & PCB 482C05 & LW011060 \\
\hline A-3 & PCB 113B28 & LW40681 & PCB 482C05 & LW011060 \\
\hline A-4 & PCB 113B28 & LW40682 & PCB 482C05 & LW011060 \\
\hline A-5 & PCB 113B28 & LW40743 & PCB 482C05 & LW011652 \\
\hline A-6 & PCB 113B28 & LW40744 & PCB 482C05 & LW011652 \\
\hline A-7 & PCB 113B28 & LW40754 & PCB 482C05 & LW011652 \\
\hline A-8 & PCB 113B28 & LW38322 & PCB 482C05 & LW011652 \\
\hline
\end{tabular}

Table A-2. Serial numbers of sensors, signal conditioners, and preamps in Array B'

\begin{tabular}{|c|c|c|c|c|}
\hline Position Label & Sensor Model & Serial \# & $\begin{array}{c}\text { Signal Conditioner / } \\
\text { Preamp Model }\end{array}$ & $\begin{array}{c}\text { Signal Conditioner / } \\
\text { Preamp Serial \# }\end{array}$ \\
\hline B-1 & PCB 113B28 & LW40745 & PCB 482C05 & LW011651 \\
\hline B-2 & PCB 113B28 & LW40750 & PCB 482C05 & LW011651 \\
\hline B-3 & PCB 113B28 & LW40752 & PCB 482C05 & LW011651 \\
\hline B-4 & PCB 113B28 & LW40753 & PCB 482C05 & LW011651 \\
\hline B-5 & GRAS 4ODP & 56396 & B\&K Type 2639 & 1415242 \\
\hline B-6 & GRAS 4ODP & 56381 & B\&K Type 2639 & 1415245 \\
\hline B-7 & GRAS 4ODP & 334602 & B\&K Type 2639 & 1474629 \\
\hline B-8 & GRAS 4ODP & 334581 & B\&K Type 2639 & 1497488 \\
\hline
\end{tabular}

Table A-3. Serial numbers of sensors and preamps in Array C.

\begin{tabular}{|c|c|c|c|c|}
\hline Position Label & Sensor Model & Serial \# & Preamp Model & Preamp Serial \# \\
\hline C-1 & GRAS 4OBF & 41578 & Type 2639 & 1496752 \\
\hline C-2 & GRAS 4OBF & 35975 & Type 2639 & 1527834 \\
\hline C-3 & GRAS 4OBF & 41572 & Type 2639 & 1447823 \\
\hline C-4 & GRAS 4OBF & 41569 & Type 2639 & 1497489 \\
\hline C-5 & GRAS 4OBF & 35968 & Type 2639 & 1447842 \\
\hline C-6 & GRAS 4OBF & 41579 & Type 2639 & 1496585 \\
\hline C-7 & GRAS 4OBF & 35979 & Type 2639 & 1474628 \\
\hline C-8 & GRAS 4OBF & 38671 & Type 2639 & 1527833 \\
\hline
\end{tabular}

Table A-4. Sensor sensitivities

\begin{tabular}{|l|c|c|c|c|}
\hline Channel & Sensor Model & Serial \# & Sensitivity & Units \\
\hline \multicolumn{1}{|c|}{ A-1 } & PCB 113B28 & LW40679 & 14.87 & $\mathrm{mV} / \mathrm{kPa}$ \\
\hline A-2 & PCB 113B28 & LW40680 & 14.89 & $\mathrm{mV} / \mathrm{kPa}$ \\
\hline A-3 & PCB 113B28 & LW40681 & 15.18 & $\mathrm{mV} / \mathrm{kPa}$ \\
\hline A-4 & PCB 113B28 & LW40682 & 14.74 & $\mathrm{mV} / \mathrm{kPa}$ \\
\hline A-5 & PCB 113B28 & LW40743 & 14.76 & $\mathrm{mV} / \mathrm{kPa}$ \\
\hline A-6 & PCB 113B28 & LW40744 & 15.40 & $\mathrm{mV} / \mathrm{kPa}$ \\
\hline A-7 & PCB 113B28 & LW40754 & 14.85 & $\mathrm{mV} / \mathrm{kPa}$ \\
\hline A-8 & PCB 113B28 & LW38322 & 14.93 & $\mathrm{mV} / \mathrm{kPa}$ \\
\hline
\end{tabular}




\begin{tabular}{|l|l|c|c|c|}
\hline Channel & Sensor Model & Serial \# & Sensitivity & Units \\
\hline B-1 & PCB 113B28 & LW40745 & 15.17 & $\mathrm{mV} / \mathrm{kPa}$ \\
\hline B-2 & PCB 113B28 & LW40750 & 14.24 & $\mathrm{mV} / \mathrm{kPa}$ \\
\hline B-3 & PCB 113B28 & LW40752 & 14.80 & $\mathrm{mV} / \mathrm{kPa}$ \\
\hline B-4 & PCB 113B28 & LW40753 & 14.80 & $\mathrm{mV} / \mathrm{kPa}$ \\
\hline B-5 & GRAS 4ODP & 56396 & 0.82 & $\mathrm{mV} / \mathrm{Pa}$ \\
\hline B-6 & GRAS 4ODP & 56381 & 0.81 & $\mathrm{mV} / \mathrm{Pa}$ \\
\hline B-7 & GRAS 4ODP & 334602 & 0.94 & $\mathrm{mV} / \mathrm{Pa}$ \\
\hline B-8 & GRAS 4ODP & 334581 & 0.79 & $\mathrm{mV} / \mathrm{Pa}$ \\
\hline C-1 & GRAS 4OBF & 41578 & 3.06 & $\mathrm{mV} / \mathrm{Pa}$ \\
\hline C-2 & GRAS 4OBF & 35975 & 3.48 & $\mathrm{mV} / \mathrm{Pa}$ \\
\hline C-3 & GRAS 4OBF & 41572 & 3.49 & $\mathrm{mV} / \mathrm{Pa}$ \\
\hline C-4 & GRAS 4OBF & 41569 & 3.35 & $\mathrm{mV} / \mathrm{Pa}$ \\
\hline C-5 & GRAS 4OBF & 35968 & 3.37 & $\mathrm{mV} / \mathrm{Pa}$ \\
\hline C-6 & GRAS 4OBF & 41579 & 3.44 & $\mathrm{mV} / \mathrm{Pa}$ \\
\hline C-7 & GRAS 4OBF & 35979 & 3.40 & $\mathrm{mV} / \mathrm{Pa}$ \\
\hline C-8 & GRAS 4OBF & 38671 & 3.05 & $\mathrm{mV} / \mathrm{Pa}$ \\
\hline Accel-1 & PCB 333B32 & 40467 & 98.02 & $\mathrm{mV} / \mathrm{g}$ \\
\hline Accel-2 & PCB 333B32 & 40468 & 99.63 & $\mathrm{mV} / \mathrm{g}$ \\
\hline
\end{tabular}

Table A-5. Sensor locations with respect to the origin at the intersection of the optical axis and the trajectory. $\mathrm{X}$ is positive uprange, $\mathrm{Y}$ is positive toward the illuminator section, $\mathrm{Z}$ is positive upwards. $\mathrm{R}$ is the distance to the sensor perpendicular to the trajectory.

\begin{tabular}{|l|c|c|c|c|}
\hline Sensor & $\mathbf{X}(\mathbf{c m})$ & $\mathbf{Y}(\mathbf{c m})$ & $Z(\mathbf{c m})$ & $\mathbf{R}(\mathbf{c m})$ \\
\hline A-1 & -49.4 & 0.0 & -15.2 & 15.2 \\
\hline A-2 & -47.9 & 0.0 & -15.2 & 15.2 \\
\hline A-3 & -43.4 & 0.0 & -15.2 & 15.2 \\
\hline A-4 & -40.4 & 0.0 & -15.2 & 15.2 \\
\hline A-5 & -37.4 & 0.0 & -15.2 & 15.2 \\
\hline A-6 & -34.4 & 0.0 & -15.2 & 15.2 \\
\hline A-7 & -28.4 & 0.0 & -15.2 & 15.2 \\
\hline A-8 & -22.4 & 0.0 & -15.2 & 15.2 \\
\hline B-1 & -46.7 & -15.2 & 0.0 & 15.2 \\
\hline B-2 & -45.4 & -15.8 & 0.0 & 15.8 \\
\hline B-3 & -41.2 & -17.6 & 0.0 & 17.6 \\
\hline B-4 & -38.5 & -18.8 & 0.0 & 18.8 \\
\hline B-5 & -35.7 & -20.0 & 0.0 & 20.0 \\
\hline B-6 & -33.0 & -21.2 & 0.0 & 21.2 \\
\hline B-7 & -27.5 & -23.6 & 0.0 & 23.6 \\
\hline B-8 & -22.0 & -26.0 & 0.0 & 26.0 \\
\hline C-1 & 52.1 & 30.5 & 0.0 & 30.5 \\
\hline C-2 & 52.1 & 40.5 & 0.0 & 40.5 \\
\hline C-3 & 52.1 & 50.5 & 0.0 & 50.5 \\
\hline C-4 & 52.1 & 60.5 & 0.0 & 60.5 \\
\hline C-5 & 52.1 & 70.5 & 0.0 & 70.5 \\
\hline C-6 & 52.1 & 80.5 & 0.0 & 80.5 \\
\hline C-7 & 52.1 & 90.5 & 0.0 & 90.5 \\
\hline C-8 & 52.1 & 100.5 & 0.0 & 100.5 \\
\hline
\end{tabular}




\section{Appendix B: Shot Log}

Table B-1. Shot Log.

\begin{tabular}{|c|c|c|c|c|c|c|c|c|c|}
\hline Day & Time & Shot\# & Projectile & $\begin{array}{l}\text { Target Speed } \\
(\mathrm{m} / \mathrm{s})\end{array}$ & \begin{tabular}{|c|}
$\begin{array}{c}\text { Target Speed } \\
\text { (fps) }\end{array}$ \\
\end{tabular} & $\begin{array}{c}\text { Kirana Speed } \\
(\mathrm{m} / \mathrm{s})\end{array}$ & $\begin{array}{c}\text { Chronograph } \\
\text { Speed (fps) }\end{array}$ & $\begin{array}{c}\text { Frame Rate } \\
\text { (frames/s) }\end{array}$ & $\begin{array}{c}\text { Schlieren Lamp } \\
\text { f-stop }\end{array}$ \\
\hline $3 / 21$ & 1538 & 1 & M33 & 857.5 & 2813 & 913.0 & 2998 & 400000 & NR \\
\hline $3 / 21$ & 1630 & 2 & M33 & 857.5 & 2813 & 841.9 & 2764 & 200000 & NR \\
\hline $3 / 21$ & 1655 & 3 & M33 & 857.5 & 2813 & 880.1 & 2885 & 400000 & NR \\
\hline $3 / 22$ & 1000 & 4 & M33 & 857.5 & 2813 & $\mathrm{NR}$ & 2862 & 2000000 & NR \\
\hline $3 / 25$ & 1010 & 5 & M33 & 857.5 & 2813 & 879.9 & 2884 & 200000 & $N R$ \\
\hline $3 / 25$ & 1700 & 6 & M33 & 857.5 & 2813 & 869.4 & 2849 & 200000 & NR \\
\hline $3 / 25$ & 1746 & 7 & M33 & 857.5 & 2813 & 876.0 & 2870 & 200000 & $\mathrm{NR}$ \\
\hline $3 / 26$ & 1103 & 8 & M33 & 857.5 & 2813 & 859.0 & 2815 & 200000 & $\mathrm{NR}$ \\
\hline $3 / 26$ & 1350 & 9 & M33 & 857.5 & 2813 & 848.0 & 2779 & 200000 & NR \\
\hline $3 / 26$ & 1504 & 10 & M33 & 857.5 & 2813 & 860.1 & 2822 & 200000 & NR \\
\hline $3 / 26$ & 1526 & 11 & M33 & 857.5 & 2813 & 857.9 & 2815 & 200000 & NR \\
\hline $3 / 26$ & 1538 & 12 & M33 & 857.5 & 2813 & 863.5 & 2831 & 200000 & $\mathrm{NR}$ \\
\hline $3 / 26$ & 1613 & 13 & M33 & 857.5 & 2813 & 864.2 & 2831 & 200000 & $\mathrm{NR}$ \\
\hline $3 / 26$ & 1701 & 14 & M33 & 857.5 & 2813 & 864.2 & 2815 & 200000 & $\mathrm{NR}$ \\
\hline $3 / 27$ & 0957 & 15 & Jeffery & 857.5 & 2813 & 897.1 & 2943 & 1000000 & 287 \\
\hline $3 / 27$ & 1018 & 16 & Jeffery & 857.5 & 2813 & 842.4 & 2764 & 1000000 & 250 \\
\hline $3 / 27$ & 1044 & 17 & Jeffery & 857.5 & 2813 & 860.2 & 2822 & 1000000 & 233 \\
\hline $3 / 27$ & 1122 & 18 & Nitro & 857.5 & 2813 & 858.5 & 2815 & 1000000 & 233 \\
\hline $3 / 27$ & 1150 & 19 & FSP & 857.5 & 2813 & 902.7 & 2967 & 1000000 & 233 \\
\hline $3 / 27$ & 1419 & 20 & M33 & 857.5 & 2813 & 862.4 & 2825 & 1000000 & 233 \\
\hline $3 / 27$ & 1435 & 21 & M33 & 857.5 & 2813 & $\mathrm{NR}$ & 2822 & 1000000 & 233 \\
\hline $3 / 27$ & 1504 & 22 & M33 & 857.5 & 2813 & 864.7 & 2834 & 1000000 & 233 \\
\hline $3 / 27$ & 1514 & 23 & M33 & 857.5 & 2813 & 870.3 & 2854 & 1000000 & 233 \\
\hline $3 / 27$ & 1527 & 24 & Nitro & 857.5 & 2813 & 859.3 & 2822 & 1000000 & 233 \\
\hline $3 / 27$ & 1539 & 25 & Jeffery & 857.5 & 2813 & 866.6 & 2841 & 1000000 & 233 \\
\hline $3 / 27$ & 1550 & 26 & Nitro & 857.5 & 2813 & 860.9 & 2833 & 1000000 & 233 \\
\hline $3 / 27$ & 1557 & 27 & Nitro & 857.5 & 2813 & 855.2 & 2809 & 1000000 & 233 \\
\hline $3 / 27$ & 1606 & 28 & Nitro & 857.5 & 2813 & 858.6 & 2825 & 1000000 & 233 \\
\hline $3 / 27$ & 1615 & 29 & Nitro & 857.5 & 2813 & 855.2 & 2814 & 1000000 & 233 \\
\hline $3 / 27$ & 1621 & 30 & Nitro & 857.5 & 2813 & $\mathrm{NR}$ & 2812 & 1000000 & 233 \\
\hline $3 / 27$ & 1628 & 31 & Nitro & 857.5 & 2813 & 862.6 & 2834 & 1000000 & 233 \\
\hline $3 / 27$ & 1635 & 32 & Nitro & 857.5 & 2813 & 854.7 & 2798 & 1000000 & 233 \\
\hline $3 / 27$ & 1647 & 33 & Jeffery & 857.5 & 2813 & 861.7 & 2825 & 1000000 & 233 \\
\hline $3 / 27$ & 1654 & 34 & Jeffery & 857.5 & 2813 & 864.0 & 2833 & 1000000 & 233 \\
\hline $3 / 28$ & 0922 & 35 & Jeffery & 857.5 & 2813 & 825.1 & 2707 & 1000000 & 250 \\
\hline $3 / 28$ & 0932 & 36 & Jeffery & 857.5 & 2813 & 857.4 & 2811 & 1000000 & 250 \\
\hline $3 / 28$ & 0940 & 37 & Jeffery & 857.5 & 2813 & 855.2 & 2804 & 1000000 & 250 \\
\hline $3 / 28$ & 0946 & 38 & Jeffery & 857.5 & 2813 & 860.8 & 2823 & 1000000 & 250 \\
\hline $3 / 28$ & 0955 & 39 & Jeffery & 857.5 & 2813 & 871.8 & 2857 & 1000000 & 250 \\
\hline $3 / 28$ & 1004 & 40 & Jeffery & 857.5 & 2813 & 839.2 & 2753 & 1000000 & 250 \\
\hline $3 / 28$ & 1012 & 41 & Jeffery & 857.5 & 2813 & 806.0 & 2643 & 1000000 & 250 \\
\hline $3 / 28$ & 1021 & 42 & Jeffery & 857.5 & 2813 & 861.8 & 2825 & 1000000 & 250 \\
\hline $3 / 28$ & 1026 & 43 & Jeffery & 857.5 & 2813 & 860.8 & 2823 & 1000000 & 250 \\
\hline $3 / 28$ & 1035 & 44 & M33 & 857.5 & 2813 & 861.0 & 2822 & 1000000 & 250 \\
\hline $3 / 28$ & 1041 & 45 & M33 & 857.5 & 2813 & 862.4 & 2826 & 1000000 & 250 \\
\hline
\end{tabular}




\begin{tabular}{|c|c|c|c|c|c|c|c|c|c|}
\hline Day & Time & Shot \# & Projectile & $\begin{array}{c}\text { Target Speed } \\
(\mathrm{m} / \mathrm{s})\end{array}$ & $\begin{array}{c}\text { Target Speed } \\
\text { (fps) }\end{array}$ & $\begin{array}{c}\text { Kirana Speed } \\
(\mathrm{m} / \mathrm{s})\end{array}$ & $\begin{array}{c}\text { Chronograph } \\
\text { Speed (fps) }\end{array}$ & $\begin{array}{l}\text { Frame Rate } \\
\text { (frames/s) }\end{array}$ & $\begin{array}{c}\text { Schlieren Lamp } \\
\text { f-stop }\end{array}$ \\
\hline $3 / 28$ & 1046 & 46 & M33 & 857.5 & 2813 & 858.4 & 2812 & 1000000 & 250 \\
\hline $3 / 28$ & 1051 & 47 & M33 & 857.5 & 2813 & 842.3 & 2759 & 1000000 & 250 \\
\hline $3 / 28$ & 1055 & 48 & M33 & 857.5 & 2813 & 863.1 & 2828 & 1000000 & 250 \\
\hline $3 / 28$ & 1059 & 49 & M33 & 857.5 & 2813 & 858.4 & 2814 & 1000000 & 250 \\
\hline $3 / 28$ & 1105 & 50 & M33 & 857.5 & 2813 & 864.5 & 2834 & 1000000 & 250 \\
\hline $3 / 28$ & 1110 & 51 & M33 & 857.5 & 2813 & 860.1 & 2818 & 1000000 & 250 \\
\hline $3 / 28$ & 1114 & 52 & M33 & 857.5 & 2813 & 864.4 & 2834 & 1000000 & 250 \\
\hline $3 / 28$ & 1119 & 53 & M33 & 857.5 & 2813 & 860.4 & 2818 & 1000000 & 250 \\
\hline $3 / 28$ & 1124 & 54 & Nitro & 857.5 & 2813 & 859.8 & 2820 & 1000000 & 250 \\
\hline $3 / 28$ & 1129 & 55 & Nitro & 857.5 & 2813 & 855.5 & NR & 1000000 & 250 \\
\hline $3 / 28$ & 1153 & 56 & FSP & 857.5 & 2813 & 879.0 & 2890 & 1000000 & 250 \\
\hline $3 / 28$ & 1201 & 57 & FSP & 857.5 & 2813 & 862.4 & 2836 & 1000000 & 250 \\
\hline $3 / 28$ & 1341 & 58 & FSP & 857.5 & 2813 & 869.6 & 2857 & 1000000 & 233 \\
\hline $3 / 28$ & 1405 & 59 & FSP & 857.5 & 2813 & 877.9 & 2885 & 1000000 & 233 \\
\hline $3 / 28$ & 1413 & 60 & FSP & 857.5 & 2813 & 855.0 & 2811 & 1000000 & 218 \\
\hline $3 / 28$ & 1422 & 61 & FSP & 857.5 & 2813 & 840.2 & 2762 & 1000000 & 218 \\
\hline $3 / 28$ & 1430 & 62 & FSP & 857.5 & 2813 & 849.6 & 2793 & 1000000 & 218 \\
\hline $3 / 28$ & 1437 & 63 & FSP & 857.5 & 2813 & 854.0 & 2807 & 1000000 & 218 \\
\hline $3 / 28$ & 1457 & 64 & FSP & 857.5 & 2813 & 853.8 & 2806 & 1000000 & 218 \\
\hline $3 / 28$ & 1519 & 65 & FSP & 857.5 & 2813 & 856.9 & 2817 & 1000000 & 218 \\
\hline $3 / 28$ & 1529 & 66 & FSP & 857.5 & 2813 & 458.7 & 1507 & 1000000 & 218 \\
\hline $3 / 28$ & 1538 & 67 & FSP & 857.5 & 2813 & 845.6 & 2779 & 1000000 & 218 \\
\hline $3 / 28$ & 1546 & 68 & FSP & 857.5 & 2813 & 854.2 & 2807 & 1000000 & 218 \\
\hline $3 / 28$ & 1618 & 69 & M33 & 373.7 & 1226 & 397.5 & 1303 & 1000000 & 233 \\
\hline $3 / 28$ & 1637 & 70 & M33 & 373.7 & 1226 & 359.2 & 1178 & 500000 & 233 \\
\hline $3 / 28$ & 1654 & 71 & M33 & 373.7 & 1226 & 372.3 & 1220 & 1000000 & 218 \\
\hline $3 / 28$ & 1705 & 72 & M33 & 373.7 & 1226 & 367.4 & 1205 & 1000000 & 218 \\
\hline $3 / 29$ & 0841 & 73 & M33 & 373.7 & 1226 & 385.8 & 1265 & 1000000 & 218 \\
\hline $3 / 29$ & 0849 & 74 & M33 & 373.7 & 1226 & 384.6 & 1261 & 1000000 & 218 \\
\hline $3 / 29$ & 0857 & 75 & M33 & 373.7 & 1226 & 383.0 & 1255 & 1000000 & 218 \\
\hline $3 / 29$ & 0902 & 76 & M33 & 373.7 & 1226 & 382.1 & 1253 & 1000000 & 218 \\
\hline $3 / 29$ & 0907 & 77 & M33 & 373.7 & 1226 & 368.3 & 1207 & 1000000 & 218 \\
\hline $3 / 29$ & 0914 & 78 & M33 & 373.7 & 1226 & 382.0 & 1253 & 1000000 & 218 \\
\hline $3 / 29$ & 0920 & 79 & M33 & 373.7 & 1226 & 360.7 & 1182 & 1000000 & 218 \\
\hline $3 / 29$ & 0926 & 80 & M33 & 373.7 & 1226 & 381.8 & 1252 & 1000000 & 218 \\
\hline $3 / 29$ & 0932 & 81 & M33 & 373.7 & 1226 & 376.7 & 1235 & 1000000 & 218 \\
\hline $3 / 29$ & 0942 & 82 & Jeffery & 373.7 & 1226 & 407.8 & 1323 & 1000000 & 218 \\
\hline $3 / 29$ & 0952 & 83 & Jeffery & 373.7 & 1226 & 359.3 & 1178 & 1000000 & 218 \\
\hline $3 / 29$ & 0957 & 84 & Jeffery & 373.7 & 1226 & 379.3 & 1243 & 1000000 & 218 \\
\hline $3 / 29$ & 1010 & 85 & Jeffery & 373.7 & 1226 & 379.3 & 1244 & 1000000 & 203 \\
\hline $3 / 29$ & 1016 & 86 & Jeffery & 373.7 & 1226 & 378.5 & 1241 & 1000000 & 203 \\
\hline $3 / 29$ & 1021 & 87 & Jeffery & 373.7 & 1226 & 377.9 & 1239 & 1000000 & 203 \\
\hline $3 / 29$ & 1027 & 88 & Jeffery & 373.7 & 1226 & 360.2 & 1181 & 1000000 & 203 \\
\hline $3 / 29$ & 1040 & 89 & Jeffery & 373.7 & 1226 & 354.0 & 1160 & 1000000 & 203 \\
\hline $3 / 29$ & 1051 & 90 & Jeffery & 373.7 & 1226 & 375.9 & 1232 & 1000000 & 203 \\
\hline $3 / 29$ & 1057 & 91 & Jeffery & 373.7 & 1226 & 383.3 & 1287 & 1000000 & 203 \\
\hline $3 / 29$ & 1104 & 92 & Jeffery & 373.7 & 1226 & 382.9 & 1256 & 1000000 & 203 \\
\hline $3 / 29$ & 1110 & 93 & Jeffery & 373.7 & 1226 & 383.8 & 1258 & 1000000 & 203 \\
\hline $3 / 29$ & 1118 & 94 & Nitro & 373.7 & 1226 & 394.9 & 1275 & 1000000 & 203 \\
\hline $3 / 29$ & 1125 & 95 & Nitro & 373.7 & 1226 & 395.5 & 1277 & 1000000 & 203 \\
\hline
\end{tabular}




\begin{tabular}{|c|c|c|c|c|c|c|c|c|c|}
\hline Day & Time & Shot \# & Projectile & $\begin{array}{l}\text { Target Speed } \\
(\mathrm{m} / \mathrm{s})\end{array}$ & $\begin{array}{c}\text { Target Speed } \\
\text { (fps) }\end{array}$ & $\begin{array}{c}\text { Kirana Speed } \\
(\mathrm{m} / \mathrm{s})\end{array}$ & $\begin{array}{l}\text { Chronograph } \\
\text { Speed (fps) }\end{array}$ & $\begin{array}{l}\text { Frame Rate } \\
\text { (frames/s) }\end{array}$ & $\begin{array}{l}\text { Schlieren Lamp } \\
\text { f-stop }\end{array}$ \\
\hline $3 / 29$ & 1132 & 96 & Nitro & 373.7 & 1226 & 377.6 & 1238 & 1000000 & 203 \\
\hline $3 / 29$ & 1138 & 97 & Nitro & 373.7 & 1226 & 380.3 & 1247 & 1000000 & 203 \\
\hline $3 / 29$ & 1142 & 98 & Nitro & 373.7 & 1226 & 376.1 & 1233 & 1000000 & 203 \\
\hline $3 / 29$ & 1146 & 99 & Nitro & 373.7 & 1226 & 380.2 & 1247 & 1000000 & 203 \\
\hline $3 / 29$ & 1151 & 100 & Nitro & 373.7 & 1226 & 375.6 & 1232 & 1000000 & 203 \\
\hline $3 / 29$ & 1155 & 101 & Nitro & 373.7 & 1226 & 374.9 & 1229 & 1000000 & 203 \\
\hline $3 / 29$ & 1159 & 102 & Nitro & 373.7 & 1226 & 379.3 & 1243 & 1000000 & 203 \\
\hline $3 / 29$ & 1204 & 103 & Nitro & 373.7 & 1226 & 382.9 & 1256 & 1000000 & 203 \\
\hline $3 / 29$ & 1339 & 104 & M33 & 308.7 & 1013 & 347.0 & 1138 & 1000000 & 203 \\
\hline $3 / 29$ & 1349 & 105 & M33 & 308.7 & 1013 & 346.6 & 1136 & 1000000 & 203 \\
\hline $3 / 29$ & 1429 & 106 & Nitro & 373.7 & 1226 & 376.9 & 1236 & 1000000 & 203 \\
\hline $3 / 29$ & 1435 & 107 & FSP & 373.7 & 1226 & 298.5 & 981 & 1000000 & 203 \\
\hline $3 / 29$ & 1445 & 108 & FSP & 373.7 & 1226 & 382.1 & 1256 & 1000000 & 203 \\
\hline $3 / 29$ & 1453 & 109 & FSP & 373.7 & 1226 & 348.0 & 1143 & 1000000 & 203 \\
\hline $3 / 29$ & 1459 & 110 & FSP & 373.7 & 1226 & 383.8 & 1261 & 1000000 & 203 \\
\hline $3 / 29$ & 1505 & 111 & FSP & 373.7 & 1226 & 389.9 & 1281 & 1000000 & 189 \\
\hline $3 / 29$ & 1510 & 112 & FSP & 373.7 & 1226 & 406.9 & 1337 & 1000000 & 189 \\
\hline $3 / 29$ & 1519 & 113 & FSP & 373.7 & 1226 & 862.8 & NR & 1000000 & 189 \\
\hline $3 / 29$ & 1532 & 114 & FSP & 373.7 & 1226 & 376.0 & 1236 & 1000000 & 189 \\
\hline $3 / 29$ & 1604 & 115 & M80 & 857.5 & 2813 & 826.1 & 2713 & 1000000 & 218 \\
\hline $3 / 29$ & 1613 & 116 & M80 & 857.5 & 2813 & 857.0 & 2814 & 1000000 & 218 \\
\hline $3 / 29$ & 1619 & 117 & M80 & 857.5 & 2813 & 864.4 & 2833 & 1000000 & 218 \\
\hline $3 / 29$ & 1623 & 118 & M80 & 857.5 & 2813 & 860.9 & 2823 & 1000000 & 218 \\
\hline $3 / 29$ & 1628 & 119 & M80 & 857.5 & 2813 & 862.3 & 2823 & 1000000 & 218 \\
\hline $3 / 29$ & 1632 & 120 & M80 & 857.5 & 2813 & 862.5 & 2830 & 1000000 & 218 \\
\hline $3 / 29$ & 1635 & 121 & M80 & 857.5 & 2813 & 859.9 & 2823 & 1000000 & 218 \\
\hline $3 / 29$ & 1640 & 122 & M80 & 857.5 & 2813 & 867.7 & 2846 & 1000000 & 218 \\
\hline $3 / 29$ & 1644 & 123 & M80 & 857.5 & 2813 & 859.4 & 2814 & 1000000 & 218 \\
\hline $3 / 29$ & 1648 & 124 & M80 & 857.5 & 2813 & 863.7 & 2833 & 1000000 & 218 \\
\hline $3 / 29$ & 1652 & 125 & M80 & 857.5 & 2813 & 857.7 & 2817 & 1000000 & 218 \\
\hline
\end{tabular}




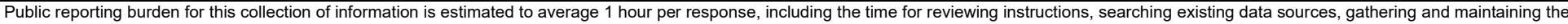

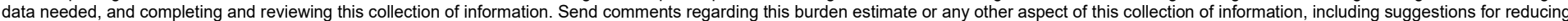

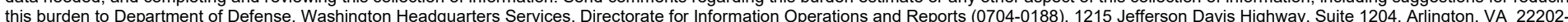

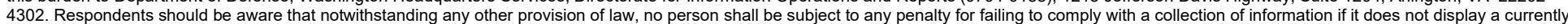
4302. Respondents should be aware that notwithstanding any other provision of law, no person shall
valid OMB control number. PLEASE DO NOT RETURN YOUR FORM TO THE ABOVE ADDRESS.
1. REPORT DATE (DD-MM-YYYY) $01 / 01 / 2021$
Final Technical Report (TR)

\section{TITLE AND SUBTITLE}

Optical and Acoustical Measurement of Ballistic Noise Signatures

Matthew G. Blevins, Gregory W. Lyons, Carl R. Hart, and Michael J. White

\section{PERFORMING ORGANIZATION NAME(S) AND ADDRESS(ES)}

U.S. Army Engineer Research and Development Center (ERDC)

Construction Engineering Research Laboratory

(CERL)

PO Box 9005,

Champaign, IL 61826-9005

Cold Regions Research and Engineering

Laboratory (CRREL)

72 Lyme Road

Hanover, NH 03755-1290

\section{DATES COVERED (From - To)}

5a. CONTRACT NUMBER

\section{5b. GRANT NUMBER}

\section{5c. PROGRAM ELEMENT}

06011102

5d. PROJECT NUMBER

$\mathrm{AB} 2$

5e. TASK NUMBER

SAB201

5f. WORK UNIT NUMBER

$52 \mathrm{C}$

8. PERFORMING ORGANIZATION REPORT NUMBER

ERDC TR-21-1

10. SPONSOR/MONITOR'S ACRONYM(S)

9. SPONSORING / MONITORING AGENCY NAME(S) AND ADDRESS(ES)

Headquarters, U.S. Army Corps of Engineers (HQUSACE)

441 G St., NW

Washington, Dc 20314-1000

11. SPONSOR/MONITOR'S REPORT NUMBER(S)

\section{DISTRIBUTION / AVAILABILITY STATEMENT}

Approved for public release; distribution is unlimited.

\section{SUPPLEMENTARY NOTES}

\section{ABSTRACT}

Supersonic projectiles in air generate acoustical signatures that are fundamentally related to the projectile's shape, size, and velocity. These characteristics influence various mechanisms involved in the generation, propagation, decay, and coalescence of acoustic waves. To understand the relationships between projectile shape, size, velocity, and the physical mechanisms involved, an experimental effort captured the acoustic field produced by a range of supersonic projectiles using both conventional pressure sensors and a schlieren imaging system. The results of this ongoing project will elucidate those fundamental mechanisms, enabling more sophisticated tools for detection, classification, localization, and tracking. This paper details the experimental setup, data collection, and preliminary analysis of a series of ballistic projectiles, both idealized and currently in use by the U.S. Military.

\section{SUBJECT TERMS}

Ballistics, Projectiles, Ultrasonic waves, Shock waves, Acoustics

\section{SECURITY CLASSIFICATION OF:}

a. REPORT
Unclassified

NSN 7540-01-280-5500

\section{b. ABSTRACT \\ Unclassified}

17. LIMITATION
OF ABSTRACT
SAR

18. NUMBER OF PAGES

c. THIS PAGE

Unclassified
64 19a. NAME OF RESPONSIBLE PERSON

19b. TELEPHONE NUMBER (include area code) 